University of Louisville

ThinkIR: The University of Louisville's Institutional Repository

8-2012

\title{
The influence of social contextual conditions and basic psychological need fulfillment on self-management and emotional distress among urban African American adults with type-2 diabetes mellitus : a mixed methods study.
}

Sula Marie Hood

University of Louisville

Follow this and additional works at: https://ir.library.louisville.edu/etd

\section{Recommended Citation}

Hood, Sula Marie, "The influence of social contextual conditions and basic psychological need fulfillment on self-management and emotional distress among urban African American adults with type-2 diabetes mellitus : a mixed methods study." (2012). Electronic Theses and Dissertations. Paper 630.

https://doi.org/10.18297/etd/630

This Doctoral Dissertation is brought to you for free and open access by ThinkIR: The University of Louisville's Institutional Repository. It has been accepted for inclusion in Electronic Theses and Dissertations by an authorized administrator of ThinkIR: The University of Louisville's Institutional Repository. This title appears here courtesy of the author, who has retained all other copyrights. For more information, please contact thinkir@louisville.edu. 


\title{
THE INFLUENCE OF SOCIAL CONTEXTUAL CONDITIONS AND BASIC PSYCHOLOGICAL NEED FULFILLMENT ON SELF-MANAGEMENT AND EMOTIONAL DISTRESS AMONG URBAN AFRICAN AMERICAN ADULTS WITH TYPE-2 DIABETES MELLITUS: \\ A MIXED METHODS STUDY
}

By

\author{
Sula Marie Hood \\ B.A., The College of Wooster, 2005 \\ M.P.H., Saint Louis University, 2008
}

\begin{abstract}
A Dissertation
Submitted to the Faculty of the School of Public Health and Information Sciences of the University of Louisville in Partial Fulfillment of the Requirements

for the Degree of
\end{abstract}

Doctor of Philosophy

Department of Health Promotion and Behavioral Sciences

University of Louisville

Louisville, Kentucky

August 2012 


\section{Copyright 2012 by Sula Marie Hood}

All rights reserved 
THE INFLUENCE OF SOCIAL CONTEXTUAL CONDITIONS AND BASIC PSYCHOLOGICAL NEED FULFILLMENT ON SELF-MANAGEMENT AND EMOTIONAL DISTRESS AMONG URBAN AFRICAN AMERICAN ADULTS WITH TYPE-S DIABETES MELLITUS:

A MIXED METHODS STUDY

By

Sula Marie Hood

B.A., The College of Wooster, 2005

M.P.H., Saint Louis University, 2008

A Dissertation Approved on

July 23, 2012

by the following Dissertation Committee:

Scott LaJoie

Dissertation Director

Muriel Harris

Latrica Best

A.O’tayo Lalude 


\section{DEDICATION}

This work is dedicated to my father, A.J. Hood, Jr., my beloved mother, Sula M. Hood, my paternal grandparents, A.J. and Louise Hood, and my maternal grandparents, Charlie and Bernice Agnew, for I am the fruit of their tremendous labor.

I have strived to learn as much as I can, so I can do as much as I can to bless others' lives through my work.

"Speak up for those who cannot speak for themselves, ensure justice for those who are perishing. Yes, speak up for the poor and helpless, and see that they get justice."

-Proverbs 31:8-9 


\section{ACKNOWLEDGEMENTS}

I would like to thank my committee members, Dr. Scott LaJoie, Dr. Muriel Harris, Dr. Latrica Best, and Dr. A. O'tayo Lalude for their assistance with my dissertation study, and for the time, advice, and resources that they contributed to ensure that I had a successful and productive learning experience. I would also like to thank my Department Chair, Dr. Richard Wilson, as well as the School of Public Health and Information Sciences (SPHIS) staff for being extremely resourceful during the last four years.

I would like to acknowledge the School of Interdisciplinary and Graduate Studies (SIGS) and Commission on Diversity and Racial Equality (CODRE) at the University of Louisville, as well as the Southern Regional Education Board (SREB), for these entities funded my dissertation research and enabled me earn my doctoral degree. I would also like to thank the Black Biomedical Graduate Student Organization (BBGSO) at the University of Louisville and the Minority Training Program in Cancer Control Research (MTPCCR) at the University of California, Los Angeles, for promoting the presence of ethnic minority researchers in the health sciences and exposing me to invaluable networks of health sciences peer mentors.

Several community-based sites played an instrumental role in my study recruitment. First, I would like to thank the following Louisville church congregations for allowing me to personally announce my study opportunity and recruit on-site: Southern Star Baptist Church, Calvary Missionary Baptist Church, Ebenezer Missionary Baptist Church, Kingdom Fellowship Christian Life Center, West Chestnut Street Baptist Church, St. Stephen Church, and Canaan Christian Church. I would also like to thank the Westside Medical Center director, Dr. A. O'tayo Lalude, as well as the Active Steps for Diabetes exercise program coordinator, Dr. Gina Pariser of 
Bellarmine University, for allowing me to recruit on-site and build a rapport with prospective participants. I would like to thank the 100 Black Men of Louisville, Prospect Masonic Lodge 109, and numerous Louisville Metro barbershops, for providing assistance with recruiting male participants for my study.

Several individuals greatly contributed to my dissertation study planning, data collection and analysis. Specifically, I would like to acknowledge Dr. Jill Adelson and Macarius Donneyong, for their guidance pertaining to path analysis. I would also like to thank Tiffany Robinson for her tremendous assistance with facilitating the focus groups for my study.

I would like to thank two very special mentors, who I hold in high regard and are near and dear to my heart. First, I would like to thank the late Dr. Theodore Williams, for believing in me and encouraging me to be steadfast in my pursuit to excel in the health sciences. I would also like to thank Dr. Vetta Sanders Thompson for being an exemplary community-based health disparities researcher and mentor who truly inspires me to be a compassionate, dedicated, hardworking and competent public health professional.

I would like to thank my friends and family. Thank you for the support, words of encouragement, and prayers whispered on my behalf over the years. I am especially thankful for my father who has been my "coach" and biggest supporter of all. I am also extremely thankful for my late mother, who is ever-present in my thoughts and whose words of encouragement I often rely upon for strength and perseverance. A hand-written note that she gave me many years ago is secured in a frame on my desk and reads, “...Always believe in yourself, and remember you can make it if you try."

Last, but certainly not least, I am eternally grateful to my Heavenly Father, for making me who I am, taking me everywhere that I have been in this journey, and equipping me to do what He has called me to do. 


\begin{abstract}
THE INFLUENCE OF SOCIAL CONTEXTUAL CONDITIONS AND BASIC PSYCHOLOGICAL NEED FULFILLMENT ON SELF-MANAGEMENT AND EMOTIONAL DISTRESS AMONG URBAN AFRICAN AMEIRCAN ADULTS WITH TYPE-2 DIABETES MELLITUS:

A MIXED METHODS STUDY
\end{abstract}

Sula Marie Hood

August 7, 2012

Introduction: African Americans are disproportionally diagnosed with Type-2 diabetes, and have been observed to have poor self-management, which increases risk of complications. Social influences are commonly associated with diabetes-related outcomes.

Purpose: The purpose of the study was to assess whether and how socio-contextual factors influence self-management and emotional distress in urban African American adults living with type-2 diabetes, as well as to assess whether social support facilitate relatedness need fulfillment within this population. The study also sought to gain an understanding of the psychosocial support needs and preferences of urban African American adults living with type- 2 diabetes.

Methods: The descriptive study employed a mixed-methods research design. African American adults were recruited to take a one-time written survey. Hypotheses one and two were tested using hierarchical linear regression, hypothesis three was assessed using 
a simple linear model, and hypotheses four and five were evaluated using path analysis.

Four gender-stratified follow-up focus groups were also conducted, to confirm quantitative findings and gain insight into the support needs and preferences of urban African American adults living with type-2 diabetes.

Study Variables: Independent study variables included social support, autonomy support, basic psychological needs (autonomy, competence, relatedness), and autonomous regulation. Primary dependent variables were diabetes self-management and diabetes-related emotional distress.

Results: 155 eligible individuals ( 67 male, 88 female) were included in the quantitative analytic sample. 23 individuals ( 10 male, 13 female) participated in follow-up focus groups, yielding a total of 6 hours of audio-recorded focus group data. Autonomy and competence significantly predicted self-management and emotional distress in hypotheses one and two, respectively. Competence was the strongest predictor of selfmanagement and emotional distress among sample participants, followed by autonomy, but relatedness was not observed to be a significant variable in the prediction of study outcomes. Social support was observed to significantly predict relatedness need fulfillment in a simple linear model for hypothesis three. Data did not support hypothesis four and five. Qualitative findings contextualized the quantitative study findings.

Conclusions: Future support programs should facilitate basic need fulfillment in urban African American adults living with type-2 diabetes. Relatedness is especially important in this collectivistic cultural group. 


\section{TABLE OF CONTENTS}

ACKNOWLEDGEMENTS




\section{LIST OF TABLES}

1.1 Operational Definitions for the Study Variables ............................................ 14

3.1 Instruments and Corresponding Variables Assessed in the Study.......................... 55

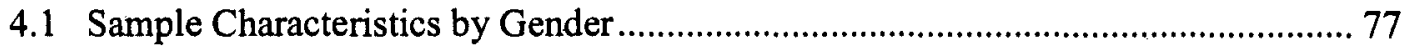

4.2 Diabetes-Specific Demographic Sample Characteristics ..................................... 79

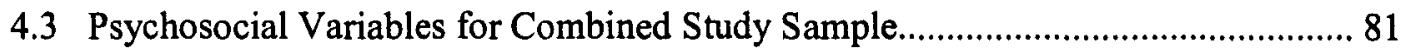

4.4 Pearson Intercorrelations, Means, and Standard Deviations for Study Variables ... 83

4.5 Bivariate Correlation Results for Basic Need and Self-Management Variables .... 85

4.6 Hierarchical Linear Regression Results for Hypothesis One .................................. 87

4.7 Bivariate Correlation Results for Basic Need and Distress Variables .................... 89

4.8 Hierarchical Linear Regression Results for Hypothesis Two................................. 91

4.9 Bivariate Correlation Results for Basic Need and Social Support Variables ........... 93

4.10 Simple Linear Regression Results for Hypothesis Three ....................................... 94

4.11 Fit Index estimates for Structural Path Models Predicting Self-Management ......... 98

4.12 Fit Index Estimates for Structural Path Models Predicting Emotional Distress..... 101

4.13 Focus Group Composition Characteristics ........................................................ 102

4.14 Focus Group Participant Demographic Characteristics...................................... 102 


\section{LIST OF FIGURES}

1.1 Autonomy-Dependent Motivation Continuum ………...................................... 6

1.2 Motivational Model of Context, Self, Action, and Outcomes ………..................... 9

1.3 Integrated Self-Determination Theory Model of Healb Behavior Change ............... 12

1.4 Hypothesized Relationships of Study Variables ……….................................... 13

3.1 Specified Models of Relationships Between Study Variables................................. 69

4.1 Full Structural Path Model for Predicting Self-Management ………..................... 96

4.2 Reduced Structual Path Model for Predicting Self-Management ……................. 97

4.3 Full Structural Path Model for Predicting Emotional Distress ……………….......... 99

4.4 Reduced Structural Path Model for Predicting Emotional Distress ....................... 100 


\section{CHAPTER 1}

\section{INTRODUCTION}

The burden of type-2 diabetes

Diabetes is a chronic disease characterized by abnormally high glucose levels and defective insulin metabolism in the body (Hall, Loehmer, \& Malone, 2008).

Approximately $90 \%-95 \%$ of all adult diabetes diagnoses are classified as being type- 2 or "adult onset," the most common form of the disease (Centers for Disease Control and Prevention, 2008). Diabetes rates have been rising so rapidly, that the disease is now recognized as an epidemic in the United States (U.S.) (Engelgau et al., 2004). Type-2 diabetes (T2DM) disparities exist, where rates are increased among racial and ethnic minorities (National Diabetes Information Clearinghouse, 2008). In particular, African Americans have been observed to have higher diabetes incidence, prevalence and mortality rates, as well as higher rates of diabetes-related complications than Whites.

Diabetes self-management

Majority of T2DM management involves self-care performed by the patient. Self-care behaviors that patients living with T2DM are responsible for include regularly taking medications, regularly monitoring blood glucose levels, engaging in physical activity, and adhering to diet/nutrition recommendations (Hwang, 2000). Additionally, patients are responsible for regularly attending their healthcare appointments. 
Recent study findings suggest that African Americans are significantly less adherent to self-management recommendations than their White counterparts, which possibly contributes to increased complications and mortality rates among this population (Melkus, Whittemore, \& Mitchell, 2009; Shenolikar, Balkrishnan, Camacho, Whitmire, \& Anderson, 2006).

\section{Diabetes and Psychological well-being}

The mental health of individuals living with T2DM is as equally important as their physical health, as psychological well-being can play a vital role in influencing behavioral decision-making regarding self-management, as well as health outcomes. Individual psychological well-being is indicated by variables such as distress and depression.

Distress is a commonly identified barrier to T2DM self-management. Participants of qualitative studies indicate that they often feel stressed, frustrated, and overwhelmed with the demands of T2DM self-management (Chlebowy, Hood, \& LaJoie, 2010; Nagelkerk, Reick, \& Meengs, 2006). In particular, emotional distress has emerged as a theme related to the psychological impact of diabetes among African American women, causing them to feel nervous, tired, and worried about self-management requirements and potential complications (Samuel-Hodge et al., 2000). Quantitative study results show also racial disparities in emotional distress, where African Americans have reported significantly higher levels of T2DM-related emotional distress than Whites (Hausmann, Ren, \& Sevick, 2010; Melkus, et al., 2009). A leading psychosocial issue identified among African Americans living with T2DM is coping with the stress that accompanies the illness (Anderson et al., 1996). 
Additionally, depression is a highly prevalent co-morbidity among individuals with diabetes. The prevalence of depressive disorders among diabetics has been observed to be twice the rate in non-diabetics (Wagner, Abbott, Heapy, \& Yong, 2009), and affects an estimated 10-20\% of individuals living with T2DM (Pouwer, 2009). Moreover, disparities exist in depression among this population as, as African Americans with T2DM have been observed to exhibit high levels of depressive symptoms, in addition to high levels of diabetes-related distress (Thomas, Jones, Scarinci, \& Brantley, 2007). Depressive symptoms have been observed to have a negative impact on recommended T2DM self-care behaviors, including non-compliance with nutrition and physical activity recommendations (Lin et al., 2004), as well as poor glucose control (Gary, Crum, Cooper-Patrick, Ford, \& Brancati, 2000).

\section{Self-determination theory}

A myriad of factors are related to self-management and psychological well-being among people living with T2DM. Factors influencing health behaviors have been observed to be psychologically and socially-rooted, in addition to biologically (Ryan \& Deci, 2000). Useful for its applicability in understanding the relationship between social influences on health behaviors and psychological well-being, the Social Determination Theory (SDT) is a theory of human motivation. In particular, SDT focuses on understanding what social-contextual conditions motivate people to act, such as performing chronic disease self-management behaviors. The theory posits that people are either intrinsically or extrinsically motivated, based upon the extent that their behaviors are autonomously self-regulated, self-endorsed, and performed for their own satisfaction or are motivated by some external source, such as rewards, satisfying others, or avoiding 
punishment (Deci \& Ryan, 2002). Intrinsically motivated individuals are characterized as being self-determined, empowered, goal-oriented individuals who make good decisions and engage in problem-solving. Thus, self-determination is associated with positive outcomes. Contrarily, extrinsically motivated individuals are generally controlled, non-self-determined, and exhibit characteristics opposite of intrinsic motivation (Ryan \& Deci, 2000). Individuals commonly are more emotionally distressed and are less likely to perform behaviors when the behavior is controlled and extrinsically motivated, as opposed to autonomously and volitionally performing the behavior because it is personally valued and the person feels empowered to do so.

\section{Basic psychological needs}

According to SDT the extent to which an individual is intrinsically or extrinsically motivated influences the perceived fulfillment of three essential psychological needs: competence, autonomy, and relatedness (Deci \& Ryan, 2002). Similar to the construct of self-efficacy, the SDT psychological need of competence refers to the overall confidence that individuals perceive themselves to have in relation to effectively performing behaviors. Autonomy refers to the extent that individuals perceive themselves to have volitional control and self-regulation over their decision-making. Relatedness refers to the extent to which individuals perceive themselves to be connected to and cared for by others. The theory posits that optimal health and well-being requires satisfaction of all three psychological needs, and that one or two are not enough (Deci \& Ryan, 2000). The fulfillment of these needs or the lack thereof can greatly influence behavior and psychological well-being among individuals. For example, fulfillment of these needs can contribute a person self initiating behaviors such as self-management of T2DM. In 
contrast, lack of basic need fulfillment is associated with poorer motivation, performance and well-being (Sheldon, Ryan, Deci, \& Kasser, 2004).

Autonomy

Autonomy is perhaps the most studied basic psychological need within SDT. Though all three psychological needs are considered to be necessary and essential to optimal functioning, autonomy is considered to be the "master" need, as it is a critical determinant of motivation (Sheldon, et al., 2003). A premise of SDT is that intrinsic motivation to perform behaviors is optimized when the behaviors are autonomous and volitional (Deci \& Ryan, 2008). An individual is considered to be intrinsically motivated and self-determined when they exhibit characteristics of being self or autonomouslyregulated and empowered. According to SDT, the extent to which autonomy facilitates intrinsic motivation exists on a continuum, which ranges from amotivation, defined as "lacking the intention to act," where no motivation exists, to intrinsic motivation, which represents completely autonomous regulation of behavior (figure 1.1) (Ryan \& Deci, 2000). 


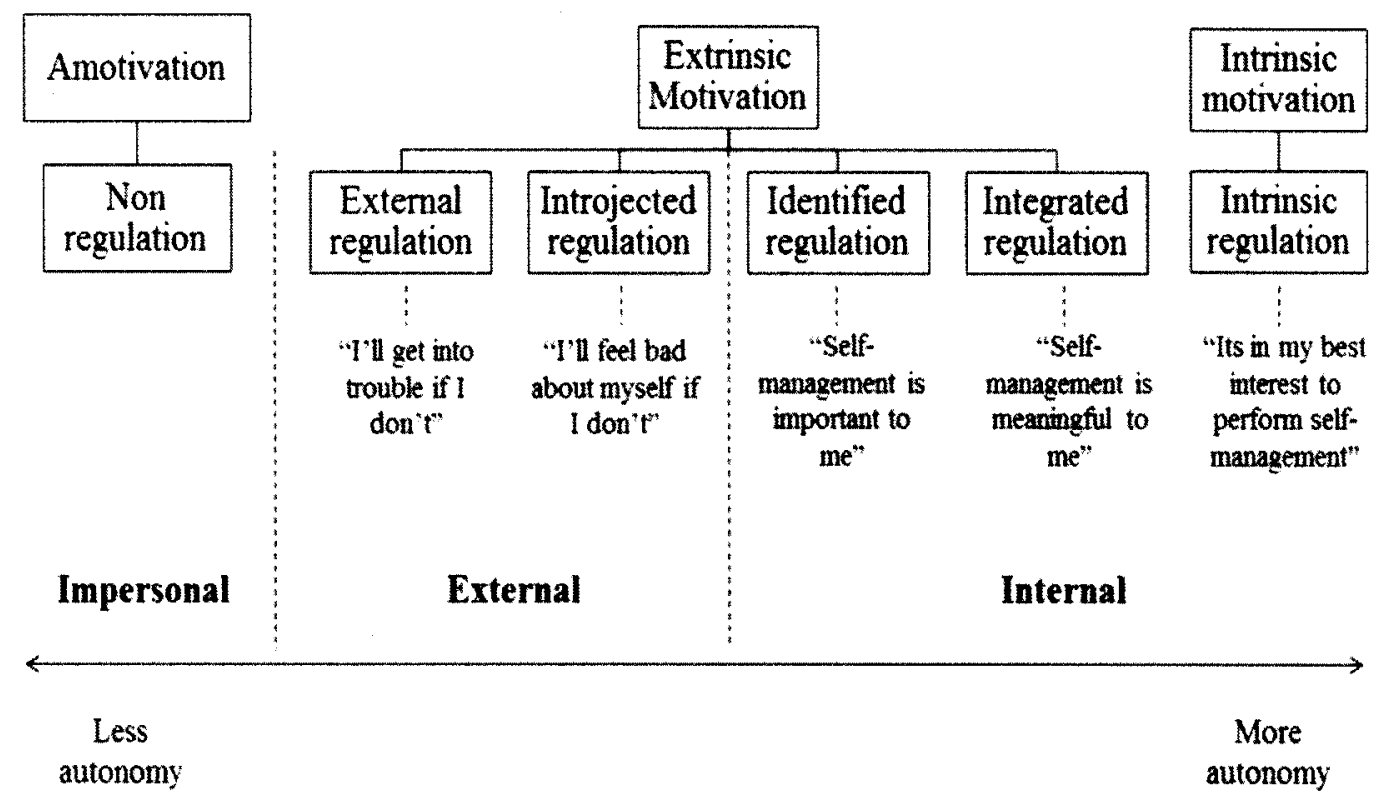

Figure 1.1 Autonomy-Dependent Motivation Continuum, adapted from (Chan, Lonsdale, Ho, Yung, \& Chan, 2009).

There are four forms of extrinsic motivation within SDT. While intrinsic motivation is completely autonomous, extrinsic motivation, resulting from controlled regulation, varies in the degree to which it is autonomous (Deci \& Ryan, 2002; Deci \& Vansteenkiste, 2004). The more controlled regulation from others is internalized and integrated as one's own, the more the extrinsically motivated behavior is experienced autonomously. External regulation, the least autonomous form of extrinsic motivation, exists when a behavior is performed for reasons outside of an individuals' own personal will, such as to get an external reward or to avoid punishment. For example, a person who performs a behavior to avoid judgment or criticism from others for not doing so is engaging in external regulation. Introjected regulation involves internalization of external regulation and occurs when a person performs a behavior because they feel 
personally pressured to do so, in an effort to avoid feelings of guilt or shame and preserve their ego and feelings of self-worth. Thus, the behavior is non-volitional. However, the behavior is controlled by oneself instead of powerful others. The third form of extrinsic motivation that exists on the motivation continuum is identified regulation, which is evident when an individual personally identifies with the value of a behavior and its regulation, and has begun to accept it as their own. Associated with an internal locus of causality, this form of extrinsic motivation is considered to be more self-determined than its predecessors because it involves a conscious valuing of a behavioral goal and acceptance that the behavior is personally important (Deci \& Ryan, 2002). Lastly, integrated regulation is the most autonomous form of extrinsic motivation. Within this form, identified regulation of the behavior is internalized as one's own and is sustainably integrated into their life. Moreover, the behavior aligns with values and goals that are already personally meaningful in the person's life. The more integrated and internalized the behavior, the more it is the basis for self-determined behavior (Deci \& Ryan, 2002). Behaviors are most sustained and long-lasting when they are autonomously regulated.

\section{Competence}

Unlike traditional self-efficacy theory, SDT posits that competence alone is not enough to ensure behavioral outcomes, such as adherence, but instead that efficacy must be accompanied by a sense of autonomy. In particular, SDT researchers suggest that when people feel more autonomous and personally endorse and value behaviors, such as engaging in T2DM self-management, they are more likely to develop the skills and efficacy needed to perform the behaviors (Williams et al., 2009). 


\section{Relatedness}

Self-determined and intrinsic motivational tendencies flourish and is optimized in supportive social contexts, where relatedness needs are being fulfilled, whereas these tendencies are diminished in non-supportive social environments (Ryan \& Deci, 2000). Thus, people function best in supportive social contexts, where they have meaningful, caring connections with others. Self-determination theory posits that relatedness, the least studied basic psychological need, is associated with improved health and wellbeing. Knowledge and skills are important, but as Bremer, Kachgal, \& Schoeller (2003) note, "it is important that key people... in the person's life provide a context conducive to self-determination"(p. 1). The provision of social support is one such mechanism for fulfilling relatedness needs which contribute to this context. A secure relational base promotes intrinsic motivation, unlike isolation. Pertaining to health behaviors, people with more supportive social contexts tend to be more proactive and engaged, whereas alienated people tend to be more irresponsible and lack initiative (Ryan \& Deci, 2000).

\section{Social contexts and basic need fulfillment}

Self-determination theory posits that certain social contexts facilitate fulfillment of basic needs. Figure 1.2 presents the SDT motivational model, which illustrates the socio-contextual characteristics which influence an individuals' perceived fulfillment or thwarting of basic psychological needs. 


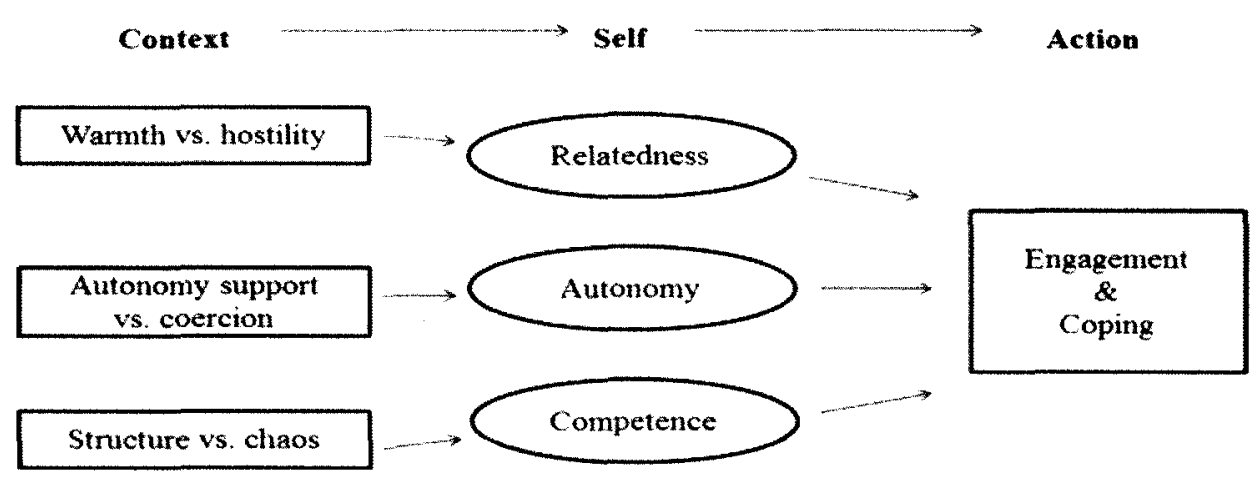

Figure 1.2. Motivational Model of Context, Self, Action, and Outcomes (Skinner \& Edge, 2002).

\section{Social support}

Supportive social contexts, such as those where individuals experience warmth and care, facilitate fulfillment of relatedness needs. For example, social support has been identified as a critical factor which influences self-management and psychological wellbeing among people with T2DM.

Within SDT, the people comprising a patient's social support network are viewed as providing relatedness support to the patient. The theory posits that the size of one's social network is important, but the perceived quality of an individual's support network and the support he or she receives is also critical to satisfying the SDT basic psychological need of relatedness (Ryan \& Deci, 2000). These theoretical assumptions warrant further research regarding the potential relationship existing between social support and perceived relatedness satisfaction. 
Disparities in social support

Racial and ethnic differences have been observed in relation to social support among type-2 diabetics, where African Americans have reported receiving less social support than persons from other ethnic and racial groups (Chlebowy \& Garvin, 2006; Misra \& Lager, 2009). Additionally, women have been found to perceive less social support than men. African American women in particular have indicated that they lack emotional and instrumental support for self-management behavior (Carter-Edwards, Skelly, Cagle, \& Appel, 2004). Other study results have shown that people who are middle-aged and people who live alone perceive themselves to have less social support than people who are young, elderly, or live with others (Toljamo \& Hentinen, 2001). The influence of social support on self-management behaviors has also been observed to vary due to interactions with demographic variables such as race and length of diagnosis (Oftedal, Bru, \& Karlsen, 2011). Collectively, these findings suggest that different population segments may have different diabetes-related social support needs. More studies are needed to investigate the support needs of individuals living with T2DM. Autonomy support

According to SDT, autonomous regulation flourishes in autonomy supportive social environments, where individuals are encouraged and empowered, for example by family members, friends, or their physician, to be actively involved in decision-making regarding their health (Kennedy, Goggin, \& Nollen, 2004). Autonomy-supportive social contexts have been found to improve long-term adherence to self-management for a variety of chronic conditions, including obesity (Silva et al., 2011; Teixeira et al., 2006), and diabetes (Heisler, Bouknight, Hayward, Smith, \& Kerr, 2002; Williams, McGregor, 
Zeldman, Freedman, \& Deci, 2004; Williams, Niemiec, Patrick, Ryan, \& Deci, 2009; Zoffmann \& Lauritzen, 2005).

Disparities in autonomy support

Within research on individuals living with T2DM, women have been observed to report more support from their healthcare team than men (Gucciardi, Wang, DeMelo, Amaral, \& Steward, 2008). Such differences in perceived support may contribute to differences in health behaviors and outcomes among men and women living with the condition.

\section{Disparities in motivation}

Similarly, motivational characteristics have been observed to vary among population sub-sets. To date, much of this research has been focused in education. In particular, research assessing the influence of motivational characteristics on class attendance found motivation to differ by gender, where females were observed to be intrinsically motivated to attend class, whereas males' motivation for class attendance was more controlled, or extrinsic (Vallerand \& Bissonnette, 1992). The study results indicated that autonomous regulation was associated with higher class attendance and better academic performance.

Motivational characteristics influencing self-management and psychological wellbeing may also vary by race. In particular, African Americans have been observed to indicate higher levels of external control regarding their diabetes (Bell, Summerson, \& Konen, 1995), a finding which suggests that this population may have a high perception of controlled regulation. 
Collectively, these research findings warrant more stratified research to be

conducted to assess potential variations in motivational characteristics among individuals living with T2DM. Findings of such studies may implicate the development of tailored interventions to meet the needs of people living with T2DM.

\section{Purpose of the study}

Relatedness, competence, and autonomy support are essential psychological needs identified within SDT. The extent to which these basic needs are fulfilled has great potential to influence decision-making related to health behaviors and can also influence health outcomes such as psychological well-being among individuals living with T2DM (figure 1.3).

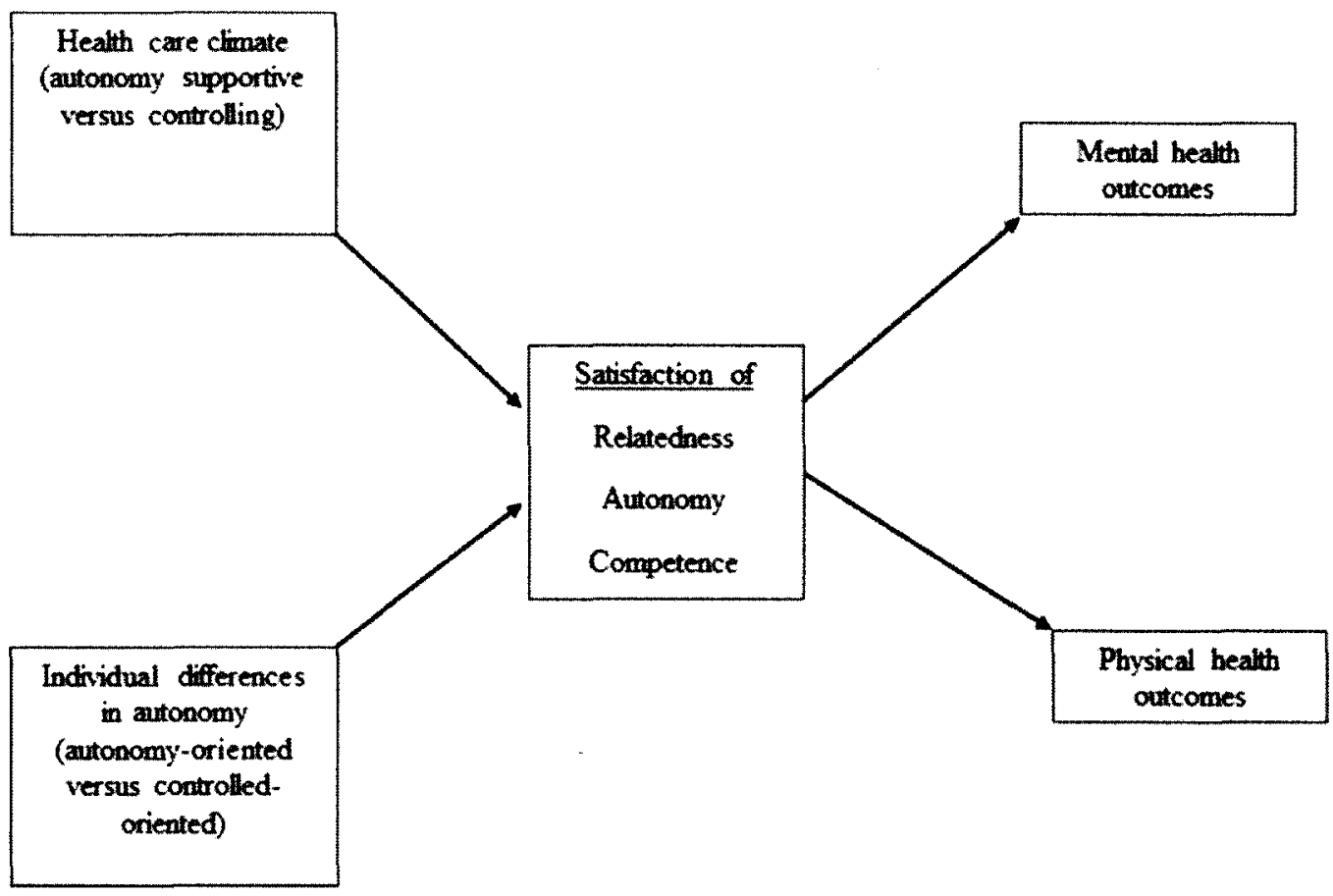

Figure 1.3. Integrated Self-determination Theory Model of Health Behavior Change, adapted from (Ryan, Patrick, Deci, \& Williams, 2008, p. 4) and (Sheldon, Williams, \& Joiner, 2003, p. 54). 
The current study sought to explore the relationships of basic psychological needs to health outcomes of adults living with T2DM, using SDT as the theoretical framework (figure 1.4). In particular, the study assessed self-management and emotional distress as physical and mental health outcomes, respectively, using path analysis.

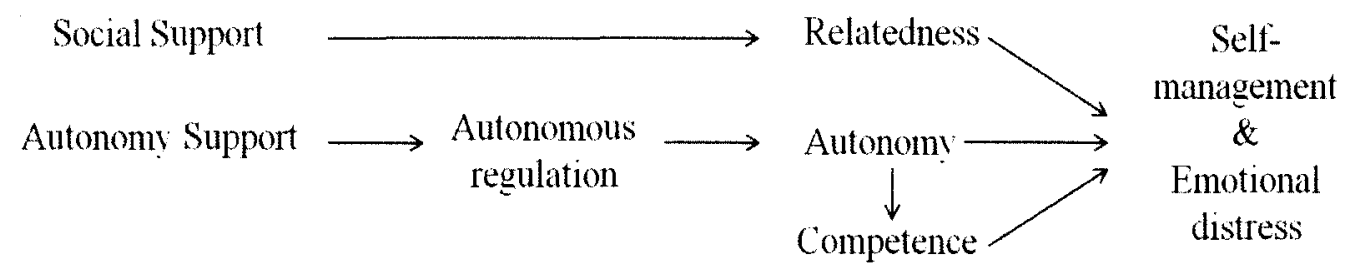

Figure 1.4. Hypothesized Relationships of Study Variables.

Additionally, emphasis was placed on understanding the social contexts which facilitate basic psychological need fulfillment. In particular, the study assessed social support as a facilitator of the SDT psychological need of relatedness. The study also assessed autonomy support as a social-contextual factor which indirectly influences perceived autonomy among individuals with T2DM, through autonomous regulation. Operational definitions for the study variables are presented in table 1.1. 
Table 1.1

Operational Definitions for the Study Variables

\begin{tabular}{|c|c|}
\hline Variable & Operational definition \\
\hline \multicolumn{2}{|l|}{ Social-contextual variables } \\
\hline Autonomy Support & $\begin{array}{l}\text { The provision of patient-centered care, } \\
\text { where healthcare providers afford patients } \\
\text { the opportunity to actively participate in } \\
\text { decision-making regarding the } \\
\text { management of their diabetes. }\end{array}$ \\
\hline Social Support & $\begin{array}{l}\text { The provision of emotional support and } \\
\text { direct assistance with care to a person with } \\
\text { diabetes. }\end{array}$ \\
\hline Autonomous regulation (motivation) & $\begin{array}{l}\text { The extent to which an individual exercises } \\
\text { autonomy and volition in managing their } \\
\text { diabetes. }\end{array}$ \\
\hline \multicolumn{2}{|l|}{ Basic psychological need variables } \\
\hline Relatedness & $\begin{array}{l}\text { One's perceived sense of care, concern, and } \\
\text { availability of, and connectedness to others } \\
\text { in his or her social support network. }\end{array}$ \\
\hline Autonomy & $\begin{array}{l}\text { One's perceived sense of personal } \\
\text { endorsement and volitional control over } \\
\text { diabetes-related decisions. }\end{array}$ \\
\hline Competence & $\begin{array}{l}\text { One's perceived confidence in his or her } \\
\text { ability to manage their diabetes. }\end{array}$ \\
\hline \multicolumn{2}{|l|}{ Outcome variables } \\
\hline Self-management & $\begin{array}{l}\text { An individual's performance of the } \\
\text { behaviors that comprise their diabetes care } \\
\text { regimen, including consuming healthy } \\
\text { foods, monitoring their blood glucose } \\
\text { levels, engaging in physical activity, taking } \\
\text { medications, and checking their feet. }\end{array}$ \\
\hline Emotional distress & $\begin{array}{l}\text { The extent to which an individual feels } \\
\text { emotionally distressed by the experience of } \\
\text { living with diabetes. }\end{array}$ \\
\hline
\end{tabular}




\section{Justification for the study}

Relatedness has been the least studied psychological need within SDT research. Moreover, studies assessing the influence of SDT basic psychological needs on diabetesrelated health outcomes have lacked the inclusion of this important variable. While many SDT studies have focused on autonomy and competence as predictors of health outcomes, the current study sought to contribute to the body of knowledge concerning SDT basic psychological needs, by investigating the under-studied psychological need of relatedness and social contexts which may facilitate fulfillment of the need. Of particular interest for the study was gaining an understanding of how relatedness influences selfmanagement and diabetes-specific emotional distress in comparison to other basic psychological needs, and assessing whether inclusion of the relatedness variable significantly improves the motivational model.

According to SDT, basic psychological needs are considered to be inherent, universal necessities that are applicable to everyone, promoting optimal functioning across gender, culture, and time (Deci \& Vansteenkiste, 2004). However, the means by which the needs are met, and the extent to which they influence outcomes has been found to differ by strata. For example, social support, a hypothesized facilitator of the psychological need relatedness, has been observed to be more influential for maintaining T2DM self-management behaviors among African Americans than Whites. This observation may be attributable to differences in socio-cultural characteristics, such as collectivism and individualism, which influence individuals' level of social engagement and reliance on others. Thus, it is important to assess whether the fulfillment of basic psychological needs vary by strata. 
Type-2 diabetes (T2DM) is a complex, overwhelming chronic condition.

Furthermore, much of the care required to manage T2DM is the responsibility of the person living with the condition. From the perspective of SDT, it is critical for the basic psychological needs of individuals living with T2DM to be met, as fulfillment of these needs ultimately has implications for individuals' physical and mental health. Numerous studies have been published which highlight the disparities between African Americans and other racial-ethnic groups, where African Americans have been consistently observed to have lower rates of adherence to self-management behaviors and worse outcomes than their counterparts. Moreover, health outcomes have been observed to vary for men and women living with T2DM. Thus, it is imperative that comparative research is conducted between strata to understand the modifiable factors, such as social support, autonomy support, competence, and motivation, which relate to these behaviors and outcomes, in an effort to inform the development of meaningful, relevant, and empowering interventions for sub-populations. 


\section{Research questions}

The current study sought to answer the following questions pertaining to individuals living with T2DM:

- How does diabetes-specific basic psychological need fulfillment relate to selfmanagement and emotional distress among urban African American adults living with T2DM?

- $\quad H_{1}$ Null: $\quad$ Basic psychological need fulfillment does not influence diabetes self-management among urban African American adults living with T2DM.

- H $_{1}$ Alternative: Basic psychological need fulfillment influences diabetes self-management among urban African American adults living with T2DM.

- $\mathbf{H}_{\mathbf{2}}$ Null: $\quad$ Basic psychological need fulfillment does not influence diabetes-specific emotional distress among urban African American adults living with T2DM.

- $\mathbf{H}_{2}$ Alternative: Basic psychological need fulfillment influences diabetes-specific emotional distress among urban African American adults living with T2DM.

\section{O} Does social support facilitate relatedness need fulfillment in urban African American adults living with T2DM?

- $\mathbf{H}_{3}$ Null: $\quad$ Social support does not facilitate relatedness need fulfillment among urban African American adults living with T2DM.

- $\mathbf{H}_{3}$ Alternative: Social support facilitates relatedness need fulfillment among urban African American adults living with T2DM. 
Does the inclusion of relatedness improve the goodness of fit of a theoretical model for predicting self-management and emotional distress among urban African American adults living with T2DM?

$\circ \quad \mathbf{H}_{4}$ Null: $\quad$ A model for predicting self-management which includes relatedness will not be a good fit for observed data in the study.

O $\mathbf{H}_{4}$ Alternative: A model for predicting self-management which includes relatedness will be a good fit for observed data in the study.

○ H $_{5}$ Null:

A model for predicting emotional distress which includes relatedness will not be a good fit for observed data in the study.

- H5 Alternative: A model for predicting emotional distress which includes relatedness will be a good fit for observed data in the study.

To what extent do qualitative focus group findings support or dispute quantitative findings?

What are the support needs and preferences of urban African American Adults living with T2DM? 


\begin{abstract}
Summary
The utilization of supportive social networks has been identified as a strategy to facilitate adherence to diabetes self-management regimens and improve psychological well-being. The findings of the current study support the importance of basic psychological need fulfillment in relation to self-management and psychological wellbeing among urban individuals living with T2DM. Moreover, the study results have implications for providing insight for future support interventions. Specifically, results have been summarized into recommendations that can inform tailored social support and empowerment interventions for urban African American adults living with the condition. Interventions are often created without the input of the target population. The current study sought to gain an understanding of the psychosocial needs of urban African American adults living with T2DM as well as gain an understanding of the intrinsic and extrinsic motivational factors that influence adherence to recommended self-management behaviors and psychological well-being within this population.
\end{abstract}




\section{CHAPTER 2}

\section{REVIEW OF LITERATURE}

\section{Introduction}

The review of literature for the current study begins with a discussion of disparities in self-management and psychological well-being among people living with type-2 diabetes (T2DM), on the basis of race, gender, and SES. The next section discusses psychosocial factors that have been observed to influence self-management, including variables that pose as barriers to adherence of T2DM self-management behaviors as well those which facilitate adherence. The goal of this chapter is to present the multitude of factors that can and oftentimes do present themselves as barriers to optimal T2DM self-management from various ecological levels of influence. The remaining review of the literature focuses on influencing factors of interest; social support, autonomy support, basic psychological needs, and motivation. These factors are of particular interest, because they are modifiable social-contextual factors, unlike many other influencing variables. Guided by self-determination theory (SDT), this portion of the review discusses the relation of basic psychological needs to self-management, and psychological well-being. This portion of the review also discusses the relevance of supportive social environments with respect to health behaviors and outcomes. While autonomy support is discussed, the review is largely focused on social support, as it was a primary variable of interest for the current study. 


\section{Purpose of the review}

The purpose of the review of literature for the current study is to present previous research findings which express the magnitude of disparities that exist among population segments regarding T2DM self-management behaviors and related health outcomes, such as psychological well-being. The results of these studies are supporting evidence that different population segments have different needs, even when living with a common chronic condition, such as T2DM. Moreover, a goal of the review is to discuss the multitude of factors that influence health decision-making and psychological well-being among people living with T2DM, and how experience with these factors vary by demographic strata, ultimately contributing to disparities. Emphasis is made on research that has addressed modifiable interpersonal and intrapersonal social-contextual factors, such as social support, autonomy support, and motivation, in an effort to illustrate the relevance of these SDT constructs with respect to health behaviors and outcomes among people living with T2DM. Primarily, the information in this shows the importance of considering social support and relatedness as social aspects which influence diabetes motivation, as well as outcomes including psychological well-being and adherence to self-management regimens.

Literature searches for this review of literature were conducted using Pub-Med via Medline and Psychinfo via Ovid. Pertaining to social support literature, the search term "diabetes" was independently combined in a search with "social support." In a subsequent search, the term "African American" was included with the combined search, in an effort to locate studies which discussed social support among African Americans with diabetes. Similarly to access literature that discussed factors influencing diabetes 
self-management, the term "diabetes" was independently combined with "facilitators," and "barriers." To locate studies on psychological well-being among people living with diabetes, the term "diabetes" was independently combined in searches with "mental health," and "emotional distress." Lastly, several searches were conducted to access relevant studies applying SDT. In particular, the terms "motivation" and "selfmanagement" were combined in independent searches with "chronic illness" and "diabetes," in an effort to locate studies discussing the influence of motivation on chronic illness and diabetes self-management. Similarly, "self-management" and "diabetes" were combined in independent searches with "autonomy support" and "patient-centered care," to access research focusing on the influence of collaborative healthcare approaches on diabetes self-management. Lastly, the SDT website (http://www.psych.rochester.edu/SDT/) was used as a resource to locate literature. The website features all known studies which have applied or discussed SDT, and presents the articles by topic. For the current study, articles were obtained from the "basic psychological needs," "experiments on intrinsic motivation and self-regulation," "motivation and self-determination across cultures," "psychological health and wellbeing," and "healthcare" topic areas. 


\section{Impact of diabetes}

It is estimated that approximately 23.6 million people or $7.8 \%$ of the U.S. population is living with diabetes. Within this estimate about 17.9 million people are diagnosed, while a remaining 5.7 million people go undiagnosed with the disease (National Diabetes Information Clearinghouse, 2007). African Americans are disproportionately impacted by the disease, having the highest diabetes-related incidence, morbidity, and mortality rates. Furthermore, African American males seem to be most affected by the disease, having the highest diabetes-related mortality rates of all gender and racial groups. National estimates suggest that $14.7 \%$ of all African Americans are living with diabetes, while $9.8 \%$ of their White counterparts live with the disease (National Diabetes Information Clearinghouse, 2007). Racial disparities in diabetes can be further observed at the Kentucky state level, where the African American diabetes mortality rate of 51.8 per 100,000 people, is nearly twice that of Whites (26.1 deaths per 100,000 people) (The Kaiser Family Foundation, 2008). Similarly, recent data for the Louisville Metropolitan area indicates that the African American age-adjusted mortality rate from diabetes of 67.3 per 100,000 people is more than double the rate for Whites (30.3 per 100,000 people) (Hall, et al., 2008).

\section{Diabetes self-management}

Diabetes can cause multiple health complications and exists with several comorbidities, including cardiovascular disease, kidney disease, hypertension, stroke, blindness, neuropathy, and dental disease (National Diabetes Information Clearinghouse, 2007). Cardiovascular disease rates among type-2 diabetics are more than twice the rates among the non-diabetic population (Stumvoll, Goldstein, \& Van Haeften, 2005). Thus, it 
is imperative that individuals perform recommended self-management behaviors.

Recommendations for successfully managing T2DM include regular physical activity, consistent monitoring of glucose levels, timely and accurate medication administration, and maintaining a healthy diet (Hwang, 2000). Additionally, patients are responsible for regularly attending their healthcare appointments.

There are numerous physiological benefits to adhering to T2DM self-management recommendations, including reduced risk of co-morbidities such as obesity, cardiovascular disease, and stroke. Additionally, adherence to T2DM self-management behaviors contributes to increased glycemic control. Conversely, non-adherence to selfmanagement behaviors has been observed to be associated with poor glycemic control (Daly et al., 2009). HbAlC, an important biomarker in people living with diabetes, provides information about patients' average glucose control during the month. A retrospective study by Rhee et al. (2005) found that patient adherence to scheduled medical appointments and medications significantly influences $\mathrm{HbAlC}$ levels. Patients who kept scheduled appointments had better $\mathrm{HbAlC}$ levels after 12 months of care than patients who missed appointments (Rhee, et al., 2005). The researchers also observed that the patients with the most adherent to medication regimens had the lowest $\mathrm{HbAlC}$ levels after a one year follow-up (Rhee, et al., 2005). Similarly, Daly, et al. (2009) observed an association between medication adherence and improved glycemic control among women with T2DM. Adherence to dietary recommendations was also found to improve glycemic control in the sample. 


\section{Psychological well-being}

Within SDT, well-being is associated with psychological functioning, and is often indicated by measures of affect, mood, vitality, and symptoms (Reis, Sheldon, Gable, Roscoe, \& Ryan, 2000). Psychology is an important aspect in understanding T2DM, as the disease not only has physical effects on the body, but also has effects on the mental health and overall quality of life of diagnosed individuals. Like selfmanagement, psychological well-being has been observed to vary between population segments. Poor psychological well-being, in particular, has been observed to contribute to poor self-management and consequent outcomes.

\section{Emotional distress and diabetes}

In a study by Verhaak, Heijmans, Peters, \& Meike (2005) assessing the average score for mental health distress among individuals living with a chronic illness, diabetes had the fourth highest score out of the nine disorders that were assessed. Overall, the intrusiveness of T2DM, such as managing a daily regimen consisting of multiple selfcare behaviors, has been identified as a source of frustration among many people living with the disease (Chlebowy, et al., 2010; Manderson \& Kokanovic, 2009). Additionally, patients are commonly overwhelmed by the many barriers they experience to managing their disease. In a mixed-methods study by DeCoster (2003), the most frequently reported emotions associated with participants' diabetes-related distress were fear, irritation, and sadness. Other emotions included anger and anxiety. In particular, study participants have reported becoming frustrated and fearful of future complications when they are sometimes non-adherent to their treatment plan. 
Having diabetes can be a very demanding and socially-isolating experience. This hypothesis is supported by qualitative research findings by Handron \& Leggett-Frazier (1994), where participants reported feeling lonely and socially isolated from others because of the requirements of their T2DM self-management. In particular, participants expressed frustrations regarding dietary restrictions and eating schedules, and indicated that they feel co-dependent on others when they require assistance with care.

For many individuals living with diabetes, support from family and friends plays a critical role in their coping and self-management. In contrast, lack of support from these sources can be detrimental to patients. Qualitative study results suggest that lack of empathy, or emotional support, from family and friends contributes to emotional distress (Handron \& Leggett-Frazier, 1994).

Reduced adherence to self-management behaviors, resulting from distress, may have negative implications for health outcomes of people with T2DM. In particular, Strine, Beckles, Okoro, Balluz, \& Mokdad (2004) observed mental distress to be associated with increased risk for cardiovascular disease, including smoking, high cholesterol, and hypertension. Additionally, distressed study participants also had lower rates of physical activity. Emotional distress also has been shown to influence diabetesspecific outcomes, including glycemic control. In a study by Yi, Vitaliano, Smith, Yi, \& Weinger (2008), diabetes-related distress was observed to be a significant predictor of glycemic control at the study's one-year follow-up assessment.

Disparities in diabetes-related emotional distress

Studies focused on diabetes-related distress have shown the mental health outcome to vary among demographic strata. In particular, gender differences have been 
observed in diabetes-related distress, where women have been found to report more distress than men (Verhaak, et al., 2005). Additionally, distress has been observed to be especially high among African American women living with diabetes, where they commonly report feeling tired and worried (Melkus, et al., 2009; Samuel-Hodge, et al., 2000). Gender disparities in distress may possibly result from the disproportionate amount of social roles that women often fulfill, including the roles of wife, mother, employee, and care-taker (Penckofer, Ferrans, Velsor-Friedrich, \& Savoy, 2007).

Diabetes-related distress has also been found to vary by race. In particular, African Americans have been observed to report more perceived interference of diabetes with daily life, perceived diabetes severity, and diabetes-related emotional distress than Whites (Hausmann, et al., 2010). Similarly, in a study by DeCoster (2003), African American study participants expressed feelings of guilt more so than Whites. In particular, participants felt guilty that they were unable to care for others like they did prior to their T2DM diagnosis.

Several studies have also found that diabetes-related distress is experienced differentially, according to factors such as treatment intensity and length of diagnosis. In a study by Delahanty et al. (2007), participants who were treated with insulin reported significantly more distress than participants who reported being treated with oral medications or dietary restrictions. Closely related, Thoolen, de Ridder, Bensing, Gorter, \& Rutten (2006) observed an interaction between participants' treatment intensity and length of diagnosis. Within this study, intensely treated patients, such as those treated with insulin, reported more distress in the first year of diagnosis, while moderately treated patients, such as those prescribed oral agents, reported more distress 2-3 years 
following diagnosis. These data mirror the findings of a similar study by West \& McDowell (2002), where treatment mode and length of diagnosis were observed to significantly influence emotional distress among individuals living with T2DM. Similarly in a mixed-methods study on diabetes-related distress, DeCoster (2003) observed that the number of distress-related emotions reported by participants was positively correlated with participants' length of diagnosis and the number of diabetesrelated complications experienced. Collectively, these findings show that distress is an issue for people living with T2DM. Additionally, the findings support the development of tailored interventions, to meet the specific needs of different sub-populations among those diagnosed with T2DM, in an effort to reduce diabetes-related stress and improve self-management.

\section{Theory-based intervention research}

Results of qualitative studies suggest that social support may be an important component to include in diabetes interventions. However, a criticism of existing research focused on social support is that the studies lack a theoretical framework that allows empirical measurement of the construct (Van Dam et al., 2005). Taking this into consideration, the current study sought to assess the relationship between social support and relatedness using SDT as an underlying theory. The remainder of this review presents literature pertaining to the theoretical model that was applied in the current study, focusing on social contextual factors, basic need fulfillment, and motivation, respectively. 


\section{Social contextual factors influencing diabetes outcomes}

Multiple factors play a role in patients' decision to adhere to recommended T2DM self-management behaviors, as well as the amount of diabetes-related distress they experience. A premise of SDT is that certain social contexts facilitate the fulfillment of basic needs which promote health and well-being. In particular, basic need fulfillment is maximized in supportive social environments.

\section{Social support}

Social support, a complex, multi-dimensional concept, is categorized into four different functional aspects, including emotional support, instrumental support, informational support, and appraisal support (Glanz, Rimer, \& Lewis, 2002). Emotional support consists of the provision of empathy, love, trust, and care, which assists individuals with coping. Instrumental support pertains to the provision of tangible resources that directly assists a person in need, such as the provision of glucose monitors, testing strips, and other supplies which are necessary for the T2DM self-management. Informational support involves the provision of advice, suggestions, and information that can be used to assist in problem-solving. Appraisal support involves the provision of reinforcing, constructive, feedback and affirmation by others that assist in the selfevaluation of one's behavior (Glanz, et al., 2002).

As noted by House, Umberson, \& Landis (1988), social support involves "positive, potentially health-promoting or stress-buffering aspects of relationships, such as instrumental aid, emotional care, or information" (p.302). Thus, from the perspective of Social Support Theory (SST), social support is intended to be helpful, where 
supportive relationships provide something that people need in order to stay healthy or adapt to stress.

Sources of social support

Study participants have identified peers, or other individuals with T2DM, as a source of emotional and informational support (Anderson, et al., 1996; Chlebowy, et al., 2010; Miller \& Davis, 2005; Toljamo \& Hentinen, 2001). Social support offered by peers has the potential to greatly improve patients' T2DM self-management. Findings from qualitative studies by Hood, Chlebowy, and LaJoie (2009) and Chlebowy, Hood, and LaJoie (2011) indicate that peer support groups are a desirable component of diabetes self-management and coping among urban African Americans. Peer support groups have been utilized as effective strategies to improve coping and self-management in several chronic diseases, including breast cancer (Stang \& Mittelmark, 2008), prostate cancer (Oliffe, Ogrodniczuk, Bottorff, Hislop, \& Halpin, 2009), and HIV (Lennon-Dearing, 2008). Additionally, numerous benefits to T2DM peer support group participation have been cited in the literature. Qualitative results by Steinhardt, Mamerow, Brown and Jolly (2009) support the effectiveness of peer support groups for African Americans with T2DM, suggesting that support group participation improves perceived social support, diabetes-related attitudes, self-management behaviors and health outcomes among this population.

Patients with T2DM have also commonly reported receiving social support from family members. In particular, study participants have often indicated that family members provide emotional support and instrumental support related to their dietary needs, such as encouragement and assistance with food preparation and grocery 
shopping, as well encouraging and reminding patients to regularly take their medications (Chlebowy, et al., 2010; Miller \& Davis, 2005; Rosland et al., 2008; Toljamo \& Hentinen, 2001). Additionally, participants have acknowledged receiving other dimensions of social support, including appraisal support for self-monitoring of blood glucose (SMBG) and dietary decisions, such as food choices and portion control, from spouses and children (Miller \& Davis, 2005). Studies have observed that female family members and friends are especially supportive to people with T2DM (Chlebowy, et al., 2010).

\section{Disparities in social support}

The impact that social support from family and friends has on T2DM selfmanagement behaviors has been observed to vary by demographic characteristics, such as race and gender. African American women in particular have indicated that they lack emotional support and reinforcement for self-management from family members (CarterEdwards, et al., 2004). In contrast, males commonly acknowledge receiving emotional support from spouses (Nagelkerk, et al., 2006). Additionally, men have reported receiving more support than women (Toljamo \& Hentinen, 2001), especially as it pertains to dietary needs (Maclean, 1991). Perceived lack of support from healthcare providers has also been associated with increased diabetes-related distress among African Americans with T2DM (Spencer et al., 2006). Differences in perceived social support may be related to differential diabetes-related health behaviors and outcomes of subpopulations. 
Social support and diabetes self-management

Numerous benefits have been associated with having a strong support network, including having positive attitudes and greater perceived success regarding T2DM selfmanagement. Additionally, individuals with strong support networks have been observed to be more proactive in their T2DM self-management, and engage in information-seeking behaviors for materials that assist with better understanding and managing their diabetes (Nagelkerk, et al., 2006). Positive social support has also been identified as an independent predictor of self-management among diabetics (Osborn \& Egede, 2010), and has been associated with increased practice of dietary and physical activity recommendations among people living with T2DM (Tang, Brown, Funnell, \& Anderson, 2008). Additionally, the availability of social support has been positively correlated with appointment-keeping, foot care, and dietary adherence among people with diabetes (Belgrave \& Lewis, 1994).

Support from family members and friends has been shown to significantly influence patient self-management behaviors. In a study by Toljamo \& Hentinen (2001), participants who received social support from family members and friends were observed to be significantly more adherent to T2DM self-management than others who did not. Specifically, support from family and friends has been associated with increased dietary adherence (Maillet, D'Eramo Melkus, \& Spollett, 1996; Nagelkerk, et al., 2006), as well as SMBG adherence (Rosland, et al., 2008).

Social support and psychological well-being in diabetes

Social support has been identified as an important component of coping with diabetes-related distress. In particular, it has been hypothesized that social support 
influences the perception of diabetes-related stress (Van Dam, et al., 2005). The literature suggests that social support has a "stress-buffering" effect that assists with coping and stress adaptation (Ford, Tilley, \& McDonald, 1998).

Studies assessing the relationship between social support and psychological wellbeing have largely been qualitative, and have primarily been conducted with African American females. Lack of empathy, or emotional support, has been identified as a stressor among African American women with T2DM (Samuel-Hodge, et al., 2000). People in their social networks, especially family members, have been identified as having a lack of understanding of their emotional needs. Despite the acknowledgement that family members have good intentions and try to provide instrumental support, lack of emotional understanding exhibited by family members causes support has been observed to be perceived negatively by African American women with T2DM (Carter-Edwards, et al., 2004). Thus, family members often provide assistance, but don't provide what the women need.

Studies have also found that African American womens' low perception of social support is influenced by their multiple roles, such as mother, wife, and employee, which often take precedence over their own T2DM self-management (Carter-Edwards, et al., 2004; Samuel-Hodge, et al., 2000). This consequently leads to women feeling overwhelmed by T2DM. Thus not surprising, in a recent qualitative study by Chlebowy, Hood, and LaJoie (in preparation), African American women reported more barriers to self-management than men, commonly referring to the stress of managing T2DM in the context of everyday living. More studies are needed to assess the relationship between 
social support and psychological outcomes within other populations, including males and other racial/ethnic groups.

\section{Autonomy support}

Healthcare providers have been identified as key members of T2DM patients' social support network, in addition to family, friends, and peers. In a recent crosssectional study, majority of survey respondents indicated that they had more support from healthcare providers than from family and friends (Oftedal, et al., 2011). In particular, study participants have acknowledged healthcare providers as a source of informational and appraisal support in relation to dietary needs and glycemic control (Miller \& Davis, 2005).

Closely related to patient-centered care, SDT suggests that an autonomy supportive social context is characterized by patients feeling heard and where providers are non-judgmental (Sheldon, et al., 2003). Such an approach requires that healthcare providers listen to their patients, rather than treating them paternalistically. Within this approach, it is important for providers to gain an understanding of patients' feelings toward the proposed treatment plan, and give patients the opportunity to choose the best option. Thus, autonomy supportive clinical contexts require practitioners to have meaningful discussions with their patients. It is not enough for supportive social contexts to simply exist in an effort to fulfill the SDT psychological need of relatedness. Selfdetermination theory posits that autonomy and volition must also be present. Specifically, environments must be autonomy supportive, such that they promote internalization of behavioral motivation. It is through this process that controlled 
regulation from healthcare providers is integrated into patients' ideology, and is perceived as autonomous regulation (Deci \& Ryan, 2002).

Autonomy support and self-management

In several recent studies, autonomy support from physicians and other healthcare providers has been positively associated with autonomous regulation for a variety of health-related behaviors, including smoking cessation (Williams et al., 2006; Williams, Niemiec, et al., 2009), physical activity (Chan, et al., 2009; Silva, et al., 2011; Teixeira, et al., 2006), and medication taking (Williams, Freedman, \& Deci, 1998). Within most of these studies, autonomous regulation has been observed to be a mediating variable in the relationship between autonomy support from healthcare providers and patient health behaviors and consequent outcomes.

Autonomy support has also been observed to facilitate autonomous regulation for self-management behaviors among people living with diabetes. Follow-up data from a longitudinal study by Zoffmann \& Lauritzen (2005) revealed that participants of a guided self-determination intervention had a significant increase in self-reported self-monitoring of blood glucose (SMBG), whereas the control groups' SMBG was largely unaffected. Autonomy support has also been observed to influence health behaviors and outcomes among individual living with T2DM. In a longitudinal study by Williams, et al. (2004), autonomy support was associated with increased autonomous regulation for diet, exercise, medication taking and SMBG. Additionally, the researchers observed autonomous regulation to be a mediating variable in the association between autonomy support and glycemic control. Similar results were found in a subsequent study, where an indirect association was observed between autonomy support and medication adherence 
among diabetic respondents, mediated by autonomous regulation (Williams, Patrick, et al., 2009). These findings demonstrate the important mediating role that autonomous regulation plays in the association of autonomy support from healthcare providers and patient behaviors and health outcomes.

In a study by Heisler, et al. (2002), increased perception of participatory decisionmaking style and satisfaction with patient-provider communication was found to be positively associated with patients' adherence to diabetes self-management behavior. Results of recent studies also suggest that the impact of support on patient selfmanagement behaviors is not limited to physicians. In particular, Rosland et al. (2008) found that support from non-physician healthcare professionals was associated with regularly checking feet and dietary adherence among people with T2DM. Such findings speak to the importance of involving non-physician healthcare professionals in collaborative care for T2DM.

While autonomy support has been observed to facilitate patient motivation for health behaviors, controlling dimensions of support from healthcare providers has been associated with diminished motivation and reduced adherence among diabetes patients. In a study by Rosland et al. (2008) support from physicians was negatively associated with dietary adherence. Seemingly, this support is a form of external regulation. The researchers of this study concluded that perhaps too much support is not helpful and is perceived negatively and is viewed as paternalistic, or controlling. The literature also suggests that lack of autonomy support from health providers is a barrier to selfmanagement among people with T2DM. In particular, some researchers have concluded that health care providers often do not collaboratively interact with their patients, such as 
understanding the complexity of the disease from the patients' perspective or understanding that patient' goals. In contrast, it has been hypothesized that many times providers simply manage patients' $\mathrm{T} 2 \mathrm{DM}$ using their $\mathrm{HbAlC}$ and fasting glucose readings (Freeman \& Loewe, 2000). However, failure to understand or gain insight into factors influencing patients' ability to self-manage their disease results in a missed opportunity for providers to work with patients to develop and suggest relevant strategies that will increase adherence to self-management recommendations and improve patient outcomes.

Autonomy support and psychological well-being

Several studies investigating the effects of autonomy support have measured indicators of psychological well-being among individuals with diabetes, and have observed positive associations between autonomy support and these outcomes. In a study by Zoffmann \& Lauritzen (2005), participation in an autonomy supportive selfmanagement education intervention was associated with improved psychological wellbeing among adults with type-1 diabetes. Specifically, the study's one-year follow-up assessment found that intervention participants had a significant decrease in diabetesspecific emotional distress from baseline, especially regarding treatment-related distress. Autonomy support has also been observed to be associated with psychological well-being among patients with T2DM. Correlation analyses, in a cross-sectional study by Williams, McGregor, King, Nelson, \& Glasgow (2005) showed perceived autonomy support from healthcare providers to be negatively associated with depressive symptoms. Additionally, regression analyses revealed that autonomy support was a significant predictor of depressive symptoms among study participants. 


\section{Basic psychological needs}

While personal needs can be infinite, SDT applies criterion to basic needs, focusing only on those that are essential to optimal functioning and well-being. From a functional perspective, basic psychological needs refer to the "innate psychological nutriments that are essential for ongoing psychological growth, integrity, and well-being" (Deci \& Ryan, 2000). From the perspective of SDT, nutriments can be viewed as social aspects which contribute to optimal physical and mental functioning. Thus, SDT posits that satisfaction of basic psychological needs is associated with the most effective functioning, and is facilitative of intrinsic motivation and integrative tendencies (Deci \& Vansteenkiste, 2004)

Previous research suggests that people whose basic psychological needs have been met tend to function more autonomously and are intrinsically motivated (Ryan, 1995). According to SDT researchers, an individual's capacity to be intrinsically motivated or to internalize extrinsic motivation is largely dependent on his or her history, such as his or her upbringing. In particular, people who have been controlled will typically exercise less autonomy, and will consequently be less intrinsically motivated to perform behaviors than individuals who have been afforded more opportunities to act autonomously. However, SDT posits that present conditions, such as those that promote fulfillment of basic psychological needs, can also play a significant role in the facilitation of intrinsically motivated behavior (Ryan, 1995). Specifically, supportive social environments promote fulfillment of the essential psychological needs of relatedness, autonomy, and competence. 
According to SDT, fulfillment of those needs ultimately facilitates intrinsically motivated behavior, and contributes to improved physical and mental health outcomes. Moreover, it has been hypothesized that each need is basic, but distinct, and has potential to independently influence individual well-being, and should thus have empirically distinguishable effects (Reis, et al., 2000). To date, most research assessing basic need fulfillment has focused on autonomy and competence needs, leaving relatedness needs largely understudied.

\section{Relatedness}

Relatedness, the need to feel related to others, is characterized by care, concern, and close connections to others (Reis, et al., 2000). Similar to autonomy and competence, relatedness is a fundamental and distinct need. Living with T2DM can be a very socially-isolating experience when individuals lack adequate social support and access to social networks. Thus, relatedness is likely a critical social component of people living with T2DM.

\section{Relatedness and diabetes self-management}

People with T2DM who live alone have been observed to have poorer adherence to recommended self-management behaviors than others who live with family members (Toljamo \& Hentinen, 2001). In particular, lack of access to social support and social networks has been found to reduce adherence to recommended diabetes self-management behaviors, including regularly taking medication (Tang, et al., 2008), engaging in physical activity (Collins-McNeil, Holston, Edwards, Benbow, \& Ford, 2009), and can ultimately contribute to poor glycemic control among diabetics (Schwartz, Coulson, Toovy, Lyons, \& Flaherty, 1991). 
Relatedness and psychological well-being

Relatedness has also been observed to be influential regarding mental health outcomes. In the existing literature, positive associations have been observed between relatedness and well-being. In particular, satisfaction of relatedness needs has been found to be predictive of positive affect and vitality (Reis, et al., 2000). Closely related, emotional reliance, a measure of individuals' willingness to rely on others for emotional support, has also been found to be positively associated with well-being (Ryan, La Guardia, Solky-Butzel, Chirkov, \& Kim, 2005).

\section{Disparities in relatedness}

Research findings suggest that emotional reliance varies by gender and cultural context (ie. collectivist vs. individualistic), where females have a greater reliance on others for emotional support, as do individuals with collectivist cultural backgrounds (Ryan, et al., 2005). More stratified research is needed, to investigate potential differential relatedness need fulfillment in contexts, such as health, as findings may increase knowledge surrounding the relationship of relatedness to psychological wellbeing among the chronically-ill.

\section{Relatedness and motivation}

While SDT suggests that relatedness satisfaction is important for physical and mental health outcomes, little research has been conducted to support this theoretical assumption. Moreover, conflicting conclusions have been observed in the literature pertaining to the relevance and role of relatedness with respect to motivation. For example, Deci \& Vansteenkiste (2004) have suggested that relatedness is less integral for supporting intrinsic motivation than the needs for autonomy and competence. In contrast, 
Ryan, Patrick, Deci, \& Williams (2008) supports relatedness needs as a critical component of motivation, suggesting that relatedness is particularly important for internalization on the SDT continuum of motivation. From this perspective, the theory posits that people adopt the values and behaviors promoted by others to whom they feel closely connected to and trust. Relatedness perceptions are thus increased in social contexts where an individual is respected, understood, and cared for. Other SDT literature suggests that relatedness is also important for of integration (Ryan, 1995). Integration, a process which involves mastery and ownership of one's actions, largely depends on relational supports. As noted by Ryan (1995), "there can be no integration of a separate individual" (p.420). More research is needed, however, to understand the relation, if any, which exists between relatedness and motivation. Social support and relatedness

To date, little research has been conducted to assess the influence of social contexts on relatedness satisfaction. However, previous studies have sought to identify conditions which facilitate fulfillment of the basic need. In particular, Reis, et al. (2000) identified the social experiences that contribute to fulfillment of relatedness needs. The authors concluded that several forms of interaction seem likely to contribute to relatedness satisfaction, including having meaningful conversation with others and feeling understood and appreciated by others. These findings seem to suggest that emotionally-supportive social interactions contribute to satisfaction of relatedness needs.

\section{Competence}

Similar to self-efficacy, competence is characterized by a person's sense of confidence and perceived capability to function in an environment or context. Self- 
determination theory posits that competence is facilitated by autonomy (Ryan, et al., 2008). Though similar, several distinctions can be made between self-efficacy and the SDT construct of competence. Within Bandura's (1977) Social Cognitive Theory, selfefficacy is considered to be a behavior-specific construct. In contrast, competence appears to represent a more general confidence in one's overall mastery of behavior. Thus, from the perspective of self-efficacy, a person may feel highly efficacious in his or her ability to take his or her medication, a specific behavioral aspect of self-management. However, from the perspective of SDT, an individual may feel highly competent in his or her overall ability to manage his or her diabetes, which takes into account all selfmanagement behaviors. Self-efficacy and diabetes self-management

Numerous studies have demonstrated that self-efficacy plays an essential role in chronic disease self-management. Moreover, studies focused on T2DM have consistently shown that diabetes self-efficacy is a critical determinant of T2DM self-management behavior performance, and ultimately impacts health outcomes within individuals living with the disease. For example, in a recent cross-sectional study, an increased perception of self-efficacy was found to be associated with increased adherence to diabetes selfmanagement regimens among study participants (Sousa, Zauszniewski, Musil, Price Lea, \& Davis, 2005). Additionally, results from regression analyses in the study found selfefficacy to be a significant predictor of diabetes self-management, after controlling for demographic variables, where the model explained a significant proportion of variance in self-management behaviors (Sousa, et al., 2005). These results mirror findings of study 
by Aljasem et al. (2001), where greater self-efficacy predicted more frequent SMBG and adherence to medication and dietary regimens.

Among studies assessing psychosocial predictors of T2DM self-management behaviors, self-efficacy has often been observed to be a leading predictor amongst other variables under consideration. For example, in a recent study by Plotnikoff et al. (2011), self-efficacy was observed to be the strongest predictor of physical activity and resistance training among individuals with T2DM. Moreover, self-efficacy has been observed to be an important and influential construct as it pertains to increasing physical activity among individuals living with T2DM. Results of a intervention study by Dutton et al. (2009) show that self-efficacy mediated the relationship between a tailored exercise intervention and physical activity outcomes of study participants.

As defined within Bandura's Social Cognitive Theory (1977), self-efficacy is a behavior-specific construct. However, for people living with diabetes, perceived selfefficacy is complicated by the multitude of self-management activities involved in their daily care regimen. Specifically, self-management of T2DM involves a complex regimen that consists of multiple self-care behaviors, each of which consists of their own selfefficacy (Rapley \& Fruin, 1999). For example, individuals must feel efficacious in their ability to perform specific behaviors, such as SMBG and engaging in physical activity.

Findings of previous research investigating the relationship between diabetes selfefficacy and self-management have observed that patients' perception of self-efficacy varies by T2DM self-management behavior. For example, in a study by Kingery and Glasglow (1989), participants rated themselves lower on exercise efficacy than other T2DM self-management behaviors, despite rating their outcome expectations highest for 
exercise. Thus, participants of this study recognized and acknowledged the health benefits of exercise, but did not feel confident in their ability to perform the behavior as much as other behaviors. Similar findings were observed in a subsequent study by Aljasem et al. (2001), where participants' perception scores were highest for reliance efficacy, or their perceived capability of getting diabetes-specific help from others, and planning efficacy regarding their meals and SMBG. Results of other studies also indicate that the influence of self-efficacy on diabetes self-management varies by selfmanagement behavior. For example, in a study by Sarkar, Fisher, and Schillinger (2006), diabetes self-efficacy was observed to be associated with an increase in all selfmanagement behaviors except medication adherence. Collectively, these findings suggest that patients do not feel equally efficacious for all diabetes self-management behaviors. Some researchers suggest that this may be due to the presence of barriers to performing the behavior, or the overall perceived difficulty of the specific behavior (Kingery \& Glasgow, 1989). Thus, from the perspective of SDT, a more general appraisal of perceived mastery, such as competence, may be more beneficial in the assessment of T2DM self-management efficacy.

Disparities in diabetes self-efficacy

Results of previous studies indicate that diabetes self-efficacy is indeed influenced by the presence of barriers. For example, findings from recent qualitative research from Chlebowy, Hood, \& LaJoie (2010) indicate that barriers reduce individuals' perceived efficacy and overall motivation to engage in T2DM self-management behaviors. In particular, barriers, such as financial constraints may reduce individuals' confidence in their ability to regularly perform self-management behaviors such as SMBG or 
purchasing healthy foods. Moreover, the disproportionate burden of barriers faced by some sub-populations living with T2DM may contribute to reduced self-efficacy within members of these groups, and may consequently lead to lower rates of self-management and worse health outcomes.

Stratified studies focused on the relationship between diabetes self-efficacy and adherence to self-management behaviors have consistently indicated that the association between self-efficacy and self-management does not vary among racial and ethnic groups (Chlebowy \& Garvin, 2006; Sarkar, et al., 2006). However, other studies have presented evidence of gender disparities in diabetes self-efficacy as it relates to self-management behaviors. For example, results of a previous study by Kingery and Glasglow (1989) showed that though exercise self-efficacy was significantly correlated with exercise adherence among all study participants, the relationship was moderated by gender. Specifically, the researchers observed that the association of exercise self-efficacy and exercise adherence was significantly stronger among female participants than males (Kingery \& Glasgow, 1989). Additionally, recent independent research studies have presented polarized results pertaining to self-efficacy scores among men and women. African American women have been observed to have high diabetes self-efficacy scores (Montague, Nichols, \& Dutta, 2005), however research consisting of a predominately White male sample found participants to have very low diabetes self-efficacy scores (Nelson, McFarland, \& Reiber, 2007). These findings suggest that potential race and gender interactions may play a role in self-efficacy outcomes among people living with T2DM. 


\section{Autonomy}

Within SDT, autonomy needs are characterized by individuals' urge to be causal agents, act volitionally, and personally-endorse their actions (Deci \& Vansteenkiste, 2004). In essence, people need to feel a sense of willingness and choice when acting. Of the three basic psychological needs, autonomy is considered to be the master need, and is defined as "regulation of the self by the self rather than by non-assented-to internal and external forces" (Sheldon, et al., 2003, p. 18). Critical to motivation, autonomy is the basis for which actions are categorized as being either intrinsically or extrinsically motivated. Autonomy will be discussed in the remainder of the literature review pertaining to motivation.

\section{Motivation}

While many factors influencing health outcomes are beyond patients' control, research has shown that motivation for performing behaviors is an important modifiable component that facilitates the sustainability of behaviors, as well as positive outcomes resulting from sustained behaviors. Within SDT, two types of motivation or regulation exist: controlled and autonomous. Self-determination theory posits that though the amount of variance in motivation is a function of physiological mechanisms in the brain, it is primarily a function of the sociocultural conditions in which people act (Deci \& Ryan, 2008). Corresponding to extrinsic motivation, behavior resulting from controlled regulation is influenced by an external locus of causality, meaning that factors external to the self are the reason behind the behavior being performed (Ryan \& Deci, 2002). Moreover, controlled regulation is associated with a sense of pressure or coercion, from self or others, to perform the behavior. Thus, the behavior is forced and non-volitional. 
In contrast, autonomous regulation is associated with intrinsic motivation resulting from an internal locus of causation (Ryan \& Deci, 2002). Autonomously regulated behavior is volitionally performed, for reasons such as the patient finding the behavior to be valuable or beneficial to his or her health. Self-determination theory researchers suggest that the type of motivation is more important than the amount, as it pertains to outcomes (Deci \& Ryan, 2008).

\section{Autonomous regulation and self-management}

Several studies have demonstrated the efficacy of autonomously regulating health behaviors. In particular, many studies using SDT as a theoretical framework have investigated the influence of autonomous regulation in research focused on dietary behaviors and weight loss. Self-determination theory posits that autonomous regulation facilitates sustained behavior, thereby improving health outcomes. Study results by Pelletier, Dion, Slovinec-D'Angelo, \& Reid (2004) support this assumption, as autonomous regulation was observed to be associated with long-term adherence to healthy dietary behaviors among female college students. In contrast, controlled regulation was associated with unhealthy eating behaviors, as indicated by bulimic symptomology. Though the study results suggest that both autonomous and controlled regulation were associated with dietary behaviors, findings indicate that the association

was stronger for autonomous regulation than controlled regulation. Similar findings were observed in a related sub-study by Pelletier, et al. (2004), where self-determined, or autonomous, regulation of dietary behaviors was a significant predictor of dietary behaviors at follow-up among individuals at risk for developing coronary artery disease. In particular, mean percent of calories from total dietary fat and saturated fat were 
reduced from baseline for self-determined individuals. Moreover, researchers observed that the more self-determined participants were with respect to practicing health dietary behaviors, the more successful they were in reducing their total and saturated fat intake over the 26-week intervention period. These results support the importance of encouraging and empowering individuals to be autonomous and intrinsically motivated to perform self-determined health behaviors, in an effort toward sustainability.

Autonomous regulation has also been associated with long-term weight-loss, resulting from adherence to physical activity regimens. In a study by Silva, et al. (2011), motivation was observed to play a mediating role in the relationship between participation in an autonomy supportive weight control intervention and three-year weight loss among study participants. In the study, the intervention group experienced greater weight loss than control participants at the one-year assessment. Additionally, intervention participants reported higher levels of physical activity accompanied by increased intensity than the control group. These findings were mirrored during the two and three-year follow-up assessment for the study. Similarly, results of a study by Teixeira, et al. (2006) showed intrinsic motivation to be significantly associated with four-month weight change in middle-aged overweight and obese women who participated in an intervention to increase competence and autonomy for physical activity. Additionally, exercise motivation was the most significant independent predictor of weight loss in the 4-16 month follow-up period. In particular, the interest/enjoyment factor of the study's exercise motivation assessment scale had the strongest correlation with weight outcomes. These findings highlight the relevance of intrinsic motivation and autonomous regulation to the sustainability of behaviors that ultimately contribute to 
improved health outcomes, such as long-term weight loss. Moreover, the findings suggest that autonomy is critical for optimal control of chronic diseases, such as T2DM, that require long-term self-management.

Several studies have demonstrated that autonomous regulation facilitates selfmanagement behaviors in people living with diabetes. In a study by Greening et al. (2004), intrinsic motivation was found to be positively associated with adherence to treatment regimens among adolescent study participants living with Type-1 diabetes. These findings have been mirrored within studies focusing on adults with T2DM. For example, Senecal, Nouwen, \& White (2000) found autonomous regulation to be significantly associated with adherence to dietary self-care activities among people living with T2DM. Similarly, a study by Shigaki et al. (2010) found that individuals with higher levels of autonomous regulation were more adherent to dietary and SMBG recommendations. Indirect relationships have also been observed between autonomous regulation and medication adherence (Williams, Patrick, et al., 2009), as well as between autonomous regulation and adherence to diet and exercise self-care activities among diabetic individuals, where the relationships are mediated by competence, a SDT construct (Williams, et al., 2004). Collectively, these findings highlight the importance of intrapersonal motivational characteristics in T2DM self-management.

Autonomous regulation and psychological well-being

Autonomous regulation has been significantly associated with life satisfaction among adults living with diabetes (Senecal, et al., 2000). Autonomous regulation has also been observed to be indirectly related to quality of life, where competence mediates the relationship (Williams, Patrick, et al., 2009). More research is needed to understand 
the relationship between motivation type (autonomous vs. controlled) and mental health outcomes specific to individuals living with diabetes, such as diabetes-related emotional distress. 


\section{Summary}

Theory-based literature presented in this review suggests that intrapersonal factors, such as motivation, can have a great impact on individual health behaviors and outcomes. In particular, the reason(s) as to why a person performs behaviors, such as T2DM self-management, has been shown to influence motivation for the behavior as well as the sustainability of the behavior. Existing research also demonstrates that motivation is an important modifiable factor, given conducive social conditions, such as supportive environments. The literature presented in this review suggests that individuals' adherence to T2DM self-management regimens is heavily influenced by healthcare providers, and flourishes in autonomy-supportive climates. Research also suggests that health outcomes are influenced by other interpersonal factors, such as social support received from family members and friends. However, more theory-based quantitative research is needed to assess the relationship(s) between social support and health outcomes, as most studies to date have been qualitative in nature.

Lastly, the literature presented in this chapter supports the SDT assumption that basic psychological need fulfillment is associated with physical and mental health outcomes among people with T2DM and other chronic conditions. Moreover, results from studies on relatedness needs support the importance of including the construct in motivational models, as well as future studies. In particular, more research is needed to understand the relationship between relatedness and health outcomes, and how relatedness functions in comparison to other, more studied basic psychological needs, such as autonomy and competence. 


\section{CHAPTER 3}

\section{METHODS AND MATERIALS}

\section{Introduction}

Chapter three provides information pertaining to the methodology of the current study. The chapter begins with a discussion of the study design and recruitment methodology that was employed by the study. Next, the chapter presents the data collection methods that were applied in the study, including the psychometric properties and corresponding validity and reliability studies of instruments for the current study. The chapter ends with a presentation of the analyses that were conducted for the study.

\section{Study design}

The study was a mixed-method descriptive study, intended to gain an in-depth understanding of how supportiveness of social contexts relates to diabetes-specific basic psychological need fulfillment (relatedness, autonomy, competence), and to assess how fulfillment of basic psychological needs influences physical and mental health outcomes among urban individuals with type-2 diabetes (T2DM). Additionally, the study sought to assess the extent to which qualitative focus group discussion confirmed or disputed quantitative survey findings. Lastly, the study intended to gain an understanding of the support needs and preferences of urban African American adults living with T2DM. 


\section{Recruitment}

Recruitment for the study took place between February 2012 and June 2012.

African Americans were recruited from barbershops, churches, health fairs, clinics, diabetes education classes, and social organizations. Some participants were referrals, recruited through snowball sampling. Additionally, participants responded to informational flyers that were located in clinical and community settings (appendix A), as well as electronic advertisements in $U$ of $L$ today.

Inclusion criteria

Individuals were eligible to participate in the study if they were Non-Hispanic black, diagnosed with T2DM, 18 years or older, and a resident of Louisville. Incentives

Following the completion of a written questionnaire for the study, participants were entered into a drawing for $\$ 100$ in Wal-mart gift cards. A total of eight drawings took place during the study. A random name drawing was made after every 20 participants.

\section{Sample size consideration}

An a priori sample size was calculated for the proposed study using the $N: q$ hypothesis (Jackson, 2003). Commonly used to estimate sample size for studies using structural equation modeling (SEM), the N:q hypothesis provides estimates by calculating a ratio of ratio of cases $(\mathrm{N})$ to the number of parameters that require statistical estimation (q). Typically, 10-20 cases are required for each estimated parameter in SEM models. The specified models in the current study each consist of 15 unknown 
parameters which needed to be estimated (see figure 3.1). Based on the N:q rule, a requirement of 150 participants was calculated for the study, using a 10:1 ratio.

\section{Quantitative data collection}

The current study recruited individuals to complete a written questionnaire regarding the association of perceived social support, perceived autonomy support, autonomous regulation, and basic psychological need fulfillment with self-management and psychological well-being. Prior to being widely administered, the questionnaire was pilot tested with a population similar to the study sample.

\section{Study variables}

Independent variables measured in the current study included perceived social support, perceived autonomy support, perceived self-regulation, perceived basic psychological need fulfillment, and demographic variables. Self-management behaviors and diabetes-related distress were assessed as dependent variables in the study.

\section{Data collection instruments}

Seven instruments were used to measure the study variables (Table 3.1). A detailed description of each instrument is included in this section. 
Table 3.1

Instruments and Corresponding Variables Assessed in the Study

\begin{tabular}{|c|c|c|}
\hline Variable & Instrument(s) & $\begin{array}{c}\text { Number of } \\
\text { items }\end{array}$ \\
\hline $\begin{array}{l}\text { Demographic } \\
\text { information }\end{array}$ & $\begin{array}{l}\text { Demographic Questionnaire- adapted from Diabetes Care } \\
\text { Profile (DCP) }\end{array}$ & 14 \\
\hline $\begin{array}{l}\text { Social } \\
\text { support }\end{array}$ & Diabetes Care Profile (DCP) scale- section V Q2a-f & 6 \\
\hline $\begin{array}{l}\text { Autonomy } \\
\text { support }\end{array}$ & Health Care Climate Questionnaire (HCCQ)- short form & 6 \\
\hline $\begin{array}{l}\text { Autonomous } \\
\text { regulation }\end{array}$ & $\begin{array}{l}\text { Treatment Self-Regulation Questionnaire (TSRQ) } \\
\text { Concerning Diabetes }\end{array}$ & 19 \\
\hline $\begin{array}{l}\text { Basic } \\
\text { psychological } \\
\text { needs }\end{array}$ & Basic Psychological Needs Scale (adapted for diabetes) & 21 \\
\hline $\begin{array}{l}\text { Self- } \\
\text { management }\end{array}$ & $\begin{array}{l}\text { Summary of Diabetes Self-Care Activities Questionnaire } \\
\text { (SDSCA) }\end{array}$ & 10 \\
\hline $\begin{array}{l}\text { Emotional } \\
\text { distress }\end{array}$ & Diabetes Distress Scale (DDS17) & 17 \\
\hline Total items & & 93 \\
\hline
\end{tabular}




\section{Demographic measure}

\section{Demographic Questionnaire}

The demographic questionnaire for the study collected information on gender, age, length of diabetes diagnosis, medication type, marital status, household size, insurance type, income, education, and employment status (Appendix D). These variables were selected for inclusion, because they were previously observed to influence the study outcomes of interest.

\section{Social support measure}

Diabetes Care Profile (DCP)

The DCP is a self-administered survey that was developed based on the Diabetes Educational Profile (DEP), an instrument constructed using the Health Belief Model (HBM) as its underlying theoretical framework (Fitzgerald et al., 1996). The DCP contains a total of 234 items and 16 scales, which assess psychosocial factors related to self-management and treatment of diabetes. Specifically, the DCP includes measures for assessing social and personal factors, positive and negative attitudes towards diabetes, self-care ability, perceived importance of self-care, self-care and dietary adherence, medical, exercise, and monitoring barriers, perceived understanding of self-management practice, perceived benefits of long-term care, and assessment of support needs, support received, and support attitudes among respondents with diabetes. The DCP has been determined to be a valid and reliable instrument for use in multiple populations. In a study by Fitzgerald (1998), reliability was found to range from $\alpha=.68$ to .96 for White respondents. The study also observed that the DCP had high internal consistency among 
African American respondents, where scale reliabilities ranged from $\alpha=.70$ to .97 (Fitzgerald, et al., 1998). Additionally, the DCP has been determined to have high construct validity via correlation of self-care ability, self-care adherence, and control problem scales with respondents' $\mathrm{HbAlC}$ levels. Construct validity was also determined by conducting ANOVAs, where responses among 3 different patient populations (type 1 diabetes, type 2 diabetes-insulin, type 2 diabetes- no insulin) were compared and, as expected, varied significantly on several DCP scales (Fitzgerald, et al., 1996). Lastly, the DCP has been determined to have high concurrent validity, as several DCP scales were found to be highly correlated with similar previously validated scales (Fitzgerald, et al., 1996).

The study used the support scale of the DCP to assess social support dimensions within the study sample (Appendix E). This specific DCP scale has been determined to have high internal consistency within ethnic minorities, where the reliability was observed to be $\alpha=.93$ for African Americans in previous validity research (Fitzgerald, et al., 1998). The support received scale consists of 6 items measured on a 5-point likerttype scale, where answer choices range from "strongly disagree" to "strongly agree." Items in this scale inquire about the extent to which patients perceive themselves to receive support from family and friends with respect to various aspects of diabetes related care, including dietary adherence, taking medication, SMBG, engaging in physical activity, and checking their feet. The scale also includes an item which assesses the extent to which patients need diabetes-related emotional support from their family and friends. The support scale is scored by adding up participants' answers to each item and dividing by the total number of items in the scale, thus providing an average score for the 
scale. Scores on the support scale range from 1 to 5 , where " 1 " indicates a poor level of support and " 5 " indicates that the respondent receives a good level of diabetes-related support from family and friends.

\section{Autonomy support measure}

\section{Health Care Climate Questionnaire (HCCQ)}

Recent preliminary research conducted with the target population of the study identified healthcare providers as a support source that facilitates self-management behaviors, via the provision of information (Chlebowy, et al., 2010). However, other study results have suggested that too much involvement by healthcare can be viewed paternalistically and yield negative results.

Self-determination theory posits that people are motivated and are more likely to engage in behaviors when the behavior is performed volitionally. Autonomouslyperformed behaviors are optimized in autonomy supportive environments, such as those where health care providers work collaboratively with patients and provide patientcentered care, in an effort to maximize their independence in disease self-management. The study used the Health Care Climate Questionnaire (HCCQ), to assess the extent to which participants perceived their healthcare providers to be autonomy supportive (Appendix F). Developed by Williams et al. (1996), the HCCQ is a valid and reliable instrument, where the Chronbach's alpha was found to be 0.95 in the original study, which focused on motivation and weight loss. Additionally, the HCCQ has been found to have high internal consistency within research on diabetes self-management (Williams, et al., 2004). 
Factor analysis of the HCCQ has found autonomy support to be the only factor that the instrument assesses (G. C. Williams, et al., 1996). Two versions of the HCCQ are available for use among patients, including a 6 -item short from and a 15 -item long form. The current study used the 6-item short version of the instrument, in an effort to reduce respondent burden. Items in the HCCQ are measured on a 7-point likert-type scale, where answers range from "strongly disagree" to "strongly agree." The short form of the HCCQ inquires about the extent to which patients disagree or agree with statements such as "I feel that my physician has provided me with choices and options," and "My physician listens to how I would like to do things." The HCCQ can be modified to inquire about perceived autonomy support from patients' team of healthcare providers by replacing "physician" with "healthcare provider" in each item. Because diabetes care often involves a variety of providers, such as dietitians, nurses, and physicians, the current study inquired about patients' perceived autonomy support from their "diabetes health care provider."

Scores for the HCCQ are calculated by adding up all item values and dividing the sum by the number of total items, resulting in an average. Higher scores indicate greater perceived autonomy support from healthcare providers.

\section{Basic psychological needs measure}

\section{Basic Psychological Needs Scale for Diabetes}

Developed as a measure for assessing individuals' perceived fulfillment of basic psychological needs in social contexts, Basic Psychological Needs scales have been used in a variety of studies using SDT. Three forms of the basic psychological needs scale 
exist; one which assesses basic need fulfillment in general life, one which assesses basic need fulfillment at work, and one which assesses the extent to which basic psychological needs are fulfilled in relationships. The basic psychological needs scale for work has been most widely used, and has been observed to have high internal consistency with a reliability score of .79 (Kasser, Davey, \& Ryan, 1992). More recently, the basic needs scale was found to be valid as a tool for assessing basic need fulfillment in interpersonal relationships, where Chronbach's $\alpha$ ranged from $.90-.92$ for perceived fulfillment from respondents' family members, friends, and romantic partners (La Guardia, Ryan, Couchman, \& Deci, 2000).

Permission was obtained from SDT developer, Edward Deci, to modify the Basic Psychological Needs scale for use among individuals living with diabetes in the current study. In particular, the Basic Psychological Needs Scale for Diabetes, which was created for this study, consisted of 21 items and three sub-scales, which assessed perception of relatedness to others involved in the respondents' diabetes care, respondents' perception of autonomy related to managing their diabetes, and a scale which measured perceived competence related to their diabetes self-management (Appendix G). Each sub-scale consisted of 7 items, and was measured on a 7-point likert-type scale. Scores for each scale range from 1 to 49 , where lower scores indicate less psychological need fulfillment, and higher scores indicate more psychological need fulfillment. Results of a readability test indicated that the Flesch-Kincaid grade level of the Basic Psychological Needs Scale adapted for diabetes is 7.9. 


\section{Autonomous regulation}

\section{Treatment Self-Regulation Questionnaire (TSRQ) Concerning Diabetes}

According to research based on SDT, the factors influencing patients' motivation for performing self-management behaviors ultimately impact on how adherent they are to these health behaviors. Self-determination theory posits that people are more adherent to behaviors that are autonomously and volitionally performed. Thus, it is not only what people do that matters, but also why they do what they do (Sheldon, et al., 2004). The Treatment Self-Regulated Questionnaire (TSRQ) concerning diabetes was used to assess types of regulation for diabetes self-management among the study sample (Appendix $\mathrm{H}$ ). Developed by Ryan and Connell (1989) the TSRQ is an instrument which assesses different types of regulation. Results of the instrument characterize individuals' behavior as being autonomously regulated or controlled, with respect to the behavior being assessed. The TSRQ has been modified to assess regulation for a variety of behaviors, including diabetes self-management (Williams, et al., 1998). The TSRQ concerning diabetes consists of two sub-scales, autonomous regulation and controlled regulation, which are comprised of 19 items presented on a 7-point likert type scale, where answer options range from "not true at all" to "very true." The TSRQ concerning diabetes inquires about factors related to patients' regulation of specific diabetes self-management behaviors, including taking medications, self-monitoring of blood glucose (SMBG), following a diet, and regularly engaging in physical activity. Within the instrument, eight items assess respondents' degree of autonomous regulation and 11 items assess the extent to which the self-management behavior is controlled by some extrinsic factor. To determine the extent or to which an individual's behavior is autonomously regulated or 
controlled, the TSRQ concerning diabetes items assess what intrinsic or extrinsic factors influence patients' decision to manage their diabetes, ultimately providing insight into why they manage their disease. Autonomous regulation items focus on the individual and their positive appraisal of self-management as the primary motivator of behavior, whereas controlled regulation items assess extrinsic factors, such as judgment from one's doctor or others, as motivators of self-management behaviors. For example, autonomous regulation items within the instrument assess the extent to which respondents feel that statement such as "I personally feel that controlling my diabetes will improve my health" or "I've carefully thought about my diet and exercising and believe it's the right thing to do" are true.

The TSRQ concerning diabetes has been found to have high internal consistency. In a study by Williams (1998) assessing diabetic patients' motivation for regularly following a diet and exercise regimen, Chronbach's alphas ranged from 0.81 0.85 for the autonomous regulation subscale. TSRQ autonomous regulation subscales are scored by calculating an average for the items on each subscale. Higher scores on the autonomy regulation subscale indicate a greater degree of autonomous regulation with respect to diabetes self-management. Such findings suggest that individuals are intrinsically or personally motivated to engage in self-care behaviors.

\section{Diabetes self-management measure}

\section{Summary of Diabetes Self-Care Activities (SDSCA) measure}

In an effort to meet the self-management needs of individuals living with T2DM, it is important to understand strengths and weaknesses, particularly surrounding 
adherence. Specifically, it is imperative to gain insight regarding which self-management behaviors population segments are more or less adherent. The current study used the Summary of Diabetes Self-Care Activities (SDSCA) measure (Toobert, Hampson, \& Glasgow, 2000) to assess adherence to recommended T2DM self-management behaviors. In particular, the study used five subscales of the SDSCA to assess adherence to selfmanagement behaviors, including diet, physical activity, SMBG, foot care, and medication taking (Appendix I). Each item requested respondents to recall their adherence to self-management behaviors over the past seven days. Answer options are presented on an ordinal scale, and ranges from "0", indicating no adherence in the past week, to " 7 ," which indicates full adherence for the particular behavior being assessed. To derive a score for each self-management behavior, items within the corresponding sub-scale are summed and divided by the total number of items in the sub-scale, thus providing a mean. An aggregate mean was calculated for the assessment of selfmanagement in the study.

The SDSCA subscales have been found to have high face validity, as well as good concurrent and construct validity. Additionally, the instrument has been determined to have good internal consistency, where Chronbach's $\alpha$ has ranged from . 55-.91 for adherence to diet, exercise, and SMBG in both type 1 and 2 diabetic patients (Bradley, 1994). 


\section{Emotional distress measure}

\section{Diabetes Distress Scale (DDS17)}

The Diabetes Distress scale (DDS17) was used to assess diabetes-related emotional distress among participants in the study (Appendix $\mathrm{J}$ ). The DDS17 is a 17item instrument consisting of 4 subscales, which assess perceived distress related to diabetes self-care ( 5 items), the emotional burden of diabetes ( 5 items), physician-related distress (4 items), and diabetes-related interpersonal distress involving family and friends (3 items) (Polonsky et al., 2005). In particular, respondents are asked to indicate the extent to which each item statement is perceived to be a problem. For example, the instrument inquires about the extent to which respondents perceive concerns such as "feeling that I am often failing with my diabetes routine," or "feeling that diabetes is taking up too much of my mental physical energy every day," to be a problem. Items within the DDS17 are presented on a 6-point scale, where answer options range from "not a problem," which indicates low perceived distress, to "a very serious problem," which corresponds to a high level of perceived distress regarding the aspect of distress. A mean score can be calculated for the total DDS17 by obtaining a sum for answers to each item, and then dividing the sum by the total number of completed items. Mean scores can also be calculated for each of the four DDS17 subscales by obtaining a sum for the items in each subscale and dividing by the number of completed items in each subscale. An aggregate score was estimated for analysis, by calculating the average of the sum of the subscale mean scores. DDS17 developers have suggested that a mean score of " 3 " or higher is indicative of moderate distress, which warrants clinical attention. 
The DDS17 has been widely used in a variety of studies researching psychological outcomes among individuals living with diabetes. Moreover, the instrument has been used in studies that specifically focus on T2DM. Previous research has observed the DDS17 to be a valid and reliable instrument. In a validation study by Polonsky et al. (2005), testing the DDS17 in patients recruited from 4 different healthcare sites, internal consistency for the entire 17 -item instrument, as well as the 4 distress subscales, was found to be high. In particular, Chronbach's alpha for the total instrument was $0.93, \alpha=0.90$ for the regimen-related distress subscale, and $\alpha=0.88$ independently for the emotional burden, physician-related, and interpersonal-distress subscales. Additionally, research supports that the DDS17 has high concurrent validity, as subscale items have been observed to be positively correlated with corresponding items on similar previously validated instruments, including the Center for Epidemiological Studies Depression scale (CES-D) and the SDSCA (Polonsky, et al., 2005).

Research findings support that the DDS17 is appropriate for use in multiple populations, as studies have not observed significant differences in subscales on the basis of demographic characteristics such as sex, ethnicity, education level, or diabetes duration (Polonsky, et al., 2005). An additional strength of the DDS17 is the 7.3 FleschKincaid grade level at which it is written, in an effort to minimize error related to respondent literacy issues. 


\section{Quantitative Data Analysis}

SPSS 20.0 (Chicago, IL) quantitative data analysis software was used to analyze questionnaire data for the current study. Prior to analysis, all independent psychosocial study variables were correlated, to assess for multicollinearity, in an effort to ensure that all variables were distinct. Values for missing cases in continuous psychosocial outcome variables for the analyses were estimated using regression imputation (Kline, 2011). Other missing cases were coded "99" and excluded pair wise from analyses.

\section{Sample characteristics}

Basic descriptive statistics were obtained to assess the demographic make-up of the study sample. Several demographic variables were assessed as categorical data, including gender, medication type, marital status, education level, employment status, and insurance type. Frequency distributions and percentages were used to summarize categorical data. Additionally, chi-square analysis was conducted to assess for significant differences in categorical variables by gender.

Age, length of diagnosis, household size, and income were assessed as continuous variables. Means and 95 percent confidence intervals were obtained to summarize continuous variables. Significance testing for continuous variables was conducted using independent sample $t$-tests. Level of significance was set at $p \leq .05$ for all descriptive statistics analyses.

Descriptive analyses were conducted on psychosocial variables within the sample, including social support, autonomy support, autonomous regulation, relatedness, autonomy, competence, diabetes-related emotional distress, and self-management. Each psychosocial outcome was assessed as a continuous variable. Means and standard 
deviations were reported for psychosocial outcome variables. Additionally, independent sample t-tests were conducted to assess outcomes by gender. Level of significance was set at $\mathrm{p} \leq .05$.

The study also conducted correlation analyses to assess bivariate associations between continuous variables of interest. The correlation analyses provided insight regarding the strength and direction of the relationships between continuous variables in the dataset. Bivariate correlates were estimated using Pearson's correlation coefficient. Specifically, relationships were assessed between perceived social support, perceived autonomy support, perceived relatedness, autonomy, competence, autonomous regulation, diabetes-related distress, and self-management. The level of significance for the bivariate associations was $\mathrm{p} \leq .05$.

\section{Outcomes Analysis}

\section{Linear regression}

Hypotheses one, two, and three were tested using regression analysis.

Specifically, hierarchical linear regression was used to test hypotheses one and two, where hierarchical models predicted aggregate T2DM self-management and emotional distress, respectively. Simple linear modeling was used to test hypothesis three, where social support was assessed as a potential predictor of relatedness need fulfillment. Level of significance was set at $\mathrm{p} \leq .05$ for all regression analyses.

\section{Path analysis}

The current study also employed path analysis to test hypotheses four and five, using SPSS Amos 19.0 structural equation modeling software (Arbuckle, 2006). Path analysis is a multivariate analysis method, from which structural equation modeling 
(SEM) is derived. SEM assesses models that include both observed variables, or variables that are directly measured, and latent variables, or constructs that are not directly measured, but are instead measured through multiple indicators. However, path analysis is used to assess models that only consist of observed variables. Path analysis was selected as an appropriate method of analysis in the current study because the hypothesized models for the study consisted entirely of observed variables.

Because path analysis is regression-based, the statistical approach shares several similarities with linear regression. In particular, both path analysis and regression are multivariate modeling approaches, based on linear models. Additionally, both approaches require statistical assumptions to be met. Lastly, both approaches do not infer causality in predicting the relationship between variables (Suhr, 2008).

The most widely recognized advantage of path analysis over regression is the ability to estimate the goodness of fit of a model, taking into account hypothesized or specified relationships between variables of interest, based on an underlying theoretical framework. In particular, path analysis allows for several regressions to be conducted simultaneously. Moreover, unlike traditional regression, which relies solely upon significance tests to assess model outcomes, path analysis uses multiple fit indices, such as chi-square, Tucker-Lewis Index (TLI), and Comparative Fit Index (CFI) collectively, to assess overall model fit (Kline, 2011). Thus, path analysis affords researchers the ability to make inferences about whether the hypothesized relationships between study variables are applicable within population under study. Additionally, path analysis provides a graphical representation of the specified relationships between variables in a 
structural model. For these reasons, path analysis is acknowledged as a comprehensive statistical modeling approach .

Specified relationships between variables in the current study were derived from SDT literature. Path analysis was used to assess direct and indirect relationships, as well as associations, between observed variables in the hypothesized structural models. The structural models that were proposed for estimation in the current study are presented in figures $3.1 \mathrm{a}$ and $\mathrm{b}$.
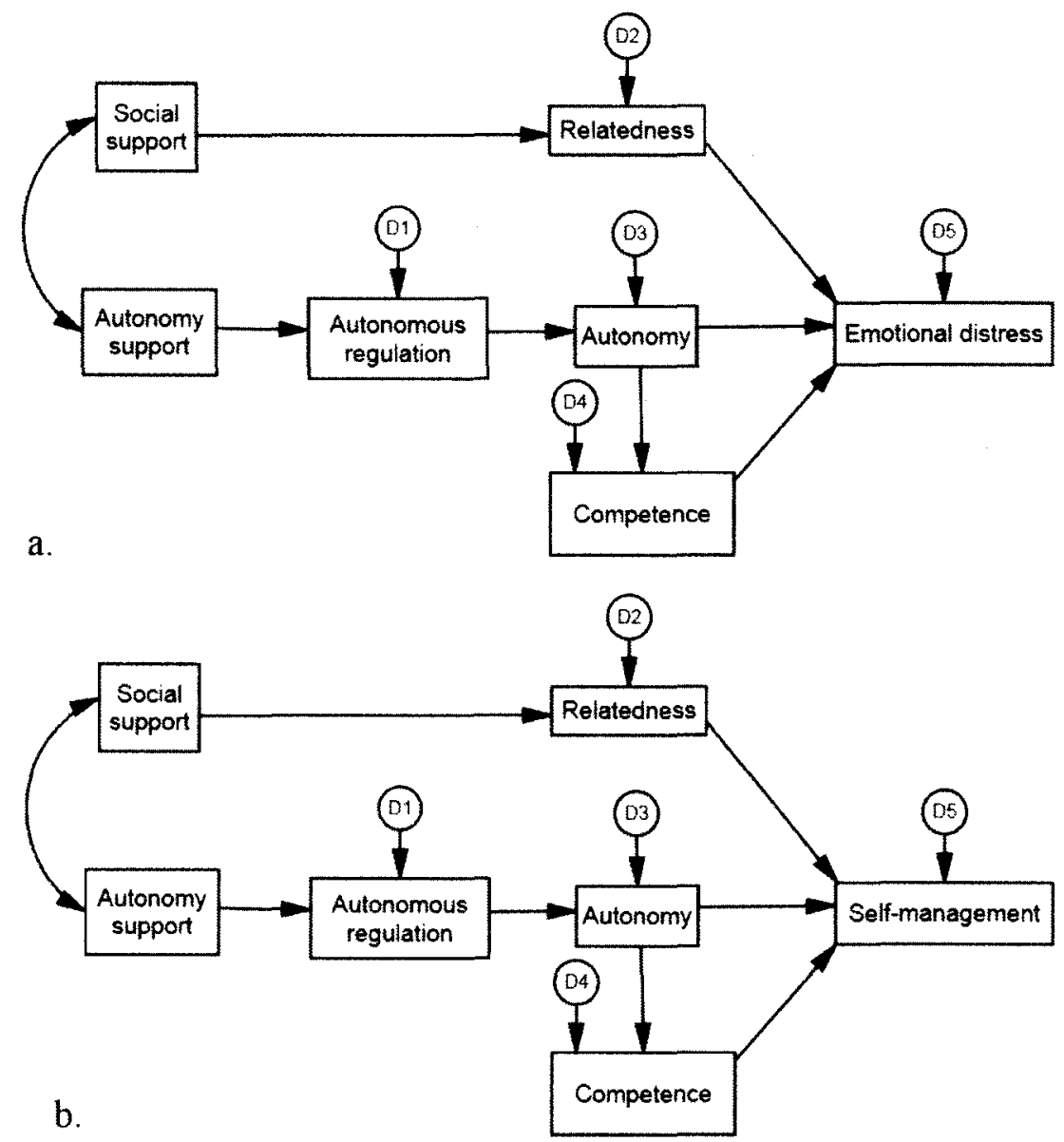

Figure 3.1 Specified Models of Relationships Between Study Variables. Models a and b represent the hypothesized relationships between study variables predicting emotional distress and self-management, respectively. Exogenous variables are correlated in path models, as observed with social support and autonomy support. D1-D5 are disturbance terms, which represent unexplained variance in endogenous variables. 
Each specified full model for estimation consisted of seven variables; two exogenous variables and five endogenous variables. In the models, social support and autonomy support are exogenous variables, because their variance is explained by variables outside the hypothesized model. Autonomous regulation, relatedness, autonomy, competence, self-management, and emotional distress are endogenous variables because they are explained by other variables in the specified models.

Path analysis graphically illustrates the proportion of variance in an endogenous variable accounted for by its predictor(s). Additionally, path analysis allows disturbance terms to be calculated, which represents unexplained or unmeasured causes of variance in the corresponding endogenous variable (Kline, 2011). The number of unknown elements in a model represents the number of parameters that need to be estimated in a model, and is equal to the sum of the number of exogenous variables, correlations, disturbance terms, and direct paths associated with the specified model. Both specified models for the proposed study were determined to have 15 unknown elements (two exogenous variables, one correlation, five disturbance terms, and seven direct paths).

\section{Model fit}

In determining model fit using path analysis, estimated values are compared against the criteria established for the individual fit indices. When assessing chi-square, a badness of fit index, a significant $\mathrm{p}$-value indicates that a model is not a good fit for the existing data (Kline, 2011). Additionally, for goodness of fit indices TLI and CFI, estimates greater than 0.90 indicate that a model is a good fit for the existing data (Hu \& Bentler, 1999). Several factors may compromise model fit, including sample size, poor reliability of testing instruments, multivariate normality, outliers, and missing data. 
Additionally, the accuracy of fit index interpretations can largely influence researchers' conclusions about the fit of their specified model (Schumacker \& Lomax, 1996).

Results for the regression and path analyses conducted to test hypotheses one

through five are presented in chapter four. The remainder of this chapter focuses on the methodology and analysis pertaining to follow-up focus groups that were conducted after survey data was collected for the current study. 


\section{Qualitative Data Collection}

\section{Purpose}

Focus group interviews were conducted to confirm and/or clarify summarized quantitative results of the previously administered questionnaire. The qualitative substudy was confirmatory in that the focus group questions asked reflected data collected in the earlier quantitative study. The focus group was also conducted to better inform recommendations for future community-based support interventions for people living with T2DM.

\section{Methodology}

Recruitment

Following completion of the study questionnaire, respondents were informed about the opportunity to participate in a follow-up qualitative focus group study. On the back of the survey, individuals were asked to indicate whether or not they were interested in participating the focus group, by checking a boxes labeled "yes" or "no." Contact information was retained on individuals who wanted to be contacted for the focus groups. The portion containing their contact information was removed from the survey, and stored in a separate locked filing cabinet.

Focus groups

Four open-ended focus group interviews were conducted for the study. Focus groups were stratified by gender. In particular, the follow-up study consisted of two male focus groups and two female focus groups. Prior to start of each focus group, participants were provided an informed consent form (Appendix C). Participants were 
also asked to complete a brief demographic form, to assist with the description of the focus group sample (Appendix D).

To gain insight regarding the development of relevant community-based support interventions for people living with T2DM, focus group participants were asked to discuss their perceptions of psychosocial outcomes assessed in the previously administered quantitative questionnaire. Specifically, participants were asked openended questions about their perceived diabetes-related distress, perceived motivational characteristics (intrinsic vs. extrinsic) for managing their condition, perceived competence in relation to managing their diabetes, perceived social support received from family and friends, as well as their perceived relatedness to others. The questions were framed such that participants discussed their perception of the relationship the psychosocial variables in the hypothesized structural model from the quantitative study. Of particular interest was gaining an understanding of how participants perceive psychosocial predictor variables to relate to their self-management and diabetes-related emotional distress.

Lastly, participants were asked to discuss their preferences for characteristics of future community-based diabetes support interventions, in an effort to make recommendations which reflect the input of the target audience. In particular, participants were asked to discuss the types of resources that would assist them with better managing and coping with their condition, such as relevant activities, topics, and formats. A list of the questions asked during the focus group is presented in Appendix $\mathrm{K}$. Each focus group was held at a local community organization. The researcher facilitated each focus group, and was accompanied by a trained observer. Each focus group was 
audio recorded, using two recorders for accuracy. Each participant was compensated with a $\$ 25$ gift card to Target or Wal-mart.

\section{Qualitative Data Analysis}

Audio files were professionally transcribed for each focus group. Thematic analysis of the focus group transcriptions was done using Atlas $t^{(\mathbb{B})}$ version 6.2 qualitative data analysis software. Codes were created post hoc, and assigned to text using open coding methodology. The same list of codes was used for each focus group, and codes were linked to text when applicable. A list of codes used to analyze the focus groups is presented in Appendix L.

Aggregate thematic analyses were conducted on the entire focus group sample, to assess common themes across all groups. Stratified analyses were also conducted on the basis of gender. In particular, the stratified qualitative analyses sought to provide insight into the unique perception of psychosocial factors and their relationship to selfmanagement and diabetes-emotional distress. Additionally, the stratified analyses assisted in creating recommendations for tailored interventions.

The results of the focus group analyses are presented in chapter four. 


\section{CHAPTER 4}

\section{RESULTS}

\section{Introduction}

Chapter four discusses the results for the study. The chapter begins with a discussion of the results of analyses that were conducted with the sample data, including participant demographics and outcomes for psychosocial variables. The next sections present the results for each hypothesis tested in the study. The chapter ends with a discussion of the qualitative results that were generated from the follow-up focus groups.

\section{Participants}

At the conclusion of the recruitment period, the final study sample consisted of 155 eligible individuals. Specifically, the analytic sample included 67 African American males and 88 African American females. Eligibility for inclusion in the final analytic sample was limited to Non-Hispanic blacks in April 2012, due to low enrollment of NonHispanic whites. 


\section{Quantitative Results}

Sample characteristics

Basic descriptive statistics were obtained to assess the demographic make-up of the study sample (table 4. 1). Marital status, education level, employment status, and insurance type were assessed as categorical variables. Chi-square analysis was conducted to assess for significant differences in categorical variables by gender. Age, household size, and income were assessed as continuous variables. Independent sample t-tests were conducted to assess for significant differences in continuous variables by gender. Level of significance was set at $\mathrm{p} \leq .05$ for all descriptive statistics analyses. 
Table 4.1

Sample Characteristics by Gender

\begin{tabular}{|c|c|c|c|c|c|}
\hline \multirow[b]{2}{*}{ Characteristics } & \multicolumn{2}{|c|}{$\begin{array}{c}\text { Male } \\
(n=67)\end{array}$} & \multicolumn{2}{|c|}{$\begin{array}{l}\text { Female } \\
(\mathrm{n}=88)\end{array}$} & \multirow[b]{2}{*}{$\mathrm{p}$-value } \\
\hline & $\mathrm{N}$ & $\%$ & $\mathrm{~N}$ & $\%$ & \\
\hline Age (yrs)* & 55.2 & & 57.2 & & .226 \\
\hline Marital status & & & & & $<.001^{ \pm}$ \\
\hline Never married & 15 & 22.7 & 23 & 26.1 & \\
\hline Married & 37 & 56.1 & 21 & 23.9 & \\
\hline Separated/Divorced & 13 & 19.7 & 31 & 35.2 & \\
\hline Widowed & 1 & 1.5 & 13 & 14.8 & \\
\hline Household size* & 1.4 & & 1.2 & & .220 \\
\hline Income* & 49,695 & & 31,859 & & $.024^{ \pm}$ \\
\hline Education & & & & & .960 \\
\hline Less than high school & 3 & 4.5 & 2 & 2.3 & \\
\hline Some high school & 3 & 4.5 & 5 & 5.7 & \\
\hline High School graduate or GED & 13 & 8.4 & 19 & 21.6 & \\
\hline Some college & 26 & 19.4 & 34 & 38.6 & \\
\hline College degree & 11 & 38.8 & 16 & 18.2 & \\
\hline Graduate degree & 11 & 16.4 & 12 & 13.6 & \\
\hline Employment & & & & & .460 \\
\hline Employed & 35 & 52.2 & 38 & 43.2 & \\
\hline Unemployed & 4 & 6.0 & 5 & 5.7 & \\
\hline Homemaker & 0 & 0.0 & 1 & 1.1 & \\
\hline Student & 0 & 0.0 & 2 & 2.3 & \\
\hline Retired & 16 & 23.9 & 29 & 33.0 & \\
\hline Disabled & 9 & 13.4 & 12 & 13.6 & \\
\hline Other & 3 & 4.5 & 1 & 1.1 & \\
\hline
\end{tabular}

*Mean values reported

${ }^{ \pm}$Significant at $\mathrm{p} \leq .05$ level 
Male and female participants did not significantly differ in chronological age, household size, educational status, or employment status. However, significant gender differences were observed for marital status and income. In the study sample, a greater percentage of male participants were married than females. In contrast, a greater percentage of female participants were "never married," "separated/divorced," or "widowed" than males. Male participants were also observed to have a significantly higher income than females in the study.

Analyses were also conducted to assess diabetes-specific outcomes within the sample, including family history, length of diagnosis, medication type, primary source of help, and diabetes education history. These analyses were stratified by gender (Table $4.2)$. 
Table 4.2

Diabetes-Specific Sample Characteristics

\begin{tabular}{|c|c|c|c|c|c|}
\hline \multirow[b]{2}{*}{ Characteristics } & \multicolumn{2}{|c|}{$\begin{array}{c}\text { Male } \\
\underline{(n=67)}\end{array}$} & \multicolumn{2}{|c|}{$\begin{array}{l}\text { Female } \\
(\mathrm{n}=88)\end{array}$} & \multirow[b]{2}{*}{$\mathrm{p}$-value } \\
\hline & $\mathrm{N}$ & $\%$ & $\mathrm{~N}$ & $\%$ & \\
\hline Family history of diabetes & & & & & $.007^{ \pm}$ \\
\hline Yes & 55 & 82.1 & 84 & 95.5 & \\
\hline No & 12 & 17.9 & 4 & 4.5 & \\
\hline Length of diagnosis (yrs)* & 9.1 & & 9.7 & & .649 \\
\hline Medication type & & & & & .224 \\
\hline Insulin only & 14 & 20.9 & 12 & 13.6 & \\
\hline Pills only & 30 & 44.8 & 53 & 60.2 & \\
\hline Insulin and pills & 20 & 29.9 & 18 & 20.5 & \\
\hline No medication & 3 & 4.5 & 5 & 5.7 & \\
\hline Primary source of help & & & & & $<.001^{ \pm}$ \\
\hline Spouse & 29 & 43.3 & 6 & 6.8 & \\
\hline Other family members & 4 & 6.0 & 15 & 17.0 & \\
\hline Friends & 2 & 3.0 & 4 & 4.5 & \\
\hline Doctor & 11 & 16.4 & 31 & 35.2 & \\
\hline Nurse & 1 & 1.5 & 2 & 2.3 & \\
\hline Other healthcare professional & 4 & 6.0 & 5 & 5.7 & \\
\hline No one & 16 & 23.9 & 25 & 28.4 & \\
\hline Diabetes education class & & & & & .955 \\
\hline Yes & 49 & 73.1 & 64 & 72.7 & \\
\hline No & 18 & 26.9 & 24 & 27.3 & \\
\hline
\end{tabular}

* Mean values reported

${ }^{ \pm}$Significant at $p \leq .05$ level 
Male and female participants did not significantly differ in the length of their diabetes diagnosis, medication type for managing their condition, or their history of attending a diabetes education class. Both male and female participants primarily managed their condition with pills only. Additionally, majority of the participants had attended a diabetes education class.

Most of the study participants also had a family history of diabetes. However, family history was observed to differ significantly by gender, where a greater percentage of female participants had a family history of diabetes than males. Female participants also reported a stronger family history of diabetes than males ( 2.4 vs. 1.5 mean family members, respectively).

The primary source of help for diabetes care was also observed to differ significantly by gender. In particular, male participants identified their spouse as their primary source of help for type-2 diabetes (T2DM), while female participants indicated that their doctor helped them the most with their T2DM.

Descriptive data for psychosocial variables in the study is presented in Table 4.3. No significant differences in the outcomes were observed between male and female participants. Therefore, data for psychosocial outcome variables were generated using the combined study sample. 


\section{Table 4.3}

Psychosocial Variables for Study Sample

\begin{tabular}{|c|c|c|c|c|c|c|}
\hline \multirow[b]{2}{*}{ Characteristics } & \multirow[b]{2}{*}{$\overline{\mathrm{x}}$} & \multicolumn{2}{|c|}{ Male } & \multicolumn{2}{|c|}{ Female } & \multirow[b]{2}{*}{$\mathrm{p}$} \\
\hline & & M & $\mathrm{SD}$ & M & $\mathrm{SD}$ & \\
\hline Social support ( 1 to 5 ) & 3.9 & 3.9 & 1.2 & 3.9 & 1.0 & 0.94 \\
\hline Autonomy support ( 1 to 7 ) & 5.9 & 5.7 & 1.7 & 6.0 & 1.3 & 0.27 \\
\hline Autonomous regulation ( 1 to 7 ) & 6.1 & 6.0 & 0.8 & 6.2 & 0.7 & 0.12 \\
\hline \multicolumn{7}{|l|}{ Basic needs ( 1 to 7 ) } \\
\hline Relatedness & 5.6 & 5.2 & 0.9 & 5.2 & 0.8 & 0.45 \\
\hline Autonomy & 5.2 & 5.5 & 0.8 & 5.6 & 0.7 & 0.71 \\
\hline Competence & 5.1 & 5.1 & 0.8 & 5.2 & 0.8 & 0.71 \\
\hline Self-management ( 0 to 7 ) & 4.0 & 4.1 & 1.4 & 3.8 & 1.4 & 0.07 \\
\hline Emotional distress ( 1 to 6 ) & 2.1 & 2.0 & 1.0 & 2.2 & 1.0 & 0.33 \\
\hline
\end{tabular}

$\overline{\mathrm{x}}=$ sample mean, ${ }^{*}$ Aggregate mean reported

Social support was assessed using a 5-point Likert-type scale, while a 7-point Likert-type scale was used to assess autonomy support among the sample. On average, participants scored highly on measures of perceived social support from family and friends, as well as perceived autonomy support received from their physicians $(\overline{\mathrm{x}}=3.9$ and 5.9, respectively). A high average was calculated for the autonomous regulation variable $(\bar{x}=6.1)$, suggesting that study participants managed their condition for intrinsic reasons. The sample yielded moderate averages on the basic psychological need fulfillment measures, which were estimated using 7-point Likert-type scales. In particular, the highest average was observed for relatedness $(\bar{x}=5.6)$, followed by autonomy $(\overline{\mathrm{x}}=5.2)$ and competence $(\mathrm{x}=5.1)$. The sample was observed to be moderately 
adherent to recommended T2DM self-management behaviors, where participants adhered to guidelines an average of 4 days per week, or a little over half of the week. The sample had an average score of 2.1 for distress, suggesting that study participants reported experiencing a minimal amount of diabetes-related distress.

Bivariate correlation of psychosocial outcome variables

Bivariate correlations were conducted among psychosocial variables in the current study, to assess for multicollinearity. In particular, assessments were made using Pearson's correlation coefficient ( $r$ ) to ensure that predictor variables were measuring independent constructs. As suggested by Cohen, $r$ values of 0.1 suggest that a weak association exists between variables, while values of .3 indicate that two variables are moderately associated. Under the same principle, values of 0.5 or greater are considered to be strong associations (Cohen, 1988).

All associations between predictor variables in the current study were observed to be low to moderate, with the exception of the association between social support and autonomy support $(r=0.6)$. Results of the bivariate correlations conducted for psychosocial variables are presented in table 4.4 . 
Table 4.4

Pearson Intercorrelations, Means, and Standard Deviations for Study Variables

\begin{tabular}{|c|c|c|c|c|c|c|c|c|c|c|}
\hline Measure & 1 & 2 & 3 & 4 & 5 & 6 & 7 & 8 & $\bar{M}$ & $\mathrm{SD}$ \\
\hline 1. Social support & - & & & & & & & & 3.89 & 1.06 \\
\hline 2. Autonomy support & $.60^{* *}$ & 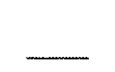 & & & & & & & 5.91 & 1.50 \\
\hline 3. Autonomous regulation & $.26^{* *}$ & $.29^{* *}$ & - & & & & & & 6.15 & 0.76 \\
\hline 4. Autonomy & $.23^{* *}$ & $.40^{* *}$ & $.21^{* *}$ & & & & & & 5.18 & 0.81 \\
\hline 5. Relatedness & $.35^{* *}$ & $.31^{* *}$ & $.20^{*}$ & $.41^{* *}$ & & & & & 5.58 & 0.76 \\
\hline 6. Competence & $.34^{* *}$ & $.25^{* *}$ & $.21^{* *}$ & $.42^{* *}$ & $.45^{* *}$ & & & & 5.14 & 0.81 \\
\hline 7. Self-management & $.38^{* *}$ & $.25^{* *}$ & $.35^{* *}$ & $.34^{* *}$ & $.22^{* *}$ & $.43^{* *}$ & - & & 3.95 & 1.39 \\
\hline 8. Emotional distress & $-.29^{* *}$ & $-.36^{* *}$ & -.16 & $-.39^{* *}$ & $-.36^{* *}$ & $-.53^{* *}$ & $-.37^{* *}$ & 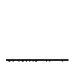 & 2.09 & 0.99 \\
\hline
\end{tabular}

${ }^{* *} \mathrm{p} \leq .001$

$\mathrm{p} \leq .05$ 


\section{Quantitative Analysis of Hypotheses}

Statistical analyses were conducted to explore the relationship between selfdetermination theory (SDT) basic psychological need variables and diabetes-related outcomes, including diabetes self-management and diabetes-related distress. In particular, efforts were made to understand how influential relatedness, the least studied basic need, was in comparison to the more-often studied needs autonomy and competence, with respect to diabetes-related outcomes. Additionally, the study sought to explore social support as a potential facilitator of relatedness, since SDT suggests that socially-supportive environments promote relatedness need fulfillment.

Missing data for the psychosocial variables were replaced via regression imputation using SPSS Amos (Arbuckle, 2006). Specifically, 16 cases had missing values for relatedness, 15 cases had missing values for competence, 12 cases had missing values for social support, 11 cases had missing values for autonomy, 7 cases had missing values for autonomy support, and 6 cases had missing values for autonomous regulation. Overall, missing values for psychosocial variables were imputed for 38 of the 155 cases in the study sample. The researcher's addition of a "does not apply" option to each of the study subscales was observed to be a source of excessive missing data. Following this discovery, subsequent participants were asked to ignore the "does not apply" answer option, and were instructed to instead select an answer on the Likert-type scales. Analyses for evaluating the study hypotheses were conducted using the original dataset, where missing cases were excluded, and the same syntax was also ran for the dataset containing imputed values for the missing cases. Both analyses yielded similar results. 
Thus, the imputed dataset was used in the primary quantitative analyses, in an effort to have a larger study sample and increase statistical power.

\section{Hypothesis 1}

Hypothesis one tested whether SDT basic psychological needs (autonomy, competence, and relatedness) significantly influences self-management among urban adults living with T2DM. Hypothesis one was evaluated using data from 155 cases. Bivariate correlations were first conducted to assess the strength and direction of the association between each basic psychological need and aggregate self-management (Table 4.5). Estimates were assessed using Pearson's correlation coefficient (r).

\section{Table 4.5}

Bivariate Correlation Results for Basic Need and Self-Management Variables Variable Statistic Autonomy Relatedness Competence

\begin{tabular}{l|l|c|c|c}
\hline Self-management (aggregate) & Correlation & $\begin{array}{c}.343^{* *} \\
\text { p-value }\end{array}$ & $\begin{array}{c}.000 \\
.223^{* *} \\
.005\end{array}$ & $\begin{array}{c}.430^{* *} \\
.000\end{array}$ \\
\hline \multirow{2}{*}{ Diet } & Correlation & $.350^{* *}$ & $.287^{* *}$ & $.430^{* *}$ \\
& p-value & .000 & .000 & .000 \\
\hline Physical activity & Correlation & $.161^{*}$ & .090 & $.261^{* *}$ \\
& p-value & .045 & .264 & .001 \\
\hline Blood glucose monitoring & Correlation & $.266^{* *}$ & .157 & $.336^{* *}$ \\
& p-value & .001 & .051 & .000 \\
\hline Foot care & Correlation & $.173^{*}$ & .077 & $.167^{*}$ \\
& p-value & .032 & .339 & .038 \\
\hline
\end{tabular}

$* *$ Significant at $\mathrm{p} \leq .01$ level

$*$ Significant at $p \leq .05$ level 
All basic psychological needs were observed to have a significant positive correlation with aggregate self-management. In particular, competence was observed to have the strongest association with T2DM self-management $(r=.430)$, followed by autonomy $(\mathrm{r}=.343)$ and relatedness $(\mathrm{r}=.223)$. A similar trend was observed when the basic needs were correlated with dietary self-management, where competence was most strongly associated with diet and relatedness had the weakest correlation of all the SDT basic needs with diet. Additionally, relatedness was not significantly associated with physical activity, self-monitoring of blood glucose (SMBG), and foot care in the study sample, while autonomy and competence were. Each basic need had a stronger association with diet than with other specific T2DM self-management behaviors.

Because SDT posits that each basic need has a distinct influence on outcomes, hypothesis one was evaluated by conducting hierarchical linear regression. Basic psychological need variables autonomy, competence, and relatedness were entered as independent variables in the prediction of aggregate self-management. Specifically, the predictors were entered into three blocks, in an effort to assess the additional variance that was accounted for in the model with the addition of each new variable (Field, 2005). The results of the hierarchical linear regression are presented in table 4.6. 


\section{Table 4.6}

Hierarchical Linear Regression Results for Hypothesis One

\begin{tabular}{|c|c|c|c|}
\hline Predictor & $\Delta \mathrm{R}^{2}$ & Unstandardized $\beta$ & Standardized $\beta$ \\
\hline $\begin{array}{l}\text { Block } 1 \\
\text { Autonomy }\end{array}$ & $.118^{* *}$ & $.59^{* *}$ & $.34^{* *}$ \\
\hline $\begin{array}{l}\text { Block } 2 \\
\text { Autonomy } \\
\text { Competence }\end{array}$ & $.099^{* *}$ & $\begin{array}{l}.34^{*} \\
.59^{* *}\end{array}$ & $\begin{array}{l}.20^{*} \\
.35^{* *}\end{array}$ \\
\hline $\begin{array}{l}\text { Block } 3 \\
\text { Autonomy } \\
\text { Competence } \\
\text { Relatedness }\end{array}$ & .001 & $\begin{array}{l}.34^{*} \\
.60^{* *} \\
-.03\end{array}$ & $\begin{array}{l}.20^{*} \\
.35^{* *} \\
-.06\end{array}$ \\
\hline $\begin{array}{l}\text { Total } R^{2} \\
\mathbf{n}\end{array}$ & $\begin{array}{l}.217^{* * *} \\
155\end{array}$ & & \\
\hline
\end{tabular}

The first block in the analysis consisted of autonomy, as a single predictor of aggregate self-management. Within this model, autonomy was observed to account for 12 percent, a significant amount of the sample variance in self-management $(p<.001)$. An additional 10 percent of the sample variance in self-management was explained by the inclusion of competence to the model in block two $\left(\mathrm{R}^{2}=.217\right)$. Moreover, this 10 percent of variance in self-management accounted for by competence was observed to be significant $(\mathrm{p}<.001)$. Relatedness, however, was only observed to account for a negligible additional amount of variance $\left(\Delta R^{2}=.001\right)$ in self-management in the full-model in block 3, and thus did not add to the explanatory power of the model represented in bock 2 . 
Within the final regression model in block 3 , competence and autonomy were observed to have positive unstandardized beta coefficients ( $\beta=.34$ and .60 , respectively). Competence and autonomy were also observed to be significant predictors of selfmanagement in the final model in block 3 ( $\mathrm{p}=.016$ and $<.001$, respectively).

The final model consisting of autonomy and competence was observed to significantly predict self-management within the sample $(p<.001)$. Thus, the null hypothesis was rejected. Within the model, competence was observed to be the most influential basic psychological need, followed by autonomy. In contrast, relatedness did not significantly influence the self-management, and is therefore no included in the final model. A more in-depth discussion of these results is presented in chapter 5 . 


\section{Hypothesis 2}

Hypothesis two tested whether SDT basic psychological needs (autonomy, competence, and relatedness) significantly influences diabetes-related emotional distress among urban adults living with T2DM. Hypothesis two was evaluated using data from 155 cases. Bivariate correlations were first conducted to assess the strength and direction of the association between each basic psychological need and diabetes-related emotional distress (Table 4.7). Estimates were assessed using Pearson's correlation coefficient (r).

Table 4.7

Bivariate Correlation Results for Basic Need and Distress Variables Variable Statistic Autonomy Relatedness Competence

\begin{tabular}{|c|c|c|c|c|}
\hline Emotional distress (aggregate) & $\begin{array}{l}\text { Correlation } \\
\text { p-value }\end{array}$ & $\begin{array}{c}-.391^{* *} \\
.000\end{array}$ & $\begin{array}{c}-.355^{* *} \\
.000\end{array}$ & $\begin{array}{r}-.525^{* *} \\
.000\end{array}$ \\
\hline Emotional burden & $\begin{array}{l}\text { Correlation } \\
\mathrm{p} \text {-value }\end{array}$ & $\begin{array}{c}-.342^{* *} \\
.000\end{array}$ & $\begin{array}{c}-.236^{* *} \\
.003\end{array}$ & $\begin{array}{c}-.450^{* *} \\
.000\end{array}$ \\
\hline Physician-related distress & $\begin{array}{l}\text { Correlation } \\
\mathrm{p} \text {-value }\end{array}$ & $\begin{array}{c}-.235^{* *} \\
.003\end{array}$ & $\begin{array}{c}-.326^{* *} \\
.000\end{array}$ & $\begin{array}{r}-.286^{* *} \\
.000\end{array}$ \\
\hline Regimen-related distress & $\begin{array}{l}\text { Correlation } \\
\text { p-value }\end{array}$ & $\begin{array}{c}-.429^{* *} \\
.000\end{array}$ & $\begin{array}{c}-.342^{* *} \\
.000\end{array}$ & $\begin{array}{r}-.569^{* *} \\
.000\end{array}$ \\
\hline Interpersonal distress & $\begin{array}{l}\text { Correlation } \\
p \text {-value }\end{array}$ & $\begin{array}{r}-.169^{*} \\
.036\end{array}$ & $\begin{array}{c}-.244^{* *} \\
.002\end{array}$ & $\begin{array}{c}-.297^{* *} \\
.000\end{array}$ \\
\hline
\end{tabular}

"Significant at $\mathrm{p} \leq .01$ level

"Significant at $p \leq .05$ level 
All three basic psychological needs (autonomy, relatedness, competence) were observed to have significant negative associations with emotional distress, as well as with specific aspects of diabetes-related distress, including emotional burden, physicianrelated distress, regimen-related distress, and interpersonal distress. Competence had the strongest correlation of all the basic needs with every aspect of diabetes-related distress aspect except physician-related distress. Regarding physician-related distress, relatedness had the strongest association of all basic psychological needs $(r=-.326)$, followed by competence $(\mathrm{r}=-.286)$ and autonomy $(\mathrm{r}=-235)$.

Because SDT posits that each basic need has a distinct influence on outcomes, hypothesis two was also evaluated by conducting hierarchical linear regression. Basic psychological need variables autonomy, competence, and relatedness were entered as independent variables in the prediction of diabetes-related emotional distress within the sample. Specifically, the predictors were entered into three blocks, in an effort to assess the additional variance that was accounted for in the model with the addition of each new variable (Field, 2005). The results of the hierarchical linear regression are presented in table 4.8 . 


\section{Table 4.8}

Hierarchical Linear Regression Results for Hypothesis Two

\begin{tabular}{|c|c|c|c|}
\hline Predictor & $\Delta \mathrm{R}^{2}$ & Unstandardized $\beta$ & Standardized $\beta$ \\
\hline $\begin{array}{l}\text { Block } 1 \\
\text { Autonomy }\end{array}$ & $.15^{* * *}$ & $-.48^{* * *}$ & $-.39^{* * *}$ \\
\hline $\begin{array}{l}\text { Block } 2 \\
\text { Autonomy } \\
\text { Competence }\end{array}$ & $.16^{* * *}$ & $\begin{array}{l}-.25^{* *} \\
-.54^{* * *}\end{array}$ & $\begin{array}{l}-.21^{* *} \\
-.44^{* * *}\end{array}$ \\
\hline $\begin{array}{l}\text { Block } 3 \\
\text { Autonomy } \\
\text { Competence } \\
\text { Relatedness }\end{array}$ & .01 & $\begin{array}{l}-.22^{*} \\
-.49^{* * *} \\
-.13\end{array}$ & $\begin{array}{l}-.18^{*} \\
-.41^{* * *} \\
-.11\end{array}$ \\
\hline $\begin{array}{l}\text { Total } \mathbf{R}^{2} \\
\mathbf{n}\end{array}$ & $\begin{array}{l}.32^{* * *} \\
155\end{array}$ & & \\
\hline $.05^{* *} \mathrm{p} \leq .01$ & & & \\
\hline
\end{tabular}

The level of significance was set at $p \leq .05$ for the hierarchical regression. The first block consisted of autonomy, as a single predictor of aggregate emotional distress. Within this model, autonomy was observed to account for 15 percent of the variance in emotional distress, and the simple linear model was observed to significantly predict emotional distress $(p<.001)$. The inclusion of competence in the second block was observed to account for an additional 16 percent of variance in emotional distress. The model was also observed to significantly predict emotional distress in the study sample $(\mathrm{p}<.001)$. Inclusion of relatedness in the third and final regression block accounted for less than 1 percent of additional variance in emotional distress, and relatedness was not observed to be a significant predictor in the final model. The full model in block 3 consisting of autonomy, competence, and relatedness was observed to significantly 
predict emotional distress among the study sample $(\mathrm{p} \leq .001)$. Thus, the null hypothesis was rejected. Autonomy and competence were observed to be significant predictors in the final model. In particular, competence was observed to be the most influential basic psychological need, followed by autonomy. In contrast, relatedness did not significantly influence the self-management, and is therefore not included in the final model. A more in-depth description of these results is presented in chapter 5 . 


\section{Hypothesis 3}

Hypothesis three tested whether social support facilitates relatedness need fulfillment among urban adults living with T2DM. Hypothesis three was evaluated using data from 155 cases. Bivariate correlations were first conducted to assess the strength and direction of the association between social support and relatedness (Table 4.9). Estimates were assessed using Pearson's correlation coefficient (r).

\section{Table 4.9}

Bivariate Correlation Results for Basic Need and Social Support Variables

\begin{tabular}{l|l|l} 
Variable & Correlation & $.349^{* *}$ \\
& p-value & .000 \\
\hline Nutrition support & Correlation & $.348^{* *}$ \\
& p-value & .000 \\
\hline Medication support & Correlation & $.305^{* *}$ \\
& p-value & .000 \\
\hline Foot care support & Correlation & $.279^{* *}$ \\
\hline Physical activity support & p-value & .001 \\
\hline Blood glucose monitoring & Correlation & $.252^{* *}$ \\
& p-value & .002 \\
\hline Emotional support & Correlation & $.274^{* *}$ \\
& p-value & .001 \\
\hline
\end{tabular}

$* *$ Significant at $p \leq 01$ level 
Social support was observed to have a moderate positive correlation with relatedness $(\mathrm{p}<.001)$, which was a significant association. Specific aspects of diabetesrelated social support were also observed to have significant positive associations with relatedness at the $\mathrm{p} \leq .001$ level of significance, including assistance with nutrition, medication taking, foot care, physical activity, SMBG, and the provision of emotional support.

Self-determination theory posits that supportive social contexts promote relatedness need fulfillment. Regression analysis was conducted with the current sample data, in an effort to assess this theoretical assumption. In particular, relatedness need fulfillment was predicted from social support, using a simple linear model. The results of the regression are presented in table 4.10.

Table 4.10

Simple Linear Regression Results for Hypothesis Three

\begin{tabular}{lcccc} 
Predictor & $\beta$ & $95 \% \mathrm{Cl}$ & $\mathrm{R}^{2}$ & $\mathrm{t}$ \\
\hline Social Support & $.25^{* *}$ & $(.14-.36)$ & 0.12 & 4.60 \\
\hline${ }^{* *} \mathrm{p} \leq .001$ & & & & \\
\end{tabular}

Within the model, social support was observed to account for a significant amount of variance in relatedness among study participants $\left(\mathrm{R}^{2}=.12\right)$. The results also indicate that social support is a significant predictor of relatedness need fulfillment within the sample $(\mathrm{p}<.001)$. Specifically, for every one unit increase in social support, there was a .25 unit increase in relatedness, based on the unstandardized beta estimate. Data from 
study sample supports the SDT theoretical assumption that supportive social contexts facilitate relatedness. Thus, the null hypothesis was rejected. 


\section{Hypothesis 4}

Hypothesis four was evaluated using data from 155 cases. Hypothesis four sought to test whether the inclusion of relatedness improves a model for predicting selfmanagement among urban adults with T2DM, using path analysis. AIC fit indices were compared for two non-nested models predicting self-management, in an effort to determine which model was a better fit for the study sample. Each model was constructed, based on SDT theoretical assumptions.

The first estimated structural path model consisted of autonomy support, autonomous regulation, autonomy, competence, social support, and relatedness as predictors of self-management. The results for the full structural model appear in figure 4.1.

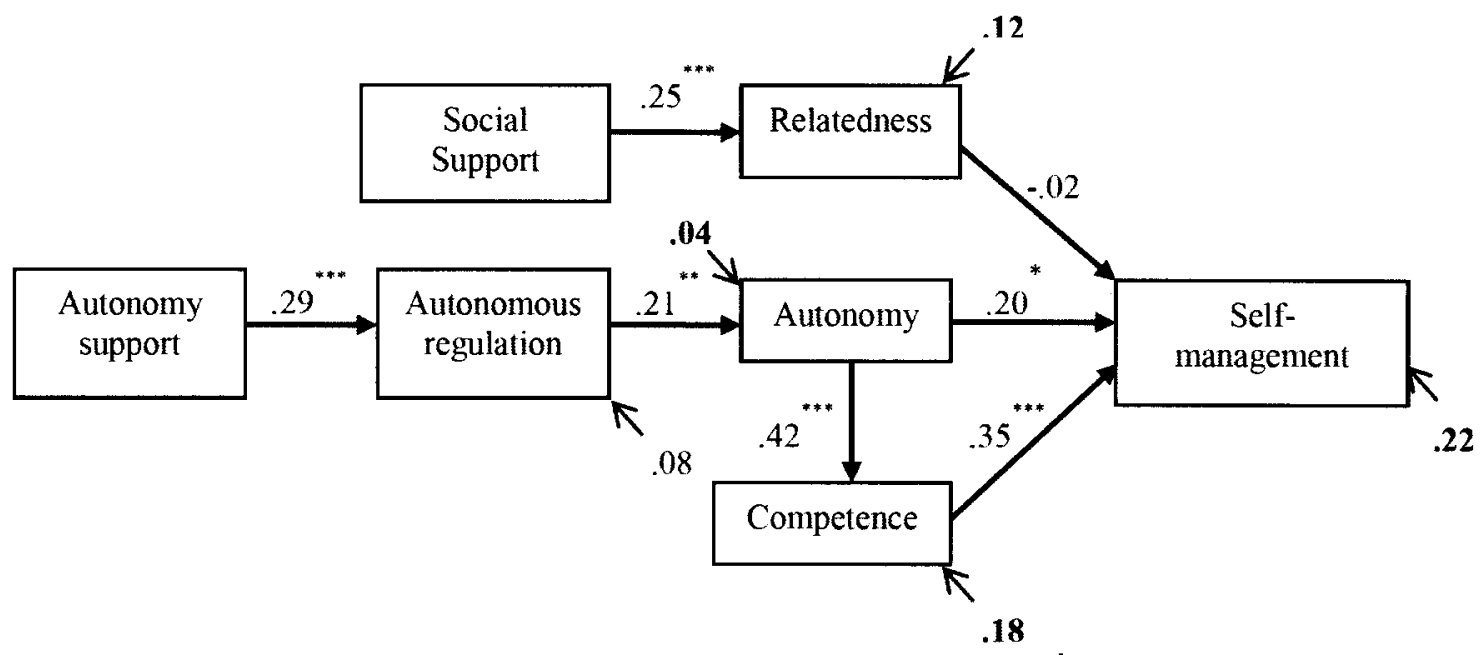

Figure 4.1 Full Structural Path Model for Predicting Self-Management. Model estimates in bold font represent the proportion of variance in an endogenous variable that is explained by the predictors of the particular variable. Path weights of direct relationships between variables are also shown in the figure.. ${ }^{* * *} \mathrm{p} \leq .001,{ }^{* *} \mathrm{p} \leq .01, ., \mathrm{p} \leq .05$. 
Within the model, perceived autonomy support related positively to autonomous regulation for diabetes self-management $(\beta=.29, \mathrm{p} \leq .001)$, autonomous regulation related positively to autonomy $(\beta=.21, \mathrm{p} \leq .01)$, autonomy related positively to both competence $(\beta=.42, p \leq .001)$ and self-management $(\beta=.20, p \leq .05)$. Competence also related positively to self-management $(\beta=.35, \mathrm{p} \leq .001)$. Additionally, social support was positively related to relatedness $(\beta=.25, p \leq .001)$. Relatedness, however, was not observed to significantly influence self-management $(\beta=-.02, p=.82)$. Overall, the model explained 22 percent of the variance in self-management within the study sample.

A comparison (reduced) structural model was also estimated, which excluded social support and relatedness in the prediction of T2DM self-management. The results for the reduced structural model appear in figure 4.2.

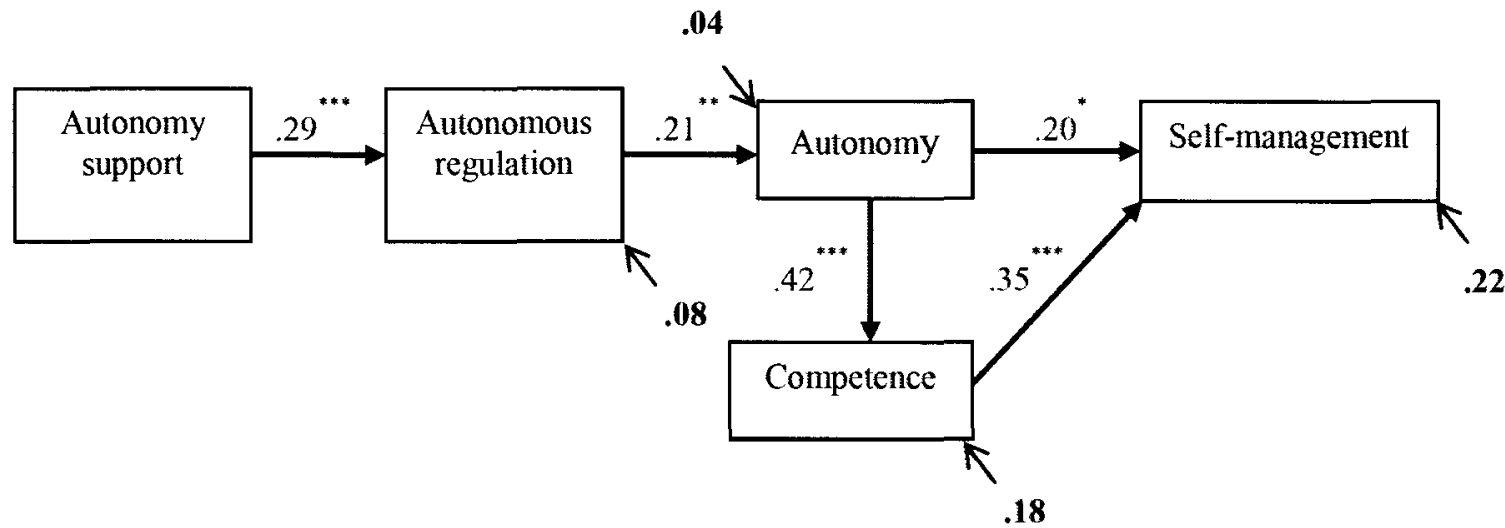

Figure 4.2 Reduced Structural Path Model for Predicting Self-Management. Model estimates in bold font represent the proportion of variance in an endogenous variable that is explained by the predictors of the particular variable. Path weights of direct relationships between variables are also shown in the figure.. ${ }^{* * *} \mathrm{p} \leq .001,{ }^{* *} \mathrm{p} \leq .01, . .{ }^{*} \mathrm{p} \leq .05$.

The path weights $(\beta)$ and squared multiple correlation $\left(R^{2}\right)$ values for the relations among autonomy support, autonomous regulation, autonomy, and competence of the full structural model were retained in the reduced structural model. The overall $\mathrm{R}^{2}$ value for 
the full structural model was also retained for the reduced structural model. Fit index estimates for the full and reduced structural models appear in table 4.11.

\section{Table 4.11}

Fit Index Estimates for Structural Path Models Predicting Self-Management

\begin{tabular}{lcccccc} 
& \multicolumn{9}{c}{ Chi-square $\left(\chi^{2}\right)$} & & & \\
\cline { 2 - 4 } Model & Estimate & $\mathrm{df}$ & $\mathrm{p}$-value & CFI & TLI & AIC \\
Full & 94.99 & 13 & $<.001$ & 0.65 & 0.48 & 138.99 \\
& & & & & & \\
Reduced & 37.65 & 5 & $<.001$ & 0.72 & 0.44 & 67.65 \\
\hline
\end{tabular}

In assessing model fit, a significant chi-square indicates that the estimated model is a bad fit for the data from which it was estimated. Additionally, CFI and TLI estimates less than 0.90 indicate that a model is not a good fit for the data from which it was estimated (Kline, 2011). Fit index results for the estimated structural models suggested that neither model was a good fit for the sample data.

When using the AIC fit index as a basis for comparison between non-nested models, the model with the smallest AIC estimate is the superior model (Kline, 2011). Though it was previously determined that neither model is not a good fit for the study data, AIC estimates for the reduced and full structural models in hypothesis four suggests that, overall, the more parsimonious reduced model, which does not include relatedness, is a better model than the full model. Thus, the conclusion was to fail to reject the null hypothesis. 


\section{Hypothesis 5}

Hypothesis five was evaluated using data from 155 cases, where regression imputation was conducted to impute missing values. Hypothesis four sought to test whether the inclusion of relatedness improves a model for predicting emotional distress among urban adults with T2DM, using path analysis. AIC fit indices were compared for two non-nested models predicting emotional distress, in an effort to determine which model was a better fit for the study sample. Each model was constructed, based on SDT theoretical assumptions.

The first estimated path model consisted of autonomy support, autonomous regulation, autonomy, competence, social support and relatedness as predictors of emotional distress. The results for the full structural model appear in figure 4.3.

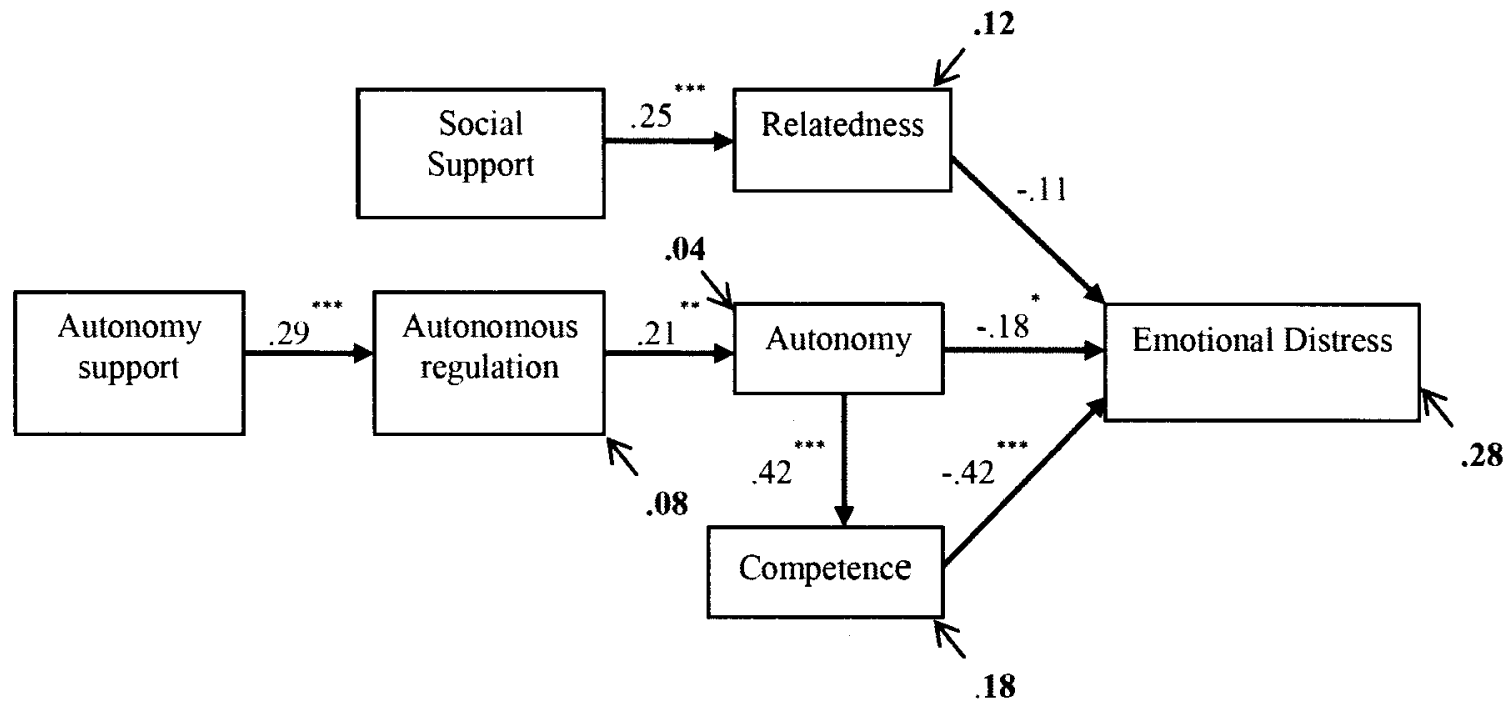

Figure 4.3 Full Structural Path Model for Predicting Emotional Distress. Model estimates in bold font represent the proportion of variance in an endogenous variable that is explained by the predictors of the particular variable. Path weights of direct relationships between variables are also shown in the figure. ${ }^{* * *} \mathrm{p} \leq .001,{ }^{* *} \mathrm{p} \leq .01,,{ }^{*} \mathrm{p} \leq .05$. 
Within the model, perceived autonomy support related positively to autonomous regulation for diabetes self-management $(\beta=.29, p \leq .001)$, autonomous regulation related positively to autonomy $(\beta=.21, \mathrm{p} \leq .01)$, autonomy related positively to competence $(\beta=.42, \mathrm{p} \leq .001)$. Both autonomy and competence related negatively to emotional distress $(\beta=-.21, p \leq .01$ and $\beta=-.44, p \leq .001$, respectively). Additionally, social support was positively related to relatedness $(\beta=.25, \mathrm{p} \leq .001)$. Relatedness, however, was not observed to significantly influence emotional distress $(\beta=-.11, p=$ .12). Overall, the model explained 31 percent of the variance in emotional distress within the study sample.

A comparison (reduced) structural model was also estimated, which excluded social support and relatedness in the prediction of emotional distress. The results for the reduced structural model appear in figure 4.4 .

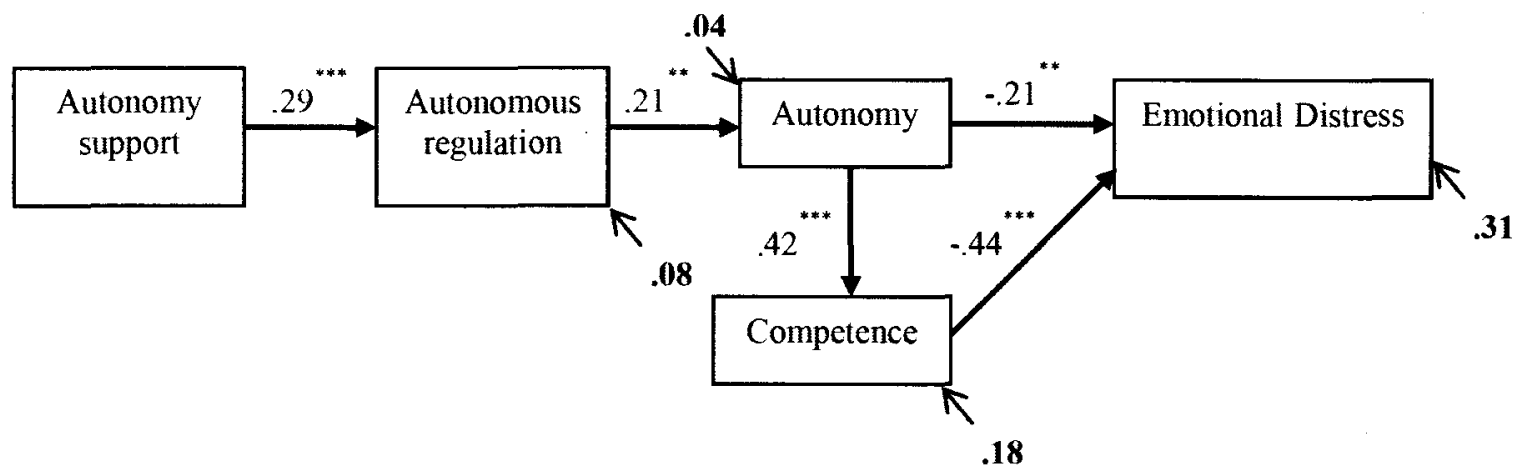

Figure 4.4 Reduced Structural Path Model for Predicting Emotional Distress. Model estimates in bold font represent the proportion of variance in an endogenous variable that is explained by the predictors of the particular variable. Path weights of direct relationships between variables are also shown in the figure, ${ }^{* * *} \mathrm{p} \leq .001,{ }^{* *} \mathrm{p} \leq .01$.

The path weights $(\beta)$ and squared multiple correlation $\left(R^{2}\right)$ values for the relations among autonomy support, autonomous regulation, autonomy, and competence of the full 
structural model were retained in the reduced structural model. The overall $\mathrm{R}^{2}$ value for the full structural model was also retained for the reduced structural model. Fit index estimates for the full and models structural models appear in table 4.12.

\section{Table 4.12}

Fit Index Estimates for Structural Path Models Predicting Emotional Distress

\begin{tabular}{lccccccc} 
& \multicolumn{9}{c}{ Chi-square $\left(\chi^{2}\right)$} & & & \\
\cline { 2 - 4 } Model & Estimate & $\mathrm{df}$ & $\mathrm{p}$-value & CFI & TLI & AIC \\
\hline Full & 80.02 & 13 & $<.001$ & 0.74 & 0.58 & 124.02 \\
Reduced & 33.16 & 5 & $<.001$ & 0.79 & 0.57 & 63.16 \\
\hline
\end{tabular}

In assessing model fit, a significant chi-square indicates that the estimated model is a bad fit for the data from which it was estimated. Additionally, CFI and TLI estimates less than 0.90 indicate that a model is not a good fit for the data from which it was estimated (Kline, 2011). Fit index results for the estimated structural models suggested that neither model was a good fit for the sample data.

When using the AIC fit index as a basis for comparison between non-nested models, the model with the smallest AIC estimate is the superior model (Kline, 2011). Though it was previously determined that neither model is not a good fit for the study data, AIC estimates for the reduced and full structural models in hypothesis four suggests that, overall, the more parsimonious reduced model, which does not include relatedness, is a better model than the full model. Thus, the conclusion was to fail to reject the null hypothesis. 


\section{Results of follow-up focus groups}

Focus groups were conducted to confirm quantitative findings, as well as to explore the study variables from a qualitative perspective. An additional purpose of the focus groups was to gain insight regarding the support needs and preferences among urban African Americans living with T2DM. Four focus groups were conducted in community settings in June 2012 (Table 4.13).

\section{Table 4.13}

Focus Group Composition Characteristics

\begin{tabular}{l|c|c|l}
\multicolumn{1}{c|}{ Group } & Participants & Length & \multicolumn{1}{|c}{ Location } \\
\hline 1-Female & 7 & $2: 23$ & University \\
\hline 2-Male & 4 & $0: 56$ & Neighborhood Place \\
\hline 3-Female & 6 & $1: 20$ & Neighborhood Place \\
\hline 4-Male & 6 & $1: 22$ & University \\
\hline Total 4 & 23 & 6 & \\
\hline
\end{tabular}

Each focus group was comprised of 4-7 participants. Most focus groups lasted approximately between 1 hour and 1 hour and 20 minutes, yielding a total of 6 hours of audio-recorded focus group data for the current study.

\section{Qualitative results}

Each participant was asked to complete a brief demographic questionnaire prior to the start of the focus group. Descriptive characteristics of the participants is presented in Table 4.14. 


\section{Table 4.14}

Focus Group Participant Characteristics

\begin{tabular}{|c|c|c|c|c|c|c|c|c|}
\hline Characteristics & \multicolumn{2}{|c|}{$\begin{array}{c}\text { Group } 1 \text { Females } \\
(\mathrm{N}=8)\end{array}$} & \multicolumn{2}{|c|}{$\begin{array}{c}\text { Group } 2 \text { Males } \\
(\mathrm{N}=4)\end{array}$} & \multicolumn{2}{|c|}{$\begin{array}{c}\text { Group } 3 \text { Females } \\
(\mathrm{N}=6)\end{array}$} & \multicolumn{2}{|c|}{$\begin{array}{l}\text { Group } 4 \text { Males } \\
\qquad(\mathrm{N}=6)\end{array}$} \\
\hline Age (yrs, mean) & 49 & & 55 & & 53 & & 55 & \\
\hline $\begin{array}{l}\text { Marital Status } \\
\text { Never Married } \\
\text { Married } \\
\text { Separated/Divorced } \\
\text { Widowed }\end{array}$ & $\begin{array}{l}2 \\
2 \\
4 \\
0\end{array}$ & $\begin{array}{r}25.0 \\
25.0 \\
50.0 \\
0.0\end{array}$ & $\begin{array}{l}1 \\
1 \\
2 \\
0\end{array}$ & $\begin{array}{l}25.0 \\
25.0 \\
50.0\end{array}$ & $\begin{array}{l}3 \\
1 \\
2 \\
0\end{array}$ & $\begin{array}{r}50.0 \\
16.7 \\
33.3 \\
0.0\end{array}$ & $\begin{array}{l}2 \\
3 \\
1 \\
0\end{array}$ & $\begin{array}{r}33.3 \\
50.0 \\
16.7 \\
0.0\end{array}$ \\
\hline $\begin{array}{l}\text { Education } \\
\text { Some high school } \\
\text { High school graduate or GED } \\
\text { Some college } \\
\text { College graduate } \\
\text { Graduate degree }\end{array}$ & $\begin{array}{l}0 \\
1 \\
4 \\
0 \\
3\end{array}$ & $\begin{array}{r}0.0 \\
12.5 \\
50.0 \\
0.0 \\
37.5\end{array}$ & $\begin{array}{l}0 \\
1 \\
3 \\
0 \\
0\end{array}$ & $\begin{array}{r}0.0 \\
25.0 \\
75.0 \\
0.0 \\
0.0\end{array}$ & $\begin{array}{l}1 \\
0 \\
3 \\
2 \\
0\end{array}$ & $\begin{array}{r}16.7 \\
0.0 \\
50.0 \\
33.3 \\
0.0\end{array}$ & $\begin{array}{l}0 \\
1 \\
2 \\
1 \\
2\end{array}$ & $\begin{array}{r}0.0 \\
16.7 \\
33.3 \\
16.7 \\
33.3\end{array}$ \\
\hline $\begin{array}{l}\text { Family history of T2DM } \\
\text { Yes } \\
\text { No }\end{array}$ & $\begin{array}{l}8 \\
0\end{array}$ & $\begin{array}{r}100.0 \\
0.0\end{array}$ & $\begin{array}{l}3 \\
1\end{array}$ & $\begin{array}{l}75.0 \\
25.0\end{array}$ & $\begin{array}{l}4 \\
2\end{array}$ & $\begin{array}{l}66.7 \\
33.3\end{array}$ & $\begin{array}{l}4 \\
2\end{array}$ & $\begin{array}{l}66.7 \\
33.3\end{array}$ \\
\hline $\begin{array}{l}\text { Medication type } \\
\text { Insulin only } \\
\text { Pills only } \\
\text { Insulin and pills } \\
\text { No medication }\end{array}$ & $\begin{array}{l}2 \\
6 \\
0 \\
0\end{array}$ & $\begin{array}{r}25.0 \\
75.0 \\
0.0 \\
0.0\end{array}$ & $\begin{array}{l}2 \\
1 \\
1 \\
0\end{array}$ & $\begin{array}{r}50.0 \\
25.0 \\
25.0 \\
0.0\end{array}$ & $\begin{array}{l}2 \\
2 \\
2 \\
0\end{array}$ & $\begin{array}{r}33.3 \\
33.3 \\
33.3 \\
0.0\end{array}$ & $\begin{array}{l}2 \\
3 \\
1 \\
0\end{array}$ & $\begin{array}{r}33.3 \\
50.0 \\
16.7 \\
0.0\end{array}$ \\
\hline
\end{tabular}




\section{Primary qualitative results}

Each focus group was asked a total of 11 open-ended questions pertaining to their overall experience of living with diabetes, as well as their perceived diabetes-related motivation, self-management, distress, and coping. Self-determination theory was used as an underlying theoretical framework in the development of the focus group questions. Specifically, questions were structured such that they assessed the same psychosocial variables that were assessed in the former quantitative study, in an effort to confirm findings as well as explore the relationships between the psychosocial variables in the hypothesized motivational models for predicting self-management and emotional distress. The focus group questions are presented in appendix $\mathrm{K}$.

The following section presents qualitative findings pertaining to psychosocial variables assessed in the current study. The section concludes with additional findings, related to participants' preferences for future diabetes support programs, as well as a brief report of participants' information-seeking behavior, to provide insight regarding dissemination of diabetes information to urban African American adults living with T2DM. 


\section{Competence}

Competence was observed to be the most influential SDT basic need in quantitative analyses for the current study. Thus, the researcher was interested in understanding participants' perception of the relationship between competence and diabetes-related motivation. Participants unanimously reported that their confidence facilitates their motivation. Male participants provided especially detailed descriptions.

Male: "My confidence is what puts my motivation in gear, you know... I think that's what makes me constantly tell myself, it's time to do this, it's time to take that blood sugar, it's time to eat that meal, it's time to follow through, follow through. Keep going, don't stop."

Male: "I think my motivation and confidence go together because I know that I can control this diabetes and I know I can get past it, so I'm confident in doing it so that motivates me even more to eat right, don't drink, and take my medicine, and also check my sugar."

Participants' perceived confidence to manage their T2DM also appeared to be associated with their relatedness to others. Specifically, some female participants discussed having a lack of overall confidence to manage their condition because they were isolated.

Female: "I don't have no confidence cause right now...because I'm homebound. I'm babysitting. That's not good."

In contrast, participation in a social network was associated with confidence.

Female: "I'm not homebound. I do that foster granny and working with the small kids from kindergarten. They keep my confidence built up. I get up and go everyday because they say "Gran, where you been? You should, you're supposed to be here with us." So they help me as I help them." 


\section{Autonomy}

Autonomy was observed to be a significant predictor of competence, T2DM selfmanagement, and diabetes-related emotional distress among survey participants. Similar findings were observed among focus group participants, especially regarding the relationship between autonomy and the primary outcomes of self-management and diabetes-related emotional distress. In particular, participants described themselves as being autonomous with respect to managing their T2DM.

Male: "I started learning stuff myself. When I get my medicine, and they give you the paper from the drug store telling you all the side effects, and how you supposed to take them. I made a little library out of them, you know, and... When I'm feeling bad or something like that, I... well, let me go back in here. Which one of these medicines is doing it to me? I confronted the doctor one time. I said, 'Every one of these medicines you've got me on [has] given me have nausea."

Similar to survey findings, focus group discussion also supported the hypothesis that perceived autonomy influences diabetes-related distress among urban African American adults living with T2DM. Participants' comments indicated that they experienced distress when healthcare providers did not provide autonomy support. In particular, participants stated that they feel stressed out when they do not feel heard by their physicians.

Male: "In my case frustration from health care providers...You tell your health care provider what's going on with you, they change the subject and keep on talking right on past. That is the most frustrating...You go to a different doctor- the same thing."

Female: "I don't know if my doctor really hears my cries all the time. Lord knows that I'm trying, but I know that I need to do more and I need more support than what I'm getting" 


\section{Relatedness}

As observed in the quantitative findings, focus group participants' sense of relatedness seemed to be associated with social support. This finding was most common among male participants, where involvement in supportive social contexts helped them to feel connected with others, and not be isolated.

Male: "I'm single, no girl, no one, I live alone by myself in the basement of a home. I try to participate in everything I can at my church, just to feel as though I have some support."

Though relatedness was not observed to be a significant predictor of T2DM selfmanagement or diabetes-related emotional distress among survey participants, focus group discussion suggested that relatedness plays an important role with regards to the motivational model among urban African American adults living with T2DM. In particular, focus group participants' comments suggested that relatedness influences their motivation for managing T2DM. Focus group participants primarily expressed extrinsic reasons for managing their condition, which contradicts conclusions drawn from the survey data, where the sample was observed to be intrinsically-motivated. Focus group Participants' relationship with their family members appeared to be a source of motivation for performing their self-care. Specifically, participants discussed being motivated to take manage their condition, so that they can be healthy and live to partake in their family members' lives.

Female: "My motivator is my granddaughter...she just thinks granny hung the moon... I'm hoping I can be around when she graduates from high school and college." 
In contrast, one male participant shared that he is not motivated, and discussed how he felt different from the other males in the group, in that he did not have a support network available, such as children or a significant other.

Male: "I'm afraid I actually have no motivation. I'm alone. I have no one in my family."

Participants also discussed other extrinsic reasons for managing their condition. In particular, several participants indicated that they chose to manage their T2DM, in an effort to avoid the development of diabetes-related complications and comorbidities.

Male: "My first reason is that I don't want to become an amputee."

Female: "You don't want to lose a limb, or have something, cause then diabetes is not a secret anymore."

Moreover, both male and female participants often related their fear of comorbidities to their family-history of diabetes.

Male: "Well my grandfather's leg was amputated, so diabetes is on my mother's side of the family, and my father's side of the family. So knowing that it's in the family, that motivates me to take care of myself."

Female: "My mother didn't have a lot of success with insulin. So that's a motivator for me. I'm trying to keep to a point that I don't get there...And dialysis, my sister had dialysis and I'm trying not to let my physical body get in that shape." 


\section{Diabetes-related distress}

Overall, diabetes-related distress seemed to be more an issue than selfmanagement among participants in the current study. Among survey participants, mean scores were observed to be elevated for specific aspects of diabetes-related distress. Specifically, the regimen-related distress subscale was observed to have the highest mean of all the distress instrument subscales. Similarly, focus group discussions from the study support these findings, as many participants shared their frustrations about their T2DM self-management regimens.

Participants expressed that they were especially frustrated with their medication regimen, as it was the most commonly discussed source of regimen-related distress. Specifically, both male and female participants were overwhelmed by the intensity and intrusiveness of their medication regimen requirements.

Male: "Sometimes I'm like God, this is my life right here-all these pills...emotionally it could just really drain you."

Female: "The biggest part is, for me anyways, is the taking of so many medications...It just stresses me out that I take so many pills every day." 
Participants also referenced distress with respect to several aspects of managing their dietary regimen. First, a common finding among female participants was the difficulty of preparing meals. In particular, some women were stressed out by the amount of effort it took to plan meals, especially due to the perceived limitations of the diabetes-friendly diet.

Female: "Annoying, frustrating...It just takes an effort for every meal for me to plan it or check what I'm eating."

Female: "Not being able to cook all the food is stressful. You stand there and try to figure out what you gonna do."

Additionally, female participants indicated that they were stressed out by the limitations of their dietary regimen during social outings at restaurants, as well as special social gatherings, such as holidays.

Female: "The eating out part is really hard...cause you see all this good food and you're like I can't do that."

Female: "You know, it gets stressful especially at Christmas or Thanksgiving cause you've got cakes, cookies, everything coming toward you." 
Lastly, both male and female participants discussed being frustrated by the immediate necessary changes in dietary behaviors. In particular, participants stated that the T2DM dietary regimen clashed with their food-related cultural traditions, routine, and overall identity.

Male: "My frustration is that you have to eat to live right? You been eating all your life a certain way, no big deal...All of a sudden you've got diabetes. Screech, put the brakes on. You've got to change everything about food and eating and I mean everything...You can't eat like you used to, you can't eat what you used to...Change it or you'll die...So that's my frustration,...trying to make that change... Trying to learn, relearn something that you've done for 49 years...Trying to relearn it just like that. You have to change it now. You can't gradually slide into it. No, you need to change it now."

Female: "Food makes me happy. Now you're telling me I gotta give it up and I've got to give it up in such a way, I've got to go to things that are foreign to me. My mother never cooked zucchini and all that other different vegetables that you're telling me that I need."

The emotional burden of diabetes was also one of the most frequently discussed topics within focus groups for the current study. This observation supports quantitative findings from the survey data, as the emotional burden subscale had the highest mean of all the DDS-17 subscales. Moreover, the mean for the emotional burden of diabetes was slightly higher than the aggregate mean for distress subscales among the sample. Male participants reported feeling depressed as a result of living with T2DM.

Male: "Depression is something else. I been depressed about this [diabetes]. I had to go to the doctor about this depression." 
Male: "[You have] depression at times...because of the fact that you know this is a every day, day in and day out thing. Nothing change about it. Every day."

A more common observation among female participants was them referencing diabetes as being controlling over their lives. Additionally, some women discussed their frustrations with the fact that diabetes is a chronic, long-term condition.

Female: "Sometimes I feel helpless, because I am no longer in control of my life... I wake up in the morning and stick myself and this little meter dictates how I am going to run the rest of my day...If I slip, I got to deal with all of that guilt... So emotionally I am not in control of my life, So, diabetes is like an emotional roller coaster for me. You know, I'm up and down."

Female: "Just knowing that it's a lifetime thing. That it's not going to go away. You could lose weight, you could do everything right and everything, it's still not going to go away, it's going to always be there. I think that's the thing that gets to me the most." 


\section{Needs and preferences for diabetes support programs}

Participants were asked to discuss their suggestions for resources and components to be considered during the development of future diabetes support programs.

Participants provided several recommendations based on their perceived needs and preferences. A common observation was participants' discussion of preferences for program components which facilitate fulfillment of their relatedness needs.

\section{Peer Support}

Several participants compared the availability of diabetes support groups and resources to other chronic conditions, such as cancer and alcoholism, which they perceived to have a greater availability of support resources. Both male and female participants indicated that they would like to have the opportunity to interact with their peers in a diabetes support program. In particular, peer support groups were described as settings which facilitate informational support among peers, as well as provide as space where people can interact with others with whom they share a common health experience.

Male: "Listening to other people, like we' re doing now is helpful. Finding out more insight about it... I don't feel so odd about it no more."

Female: "It makes you feel like you're not the only person dealing with this, and, you know, some things that I may have experienced... maybe can help her. Or things that she's talking about...[are] things I may be thinking about." 
The perceived benefits of peer support was also observed among the focus group participants, where they frequently stated that the experience of sharing with and listening to their peers encouraged and motivated them to care for their condition.

Male: "Until today... I mean I thought I was [confident], but to hear these gentlemen. Mr. Doe here, he does exercises and everything and I do nothing. And it's given me an opportunity to take a look at it and see how a terrible job...that I've been doing to save my own life."

Female: "Just listening to everybody's actual thoughts and stuff. This is motivating me. I'm learning something and I think I can work with it. If they can do it I can do it too."

Several participants suggested that "specialty" peer support groups be made available, to address the unique needs and experiences of population segments. In particular, it was suggested that newly-diagnosed individuals should be referred to a support group, to facilitate their diabetes-related coping and self-management education.

Male: "What would be helpful to a lot of them if when they're diagnosed with diabetes that the doctor would get them in some type of group. A lot of them think, you know, they got diabetes, they're gonna die."

Both male and female participants indicated that they preferred to participate in a peer support group comprised of individuals with whom they share common characteristics, including gender and race. Specifically, individuals suggested that such commonalities would allow them to feel even more connected to their peers.

Male: "I'm a black man- I want to be around my [black] brothers. You may have the same disease but for many of us it's just not physical, it's social. You know, there's a social element to that... one thing is, we always have a common thread that binds us all together...our faith and our family. And that's comforting to know... We already know. We know what's going on, you know." 
Female: "Keep in mind the target audience, "cause I know I have been to these...diabetic classes and all of this stuff, but I find myself being the only person of color...And my issues, and the things in my lifestyle is totally different...I would love to hear, you know, about the others, you know, who kinda like me..and hear what they're doing... you know their things...keep that in mind as well when it comes to program delivery."

A frequent finding among participants was the desire for their family members to be included in educational segments of diabetes support programs. Female participants described the inclusion of family members as an opportunity for them to become more empathetic and emotionally-supportive.

Female: "It would be nice to have your family to come along and let them see what we struggle with. They might feel our pain. Help us, you know, encourage us...It would help if I could have my sister over here."

Female: "Open it up to, you know, bring your sister and her kids or bring your cousin or your husband so they can hear. So they can hear [our] possible foods...or how aggravating it is to us to have to look at a portion."

Similarly, male participants desired to include family members, so that they can learn about T2DM self-management needs, especially as it pertains to diet and nutrition. Participants indicated that the education would help family members to become more supportive, and would reduce the distress experienced by individuals living with T2DM.

Male: "They need to be educated too, because if they're educated then they know not to come at you like that -that that causes you stress. If they can get it into their head and understand that there's a balance of food that you have to eat and they won't say things like 'You're not supposed to eat that, why are you eating that?...Get that education and understand the mechanics of what a diabetic has to go through...I wouldn't mind something like that." 
Male: "I could benefit if I had my lady friend here, cause she would know not to have all that candy around cause it's a, it's just a problem for me cause I want the candy so bad cause [the] sugar's calling me. I'm like you know what it's gonna do to me so I mean, open it up to like family or family and friends, something like that. I could benefit from that."

\section{Mental health needs}

An important request that was brought up was the need for mental health to be addressed in diabetes support programs, in additional to physical health.

Male: I wish that health insurance companies and health care practitioners would expand upon [mental health] and they don't... They always look at the physical Illness or the physical side of things, but they don't address the psychological."

\section{Conclusion}

Results in this chapter indicate that the study data supported hypothesis one, two, and three. However, hypothesis four and five were not supported by the study data. Focus group discussion confirmed quantitative findings, and provided insight into the relationships between study variables. Participants' discussion also greatly increased the researchers understanding of urban African Americans' diabetes support needs and preferences. A detailed discussion of results from the current study is presented in chapter five. 


\section{CHAPTER 5}

\section{DISCUSSION}

\section{Introduction}

Chapter five presents a discussion of the results from the study. The chapter begins with a discussion of the observed role and relevance of self-determination theory (SDT) basic psychological needs within the study sample. In particular, the discussion addresses quantitative results pertaining to basic psychological needs, and also includes a discussion of how qualitative results from follow-up focus groups relate to the basic psychological needs. Additionally, current study findings are presented in an integrated fashion, in an effort to illustrate how the study supports existing literature, and adds to the body of knowledge surrounding researchers' understanding of basic psychological needs. Specific emphasis is made on discussing the role and relevance of relatedness in the study sample, as few studies have given attention to this basic need. The chapter concludes with a discussion of the implications of the research study results, as it pertains to recommendations for future diabetes support programs and improving clinical practice among adults living with diabetes. Limitations of the current study and suggestions for future research are also discussed. 
A premise of SDT is that all three basic psychological needs are important and essential, and that fulfillment of one or two is not enough (Deci \& Ryan, 2002). Selfdetermination theory also posits that it is not enough for basic needs to be satisfied, but that fulfillment of the needs must be balanced (Sheldon, et al., 2004). Overall, study findings were observed to support the importance of facilitating basic psychological need fulfillment, as the needs predicted motivation, self-management, and emotional distress among urban African American adults living with T2DM.

\section{Autonomy}

Within the sample, autonomy was observed to be a significant predictor of selfmanagement and diabetes-related emotional distress, as hypothesized. Study results also support the hypothesized relationship between autonomy and competence, which mirror findings from a previous similar study by Williams, et al. (2004), where autonomous regulation was determined to be a significant predictor of competence among individuals living with type-2 diabetes (T2DM).

Additionally, study findings support the SDT assumption that autonomy plays an integral role in individuals' motivation to perform behaviors. Specifically, quantitative results suggest that participants' T2DM self-management was autonomously regulated, meaning that they volitionally performed self-management behaviors for intrinsic reasons, such as because they personally valued their health. However, analysis of focus group data yielded contrasting results, as participants primarily expressed extrinsic reasons for managing their condition, such as family history and fear of comorbidity development, suggesting that participants were more controlled than autonomous with respect to their self-management regulation. The latter finding is consistent with existing 
literature, where it has been concluded that African Americans have higher levels of external control regarding their diabetes than whites (Bell, et al., 1995).

It was very apparent that family played an essential role in the lives of the study participants, especially as it related to their motivation for managing their condition. Focus group participants discussed managing their T2DM because they valued their life and longevity, but seemed to place more emphasis on the importance on their families. In particular, participants indicated that they wanted to live long lives spent with their families, and were therefore motivated to manage their T2DM. Family is an extrinsic motivator for participants' T2DM self-management, as the entity is an external source of motivation. However, from the perspective of the SDT autonomy-dependent motivation continuum (figure 1.1), performing self-management for family can be viewed as an integrated form of extrinsic motivation, because participants' family is something that they personally value and is meaningful to them. According to the autonomy-dependent motivation continuum, the attachment of meaning increases the autonomy and volition associated with behavior (Ryan \& Deci, 2000). Thus, the extrinsic motivator of family was actually experienced as an intrinsic motivator among participants. This observation corresponds to integrated regulation on the autonomy-dependent motivation continuum (Ryan \& Deci, 2000). Overall, participants in the study were observed to be very autonomous, which corresponded to them being intrinsically-motivated to manage their condition.

In the current study, physicians' provision of autonomy support was described as being a critical determinant of patient autonomy, which directly influences patients' perceived confidence to effectively manage their diabetes, and ultimately affects their 
diabetes-related behavioral and health outcomes such as adherence and glucose levels. During the follow-up focus groups, participants emphasized that they wanted to feel more supported by their physicians. Specifically, they wanted to be listened to and have the opportunity to voice their concerns, instead of being ignored. Lack of autonomy support was described as a source of great distress among focus group participants, which left them feeling helpless and discouraged with regards to managing their condition. In contrast, participants who felt supported by their physicians described themselves as being more confident and efficacious in their ability to manage their condition. These findings support similar work by Williams et al. (2009), where physicians' autonomy supportiveness was observed to be predictive of patients' sense of autonomous motivation for managing their, as well as predictive of their perceived competence, quality of life, and medication adherence among a mixed-race sample of middle income individuals living with the T2DM.

Collectively, existing research demonstrates that autonomy is an important determinant of behavioral and health outcomes for people living with T2DM, and should be facilitated through autonomy-supportive contexts. By listening to a patient's needs, a clinician is afforded the opportunity to work with the patient to develop a tailored care plan that addresses his or her specific diabetes-related issues. This approach reduces patients' perception of paternalistic treatment by the clinician, and promotes intrinsic motivation, where patients are autonomous in managing their condition.

\section{Competence}

Study findings also highlight the importance of competence within urban African Americans living with T2DM. As hypothesized, competence was found to significantly 
influence T2DM self-management and diabetes-related emotional distress within the study sample. However, it was not anticipated that competence would be a stronger predictor of study outcomes than autonomy in the hypothesized linear models. Similar results were produced in a study by Plotnikoff, et al. (2011), where self-efficacy was observed to be the strongest predictor of physical activity in individuals living with T2DM. Collectively, these findings contradict other studies, where autonomy, "the master need" has commonly been observed to have greater significance than competence, with respect to health outcomes. However, the observation that the basic psychological needs' influence varies by outcomes assessed supports the theoretical assumption proposed by Reis, et al. (2000) that each psychological need is distinct, and has potential to independently influence outcomes and produce empirically-distinguishable effects.

\section{Relatedness}

Despite relatedness not being a significant variable in hypothesized models predicting T2DM self-management and diabetes-related emotional distress within the sample, focus group discussions in the study suggest that relatedness plays an important role in the lives of urban African American adults living with T2DM. Specifically, participants' comments indicate that relatedness is important for motivation. Focus group participants who were socially-isolated expressed having a lack of motivation, whereas individuals who were socially-connected suggested that their relationship with others motivated them to manage their condition. This observation is similar to findings of a study conducted by Deci and Ryan (2000), where people with more supportive social contexts tended to be more proactive and engaged. 
Relatedness also seemed to be related to participants' competence, or overall confidence to manage their condition. To date, this finding has not been observed in the existing literature surrounding SDT and basic psychological needs. Similar to the relationship between relatedness and motivation, some focus group participants suggested that their social isolation reduced their overall confidence to manage their condition.

Relatedness was also observed to be an important underlying component of programs that participants desired to assist them with their diabetes-related selfmanagement and coping. In particular, a very common finding pertaining to participants' relatedness need fulfillment was the desire to have peer support groups available to them. Their desire for peer support groups is thought to derive from collectivistic cultural characteristics, which are commonly observed among ethnic minority groups such as African Americans. This finding aligns with the SDT assumption that the means by which basic needs are fulfilled vary between populations, and is influenced by factors such as culture (Ryan \& Deci, 2000). Participants in the current study exhibited the collectivistic characteristic of interdependence, emphasizing the importance of helping and relying upon others (Kuo, 2012). In this respect, participants' desire for peer support groups supports previous research findings, where it has been suggested that individuals with collectivistic cultural backgrounds have a greater reliance on others for emotional support than individuals with individualistic cultural backgrounds Ryan, et al. (2005). Participants in the current study not only indicated that they want to learn how to better manage their condition through education, but they also want to talk with other individuals with whom they share the common experience of living with T2DM. They want to know that their experience isn't unique. 
Peer support groups have been utilized as effective strategies to improve coping and self-management in several chronic diseases, including breast cancer (Stang \& Mittelmark, 2008), prostate cancer (Oliffe, et al., 2009), and HIV (Lennon-Dearing, 2008). While peer support resources are available for these chronic conditions, peer support groups do not appear to be as accessible to individuals living with T2DM, especially groups that primarily consist of African American attendees. Several participants in the study indicated that they were frustrated and disappointed by the fact that peer support groups are not available for African American people living with T2DM, to the same extent that peer support programs are available for individuals living with other chronic conditions. This frequent observation supports the need for support programs to be developed for urban African Americans living with T2DM. In particular, it was concluded that peer support groups and support groups in general would likely be very helpful to socially-isolated individuals, as participants tended to associate their perceived relatedness with their motivation and competence to manage their condition.

\section{Distress}

Distress seemed to be more of an issue for study participants than selfmanagement, as it was the primary source of discussion focus group participants. Moreover, self-management itself seemed to be a source of distress among study participants, rather than a separate issue. Specifically, regimen-related distress was observed to be elevated among survey participants in the study. This observation is consistent with findings in a quantitative study by Polonsky et al. (2005), and also supports findings of previous qualitative studies, where regimen-related distress has commonly been discussed as a barrier to regular T2DM self-management (Chlebowy, et 
al., 2010; Nagelkerk, et al., 2006). While quantitative findings suggested that participants were largely adherent to dietary recommendations, dietary self-management was still observed to be a primary area of concern among focus group participants. Follow-up focus group discussions in the current study contextualized this observation, providing insight into the fact that participants were especially distressed with regards to managing their dietary regimen. In particular, several participants indicated that they were overwhelmed by multiple aspects involving their dietary management, including preparing meals, incorporating and adjusting to abrupt changes in diet, and maintaining their dietary regimen in social settings. Participants' expression of their frustration with managing their diet warrants attention within this population, especially regarding problem-solving and planning, as suggested by Hill-Briggs et al. (2007).

Study participants also focused heavily on the emotional burden of living with diabetes, where they frequently reported feeling depressed as result of their diagnosis, as well as feeling controlled and helpless. Similar findings have been observed in other studies conducted in African Americans living with T2DM, participants have reported feeling controlled and overwhelmed by the condition (Chlebowy, et al., 2010). Additionally, other studies have recognized the psychological effects of diabetes, where depression has been observed to be prevalent among African Americans living with T2DM (Wagner, et al., 2009).

It is widely acknowledged that T2DM regimens are stressful to manage, however the emotional burden of the condition has been less acknowledged and consequently is less addressed in educational and support programs. The emotional burden subscale used in the current study gave insight into the extent to which participants were fatalistic about 
their diabetes-related health outcomes, as well as the extent to which participants perceived themselves to be controlled by T2DM and overwhelmed by the demands of managing their condition. As previously noted, the current study sample was observed to have an elevated emotional burden of diabetes subscale mean, indicating that this aspect of diabetes-related emotional distress was an area of concern for among the sample.

The study results suggest that the emotional or mental health impact of T2DM needs to be addressed among urban African Americans living with T2DM, in addition to providers and programs addressing the physical impact of the condition. Though mental health care is often stigmatized in the African American community, participants in the study expressed the desire to have their diabetes-related mental health issues addressed. This observation mirrors qualitative work by Egede (2002), where depression treatment was perceived to be beneficial among African Americans living with T2DM. Together, these results indicate that African Americans living with T2DM are open to discussing and having their diabetes-related mental health issues addressed, even to the extent that it involves clinical treatment.

The current findings also support other recent studies, where researchers have concluded that mental health is just as important as the physical health of individuals living with T2DM, as poor mental health has been associated with reduced selfmanagement among individuals living with T2DM (Leonard E. Egede, 2005; Park, Hong, Lee, Ha, \& Sung, 2004), and has been consequently associated with poor glycemic control (Gary, et al., 2000; Wagner, et al., 2009). Additionally, the current study findings are evidence for the growing clinical interest of incorporating mental health care into the treatment of patients with diabetes, in an effort to provide more comprehensive care. For 
example, Pouwer (2009) has suggested that T2DM patients should be screened for emotional distress, and several other studies promote the integration of mental and physical health treatment for patients living with T2DM, including work by Feifer and Tansman (1999), Egede (2006) and Bogner and De Vries (2010). Also, as previously noted, the current study findings also highlight the promising effect that peer support can have on diabetes-related mental health outcomes, such as emotional distress. 


\section{Clinical and Public Health Implications}

Research conducted for the current study has multiple implications for clinical and public health practice. In particular, the study findings have implications for improving the delivery and effectiveness of care that clinicians and public health educators provide to individuals living with T2DM. The study findings yielded recommendations that can be applied in existing and future programs targeting urban African American adults living with T2DM, as well as applied in clinical interactions. The recommendations were developed based on the input of the target population, thus ensuring relevance. The following recommendations are offered:

- Seek to improve and promote nutrition problem-solving and planning strategies among urban African Americans living with T2DM. Doing so facilitates autonomous decision-making, competence, and self-management.

- Address the mental health impact of T2DM, in addition to focusing on the physical aspects of the condition. Many clinicians and diabetes education programs tend to entirely focus on self-management, and neglect the important issue of mental health.

- Provide the opportunity for urban African American adults living with T2DM to participate in a peer support group. Peer support groups afford individuals the opportunity to interact with others with whom they have common experiences, as well as share information.

- Include patients' family members in educational program segments. Family members are likely to be more empathetic and supportive about T2DM as they become more informed. 
As previously noted, the study findings support the importance of autonomysupportive physician-patient interactions. In particular, the study findings suggest that patients would benefit from a tailored approach to managing their condition, as it would likely improve patients' regimen adherence, as well as reduce patients' diabetes-related distress. Clinical tailoring of care may include assisting patients' with problem-solving, or prescribing a medication and nutrition regimen that is both effective and conducive to patients' lifestyle.

Lastly, study findings also have potential to inform the development of targeted health communications that are likely to be relevant and effective health promotion tools for use among African Americans living with T2DM. Specifically, sociocultural factors, such as the importance of family, can be incorporated into health communications for urban adults living with T2DM. Similarly, because family history was identified as a primary motivator for self-management, health communications targeting this population can also apply evidential approaches focused on co-morbidity risk and family history. 


\section{Limitations}

Several limitations have been identified with respect to both the quantitative and qualitative portions of the study.

Quantitative limitations in the study primarily pertain to sample size and recruitment methodology. First, the researcher acknowledges the use of imputed data as a potential limitation in study. The researcher also recognizes that statistical modeling methods, such as path analysis and SEM, are extremely sensitive to sample size. The relatively small sample used for the current study may have compromised the fit of the specified models tested within the study, in addition to limiting the ability to conduct stratified analyses using sample data. Additionally, the use of incentives may have contributed to increased participation by low-income individuals, thus limiting the researcher's ability to compare participant outcomes by socio-economic status (SES).

Several potential limitations also exist with regard to the qualitative data collection and analysis in the study. First, the small number of focus groups conducted, in combination with the relatively low number of participants in each group, likely limited the study's ability to research qualitative data saturation. Additionally, social desirability may have influenced participants' responses during the focus groups, as the focus groups were facilitated by the study researcher, and the qualitative data was collected in a group setting. The group setting may have also prevented some participants from voicing their opinions, especially when it involved divulging sensitive personal information as well as when highly stigmatized topics, such as mental health, were discussed. Lastly, the qualitative data summary may have been subjected to interpretive bias, as the analysis was also conducted by the focus group facilitator. 
However, the facilitator made a conscious effort to be objective in analyzing the qualitative content, and also worked closely with the trained observer in summarizing the qualitative findings.

\section{Future research}

Findings of the current study suggest that while SDT basic needs were found to be relevant for the population, the relationships between the study variables need to be respecified in order to better fit the population under study. In particular, motivation should be tested as a mediating variable in the relationship between SDT basic psychological needs and outcomes. Moreover, relatedness should be assessed as a predictor of competence, as indicated by qualitative findings. Future work should also seek to assess whether the basic psychological needs influence subscale variables, such as specific self-management behaviors or specific aspects of diabetes-related emotional distress. Lastly, future research on this topic should include a large enough and ethnically diverse sample, such that stratified analyses can be conducted. 


\section{Summary}

The current study applied the novel approach of utilizing a theoretical framework to assess the relationships between social contextual conditions and outcomes. The purpose of the study was to assess whether and how socio-contextual factors and SDT basic needs autonomy, competence, and relatedness influence T2DM self-management behaviors and emotional distress in urban adults living with the condition.

An additional purpose of the study was to gain recommendations can be applied to improve program development, effectiveness, and delivery for this population. The resulting recommendations incorporated the input of the target population, in an effort to ensure that future and current programs are relevant as possible. Important theoretical constructs were also incorporated into the final recommendations resulting from the study, as study findings indicate that SDT basic psychological needs play a role in behavioral and health outcomes of African Americans living with T2DM. Support programs that employ the study recommendations have great potential to improve behavioral, physical, and mental health outcomes among individuals living with T2DM, through the delivery of relevant support and facilitation of basic psychological need fulfillment. 


\section{REFERENCES}

Aljasem, L. I., Peyrot, M., Wissow, L., \& Rubin, R. R. (2001). The impact of barriers and self-efficacy on self-care behaviors in type 2 diabetes. The Diabetes Educator, $27(3), 393-404$.

Anderson, R. M., Barr, P. A., Edwards, G. J., Funnell, M. M., Fitzgerald, J. T., \& Wisdom, K. (1996). Using focus groups to identify psychosocial issues of urban black individuals with diabetes. Diabetes Educator, 22(1), 28-33.

Arbuckle, J. L. (2006). Amos (Version 20.0). Chicago: SPSS.

Bandura, A., \& Adams, N. E. (1977). Analysis of Self-Efficacy Theory of Behavioral Change. Cognitive Therapy and Research, 1, 287-308.

Belgrave, F. Z., \& Lewis, D. M. (1994). The role of social support in compliance and other health behaviors for African Americans with chronic illnesses. Journal of Health and Social Policy, 5(3-4), 55-68.

Bell, R. A., Summerson, J. H., \& Konen, J. C. (1995). Racial Differences in Psychosocial Variables Among Adults with Non-insulin-dependent Diabetes Mellitus. Behavioral Medicine, 21(2), 69-73.

Bogner, H. R., \& de Vries, H. F. (2010). Integrating type 2 diabetes mellitus and depression treatment among African Americans: a randomized controlled pilot trial. The Diabetes Educator, 36(2), 284-292. 
Bradley, C. (1994). Handbook of Psychology and Diabetes: A guide to Psychological Measurements in Diabetes Research and Management. Amsterdam: Hardwood Academic Publishers.

Bremer, C. D., Kachgal, M., \& Schoeller, K. (2003). Self-determination: Supporting Successful Transition Research to Practice Brief (Vol. 2).

Carter-Edwards, L., Skelly, A. H., Cagle, C. S., \& Appel, S. J. (2004). "They care but don't understand": family support of African American women with type 2 diabetes. Diabetes Educator, 30(3), 493-501.

Centers for Disease Control and Prevention. (2008). National Diabetes Fact Sheet: General Information and National Estimates on Diabetes in the United States, 2007. Atlanta: Department of Health and Human Services Centers for Disease Control and Prevention.

Chan, D. K., Lonsdale, C., Ho, P. Y., Yung, P. S., \& Chan, K. M. (2009). Patient motivation and adherence to postsurgery rehabilitation exercise recommendations: the influence of physiotherapists' autonomy-supportive behaviors. Archives of Physical Medicine and Rehabilitation, 90(12), 1977-1982.

Chlebowy, D. O., \& Garvin, B. J. (2006). Social support, self-efficacy, and outcome expectations: impact on self-care behaviors and glycemic control in Caucasian and African American adults with type 2 diabetes. Diabetes Educator, 32(5), 777 786.

Chlebowy, D. O., Hood, S., \& LaJoie, A. S. (2010). Facilitators and barriers to selfmanagement of type 2 diabetes among urban African American adults: focus group findings. Diabetes Educator, 36(6), 897-905. 
Chlebowy, D. O., Hood, S., \& LaJoie, A. S. (2011). Gender Differences to SelfManagment Among African American Adults With Type-2 Diabetes. Joint Clinical Center and National Institute of Nursing Research (NINR) Conference. Bethesda, MD.

Chris Feifer, \& Transman, M. (1999). Promoting Psychology in Diabetes Primary Care. Professional Psychology: Research and Practice, 30(1), 14-21.

Cohen, J. (1988). Statistical Power Analysis for the Behavioral Sciences (2nd ed.). Hillsdale: Erlbaum.

Collins-McNeil, J. C., Holston, E. C., Edwards, C. L., Benbow, D., \& Ford, Y. (2009). Physical activity, depressive symptoms, and social support among AfricanAmerican women with type 2 diabetes. Canadian Journal of Nursing Research, $41(3), 24-43$.

Daly, J. M., Hartz, A. J., Xu, Y., Levy, B. T., James, P. A., Merchant, M. L., et al. (2009). An assessment of attitudes, behaviors, and outcomes of patients with type 2 diabetes. Journal of the American Board of Family Medicine, 22(3), 280-290.

Deci, E. L., \& Ryan, R. M. (2000). The "What" and "Why" of Goal Pursuits: Human Needs and the Self-Determination of Behavior. Psychological Inquiry, 1/(4), 227268.

Deci, E. L., \& Ryan, R. M. (2002). Handbook of Self-Determination Research. Rochester: The University of Rochester Press.

Deci, E. L., \& Ryan, R. M. (2008). Facilitating optimal motivation and psychological well-being across life's domains. Canadian Psychology, 49(1), 24-34. 
Deci, E. L., \& Vansteenkiste, M. (2004). Self-deterrmination theory and basic need satisfaction: Understanding human development in positive psychology. Ricerche di Psicologia, 27(1), 23-40.

DeCoster, V. A. (2003). The emotions of adults with diabetes: a comparison across race. Social Work in Health Care, 36(4), 79-99.

Delahanty, L. M., Grant, R. W., Wittenberg, E., Bosch, J. L., Wexler, D. J., Cagliero, E., et al. (2007). Association of diabetes-related emotional distress with diabetes treatment in primary care patients with Type 2 diabetes. Diabetic Medicine, 24(1), $48-54$

Dutton, G. R., Tan, F., Provost, B. C., Sorenson, J. L., Allen, B., \& Smith, D. (2009). Relationship between self-efficacy and physical activity among patients with type 2 diabetes. Journal of Behavioral Medicine, 32(3), 270-277.

Egede, L. E. (2002). Beliefs and attitudes of African Americans with type 2 diabetes toward depression. The Diabetes Educator, 28(2), 258-268.

Egede, L. E. (2005). Effect of Depression on Self-Management Behaviors and Health Outcomes in Adults with Type 2 Diabetes. Current Diabetes Reviews, I(3), 235243.

Egede, L. E. (2006). Disease-focused or integrated treatment: diabetes and depression. The Medical Clinics of North America, 90(4), 627-646.

Engelgau, M. M., Geiss, L. S., Saaddine, J. B., Boyle, J. P., Benjamin, S. M., Gregg, E. W., et al. (2004). The Evolving Diabetes Burden in the United States. Annals of Internal Medicine, $140(11), 945-950$.

Field, A. (2005). Discovering Statistics Using SPSS (2nd ed.). London: Sage. 
Fitzgerald, J. T., Anderson, R. M., Gruppen, L. D., Davis, W. K., Aman, L. C., Jacober, S. J., et al. (1998). The reliability of the Diabetes Care Profile for African Americans. Evalation \& the Health Professions, 21(1), 52-65.

Fitzgerald, J. T., Davis, W. K., Connell, C. M., Hess, G. E., Funnell, M. M., \& Hiss, R. G. (1996). Development and validation of the Diabetes Care Profile. Evaluation \& the Health Professions, 19(2), 208-230.

Ford, M. E., Tilley, B. C., \& McDonald, P. E. (1998). Social support among AfricanAmerican adults with diabetes. Part 1: Theoretical framework. Journal of the National Medical Association, 90(6), 361-365.

Freeman, J., \& Loewe, R. (2000). Barriers to communication about diabetes mellitus: Patients' and physicians' different view of the disease. The Journal of Family Practice, 49(6), 507-512.

Gary, T. L., Crum, R. M., Cooper-Patrick, L., Ford, D., \& Brancati, F. L. (2000). Depressive symptoms and metabolic control in African-Americans with type 2 diabetes. Diabetes Care, 23(1), 23-29.

Glanz, K., Rimer, B. K., \& Lewis, F. M. (2002). Health Behavior and Health Education: Theory, Research, and Practice (third ed.). San Francisco: Jossey-Bass.

Greening, L., Stoppelbein, L., Moll, G., Palardy, N., \& Hocking, M. (2004). Intrinsic motivation and glycemic control in adolescents with type 1 diabetes. Diabetes Care, $27(6), 1517$.

Gucciardi, E., Wang, S. C.-T., DeMelo, M., Amaral, L., \& Steward, D. E. (2008). Characteristics of men and women with diabetes. Canadian Family Physician, 54, 219-227. 
Hall, C. E., Loehmer, A., \& Malone, C. (2008). Health Status Assessment Report. Louisville: Louisville Metro Public Health and Wellness.

Handron, D. S., \& Leggett-Frazier, N. K. (1994). Utilizing content analysis of counseling sessions to identify psychosocial stressors among patients with type II diabetes. Diabetes Educator, 20(6), 515-520.

Hausmann, L. R., Ren, D., \& Sevick, M. A. (2010). Racial differences in diabetes-related psychosocial factors and glycemic control in patients with type 2 diabetes. Patient Preference and Adherence, 4, 291-299.

Heisler, M., Bouknight, R. R., Hayward, R. A., Smith, D. M., \& Kerr, E. A. (2002). The relative importance of physician communication, participatory decision making, and patient understanding in diabetes self-management. Journal of General Internal Medicine, 17(4), 243-252.

Hill-Briggs, F., Yeh, H. C., Gary, T. L., Batts-Turner, M., D'Zurilla, T., \& Brancati, F. L. (2007). Diabetes problem-solving scale development in an adult, African American sample. Diabetes Educ, 33(2), 291-299.

House, J. S., Umberson, D., \& Landis, K. R. (1988). Structures and Processes of Social Support. Annual Review of Sociology, 14, 293-318.

Hu, L., \& Bentler, P. M. (1999). Cutoff criteria for fit indexes in covariance structure analysis: Conventionall criteria versus new alternatives. Structural Equation Modeling, 6(1), 1-55.

Hwang, M. Y. (2000). Managing type 2 Diabetes. The Journal of the American Medical Association, 283(2), 288. 
Jackson, D. L. (2003). Revisiting sample size and number of parameter estimates: Some support for the $N: q$ hypothesis. Structural Equation Modeling, 10(1).

Kasser, T., Davey, J., \& Ryan, R. M. (1992). Motivation, dependability, and employeesupervisor discrepancies in psychiatric vocational rehabilitation settings. Rehabilitation, 37, 175-187.

Kennedy, S., Goggin, K., \& Nollen, N. (2004). Adherence to HIV medications: Utility of the theory of self-determination. Cognitive Therapy and Research, 28(5), 611628.

Kingery, P. M., \& Glasgow, R. E. (1989). Self-efficacy and outcome expectations in the self-regulation of non-insulin dependent diabetes mellitus. Health Education, $20(7), 13-19$

Kline, R. B. (2011). Principles and Practice of Structural Equation Modeling (Third ed.). New York: The Guilford Press.

Kuo, B. C. H. (2012). Collectivism and coping: Current theories, evidence, and measurements of collective coping. International journal of Psychology, 1-15.

La Guardia, J. G., Ryan, R. M., Couchman, C. E., \& Deci, E. L. (2000). Within-person variation in security of attachment: a self-determination theory perspective on attachment, need fulfillment, and well-being. Journal of Personality and Social Psychology, 79(3), 367-384.

Lennon-Dearing, R. (2008). The benefits of women-only HIV support groups. Journal of HIV/AIDS \& Social Services, 7(1), 27-45. 
Lin, E. H., Katon, W., Von Korff, M., Rutter, C., Simon, G. E., Oliver, M., et al. (2004). Relationship of depression and diabetes self-care, medication adherence, and preventive care. Diabetes Care, 27(9), 2154-2160.

Maclean, H. M. (1991). Patterns of diet self-care in diabetes. Social Science \& Medicine, $32(6), 689-696$.

Maillet, N. A., D'Eramo Melkus, G., \& Spollett, G. (1996). Using focus groups to characterize the health beliefs and practices of black women with non-insulindependent diabetes. Diabetes Educator, 22(1), 39-46.

Manderson, L., \& Kokanovic, R. (2009). "Worried all the time": distress and the circumstances of everyday life among immigrant Australians with type 2 diabetes. Chronic Illness, 5(1), 21-32.

Melkus, G. D., Whittemore, R., \& Mitchell, J. (2009). Type 2 diabetes in urban black and rural white women. Diabetes Educator, 35(2), 293-301.

Miller, C. K., \& Davis, M. S. (2005). The influential role of social support in diabetes management. Topics in Clinical Nutrition, 20(2), 157-165.

Misra, R., \& Lager, J. (2009). Ethnic and gender differences in psychosocial factors, glycemic control, and quality of life among adult type 2 diabetic patients. $J$ Diabetes Complications, 23(1), 54-64.

Montague, M. C., Nichols, S. A., \& Dutta, A. P. (2005). Self-management in African American women with diabetes. The Diabetes Educator, 31(5), 700-711.

Nagelkerk, J., Reick, K., \& Meengs, L. (2006). Perceived barriers and effective strategies to diabetes self-management. Journal of Advanced Nursing, 54(2), 151-158. 
National Diabetes Information Clearinghouse. (2007). National Diabetes Statistics.

Bethesda: U.S. Department of Health and Human Services National Institutes of Health.

National Diabetes Information Clearinghouse. (2008). Am I at Risk for type 2 Diabetes?: Taking Steps to Lower Your Risk of Getting Diabetes. In D. G. Marrero \& M. L. Parchman (Eds.). Bethesda: National Institute of Diabetes and Digestive and Kidney Diseases.

Nelson, K. M., McFarland, L., \& Reiber, G. (2007). Factors influencing disease selfmanagement among veterans with diabetes and poor glycemic control. Journal of General Internal Medicine, 22(4), 442-447.

Oftedal, B., Bru, E., \& Karlsen, B. (2011). Social support as a motivator of selfmanagement among adults with type 2 diabetes. Journal of Nursing and Healthcare of Chronic Illness, 3, 12-22.

Oliffe, J. L., Ogrodniczuk, J., Bottorff, J. L., Hislop, G. T., \& Halpin, M. (2009). Connecting humor, health, and masculinities at prostate cancer support groups. Psycho-Oncology, 18(9), 916-926.

Osborn, C. Y., \& Egede, L. E. (2010). Validation of an Information-MotivationBehavioral Skills model of diabetes self-care (IMB-DSC). Patient Education and Counseling, $79(1), 49-54$

Park, H., Hong, Y., Lee, H., Ha, E., \& Sung, Y. (2004). Individuals with type 2 diabetes and depressive symptoms exhibited lower adherence with self-care. Journal of Clinical Epidemiology, 57(9), 978-984. 
Pelletier, L. G., Dion, S. C., Slovinec-D'Angelo, M., \& Reid, R. (2004). Why do you regulate what you eat? relationships between forms of regulation, eating behaviors, sustained dietary behavior change, and psychological adjustment. Motivation and Emotion, 28(3), 245-277.

Penckofer, S., Ferrans, C. E., Velsor-Friedrich, B., \& Savoy, S. (2007). The psychological impact of living with diabetes: women's day-to-day experiences. Diabetes Educator, 33(4), 680-690.

Plotnikoff, R. C., Trinh, L., Courneya, K. S., Karunamuni, N., \& Sigal, R. J. (2011). Predictors of physical activity in adults with type 2 diabetes. American Journal of Health Behavior, 35(3), 359-370.

Polonsky, W. H., Fisher, L., Earles, J., Dudl, R. J., Lees, J., Mullan, J., et al. (2005). Assessing psychosocial distress in diabetes: development of the diabetes distress scale. Diabetes Care, 28(3), 626-631.

Pouwer, F. (2009). Should we screen for emotional distress in type 2 diabetes mellitus? Nature Reviews Endocrinology, 5(12), 665-671.

Rapley, P., \& Fruin, D. J. (1999). Self-efficacy in chronic illness: the juxtaposition of general and regimen-specific efficacy. International Journal of Nursing Practice, $5(4), 209-215$.

Reis, H. T., Sheldon, K. M., Gable, S. L., Roscoe, J., \& Ryan, R. M. (2000). Daily WellBeing: The Role of Autonomy, Competence, and Relatedness. Personality and Social Psychology Bulletin, 26(4), 419-435. 
Rhee, M. K., Slocum, W., Ziemer, D. C., Culler, S. D., Cook, C. B., El-Kebbi, I. M., et al. (2005). Patient Adherence Improves Glycemic Control. The Diabetes Educator, 3l(2), 240-250.

Rosland, A. M., Kieffer, E., Israel, B., Cofield, M., Palmisano, G., Sinco, B., et al. (2008). When is social support important? The association of family support and professional support with specific diabetes self-management behaviors. Journal of General Internal Medicine, 23(12), 1992-1999.

Ryan, R. M. (1995). Psychological Needs and the Facilitation of Integrative Processes. Journal of Personality, 63(3), 397-427.

Ryan, R. M., \& Connell, J. P. (1989). Perceived locus of causality and internalization: Examining reasons for acting in two domains. Journal of personality \& social psychology, 57, 749-761.

Ryan, R. M., \& Deci, E. L. (2000). Self-determination theory and the facilitation of intrinsic motivation, social development, and well-being American Psychologist, $55(1), 68-78$

Ryan, R. M., \& Deci, E. L. (2002). Overview of Self-Determination Theory: An Organismic Dialectical Perspective. In E. L. Deci \& R. M. Ryan (Eds.), Handbook of Self-Determination Research (pp. 4-33). Rochester: The University of Rochester Press.

Ryan, R. M., La Guardia, J. G., Solky-Butzel, J., Chirkov, V., \& Kim, Y. (2005). On the interpersonal regulation of emotions: Emotional reliance across gender, relationships, and cultures. Personal Relationships, 12, 145-163. 
Ryan, R. M., Patrick, H., Deci, E. L., \& Williams, G. C. (2008). Facilitating health behavior change and its maintenance: Interventions based on Self-Determination Theory. The European Health Psychologist, 10, 2-5.

Samuel-Hodge, C. D., Headen, S. W., Skelly, A. H., Ingram, A. F., Keyserling, T. C., Jackson, E. J., et al. (2000). Influences on day-to-day self-management of type 2 diabetes among African-American women: spirituality, the multi-caregiver role, and other social context factors. Diabetes Care, 23(7), 928-933.

Sarkar, U., Fisher, L., \& Schillinger, D. (2006). Is self-efficacy associated with diabetes self-management across race/ethnicity and health literacy? Diabetes Care, 29(4), 823-829.

Schumacker, R. E., \& Lomax, R. G. (1996). A Beginner's Guide to Structural Equation Modeling. Mahwah: Lawrence Erlbaum Associates.

Schwartz, L. S., Coulson, L. R., Toovy, D., Lyons, J. S., \& Flaherty, J. A. (1991). A biopsychosocial treatment approach to the management of diabetes mellitus. General Hospital Psychiatry, 13(1), 19-26.

Senecal, C., Nouwen, A., \& White, D. (2000). Motivation and dietary self-care in adults with diabetes: Are self-efficacy and autonomous self-regulation complementary or competing constructs?. Health Psychology, 19(5), 452-457.

Sheldon, K. M., Ryan, R. M., Deci, E. L., \& Kasser, T. (2004). The Independent Effects of Goal Contents and Motives on Well-being: It's Both What You Pursue and Why You Pursue It. Personality and Social Psychology Bulletin, 30(4), 475-486.

Sheldon, K. M., Williams, G. C., \& Joiner, T. (2003). Self-Determination Theory in the Clinic. New Haven \& London: Yale University Press. 
Shenolikar, R. A., Balkrishnan, R., Camacho, F. T., Whitmire, J. T., \& Anderson, R. T. (2006). Race and Medicationn Adherence in Medicaid Enrollees with Type-2 Diabetes. Journal of the National Medical Association, 98(7), 1071-1077.

Shigaki, C., Kruse, R. L., Mehr, D., Sheldon, K. M., Bin, G., Moore, C., et al. (2010). Motivation and diabetes self-management. Chronic Illness, 6(3), 202-214.

Silva, M. N., Markland, D., Carraca, E. V., Vieira, P. N., Coutinho, S. R., Minderico, C. S., et al. (2011). Exercise autonomous motivation predicts 3-yr weight loss in women. Medicine \& Science in Sports \& Exercise, 43(4), 728-737.

Skinner, E., \& Edge, K. (2002). Self-Determination, Coping, and Development. In E. L. Deci \& R. M. Ryan (Eds.), Handbook of Self-Determination Research (pp. 297337). Rochester: The University of Rochester Press.

Sousa, V. D., Zauszniewski, J. A., Musil, C. M., Price Lea, P. J., \& Davis, S. A. (2005). Relationships among self-care agency, self-efficacy, self-care, and glycemic control. Research and Theory for Nursing Practice, 19(3), 217-230.

Spencer, M. S., Kieffer, E. C., Sinco, B. R., Palmisano, G., Guzman, J. R., James, S. A., et al. (2006). Diabetes-specific emotional distress among African Americans and Hispanics with type 2 diabetes. Journal of Health Care for the Poor and Underserved, 17(2 Suppl), 88-105.

Stang, I., \& Mittelmark, M. B. (2008). Social support and interpersonal stress in professional-led breast cancer self-help groups. The International Journal of Mental Health Promotion, 10(2), 15-25. 
Strine, T. W., Beckles, G. L., Okoro, C. A., Balluz, L., \& Mokdad, A. (2004). Prevalence of CVD risk factors among adults with diabetes by mental distress status. American Journal of Health Behavior, 28(5), 464-470.

Stumvoll, M., Goldstein, B. J., \& Van Haeften, T. W. (2005). Type 2 diabetes: principles of pathogenesis and therapy. Lancet, 365, 1333-1346.

Suhr, D. (2008). Step your way through Path Analysis.

Tang, T. S., Brown, M. B., Funnell, M. M., \& Anderson, R. M. (2008). Social support, quality of life, and self-care behaviors among African Americans with type 2 diabetes. Diabetes Educator, 34(2), 266-276.

Teixeira, P. J., Going, S. B., Houtkooper, L. B., Cussler, E. C., Metcalfe, L. L., Blew, R. M., et al. (2006). Exercise motivation, eating, and body image variables as predictors of weight control. Medicine \& Science in Sports \& Exercise, 38(1), 179-188.

The Kaiser Family Foundation, statehealthfacts.org. (2008). Kentucky: Number of Diabetes Deaths per 100,000 Population by Race/Ethnicity, 2005. In The Kaiser Family Foundation (Ed.). D.C.: The Kaiser Family Foundation.

Thomas, J. L., Jones, G. N., Scarinci, I. C., \& Brantley, P. J. (2007). Social Support and the Association of Type 2 Diabetes and Depressive and Anxiety Disorders Among Low-income Adults Seen in Primary Care Clinics Journal of clinical psychology in medical settings, 14(4), 351-359. 
Thoolen, B. J., de Ridder, D. T., Bensing, J. M., Gorter, K. J., \& Rutten, G. E. (2006). Psychological outcomes of patients with screen-detected type 2 diabetes: the influence of time since diagnosis and treatment intensity. Diabetes Care, 29(10), $2257-2262$.

Toljamo, M., \& Hentinen, M. (2001). Adherence to self-care and social support. Journal of (linical Nursing, 10(5), 618-627.

Toobert, D. J., Hampson, S. E., \& Glasgow, R. E. (2000). The summary of diabetes selfcare activities measure: results from 7 studies and a revised scale. Diabetes Care, 23(7), 943-950.

Vallerand, R. J., \& Bissonnette, R. (1992). Intrinsic, Extrinsic, and Amotivational Sytles as Predictors of Behavior: A Prospective Study. Journal of Personality, 60(3), $599-620$

Van Dam, H. A., van der Horst, F. G., Knoops, L., Ryckman, R. M., Crebolder, H. F., \& van den Borne, B. H. (2005). Social support in diabetes: a systematic review of controlled intervention studies. Patient Education and Counseling, 59(1), 1-12.

Verhaak, P. F., Heijmans, J. W. M., Peters, L., \& Meike, R. (2005). Chronic disease and mental disorder. Social Science \& Medicine, 60, 789-797.

Wagner, J. A., Abbott, G. L., Heapy, A., \& Yong, L. (2009). Depressive symptoms and diabetes control in African Americans. Journal of Immigrant and Minority Health, 11(1), 66-70.

West, C., \& McDowell, J. (2002). The distress experienced by people with type 2 diabetes. British Journal of Community Nursing, 7(12), 606-613. 
Williams, Freedman, Z. R., \& Deci, E. L. (1998). Supporting autonomy to motivate patients with diabetes for glucose control. Diabetes Care, 21(10), 1644-165I.

Williams, McGregor, H. A., Sharp, D., Levesque, C., Kouides, R. W., Ryan, R. M., et al. (2006). Testing a self-determination theory intervention for motivating tobacco cessation: supporting autonomy and competence in a clinical trial. Health Psychology, 25(1), 91-101.

Williams, McGregor, H. A., Zeldman, A., Freedman, Z. R., \& Deci, E. L. (2004). Testing a Self-Determination Theory Process Model for Promoting Glycemic Control Through Diabetes Self-Management. . Health Pschology, 23(1), 58-66.

Williams, Niemiec, C. P., Patrick, H., Ryan, R. M., \& Deci, E. L. (2009). The importance of supporting autonomy and perceived competence in facilitating long-term tobacco abstinence. Annals of Behavioral Medicine, 37(3), 315-324.

Williams, Patrick, H., Niemiec, C. P., Williams, L. K., Divine, G., Lafata, J. E., et al. (2009). Reducing the health risks of diabetes: How self-determination theory may help improve medication adherence and quality of life. Diabetes Educator, 35(3), 484-492.

Williams, G. C., Grow, V. M., Freedman, Z. R., Ryan, R. M., \& Deci, E. L. (1996). Motivational predictors of weight loss and weight-loss maintenance. Journal of Personality and social Psychology, 70(1), 115-126.

Williams, G. C., McGregor, H. A., King, D., Nelson, C. C., \& Glasgow, R. E. (2005). Variation in perceived competence, glycemic control, and patient satisfaction: relationship to autonomy support from physicians. Patient Education and Counseling, 57(1), 39-45. 
Yi, J. P., Vitaliano, P. P., Smith, R. E., Yi, J. C., \& Weinger, K. (2008). The role of resilience on psychological adjustment and physical health in patients with diabetes. British Journal of Health Psychology, 13(Pt 2), 311-325.

Zoffmann, V., \& Lauritzen, T. (2005). Guided self-determination improves life skills with type 1 diabetes and $\mathrm{AlC}$ in randomized controlled trial. Patient Education and Counseling, 64(1-3), 78-86. 


\section{APPENDICES}
A. Survey Study Recruitment Flyer
B. Survey Study Informed Consent
C. Focus Group Study Informed Consent
D. Demographic Questionnaire
E. Perceived Social Support Received Questionnaire
F. Health Care Climate Questionnaire (HCCQ)
G. Basic Need Satisfaction in Diabetes Questionnaire
H. Treatment Questionnaire Concerning Diabetes (TSRQ)
I. Summary of Diabetes Self-Care Activities (SDSCA) measure
J. Diabetes Distress Scale (DDS-17)
K. Focus Group Questions for Social Context and Diabetes Study
L. Code Definitions for Social Contexts and Diabetes Focus Group Discussions 
Appendix-A

\section{Diabetics Needed for Survey}

Researchers at the University of Louisville seek persons with diabetes to take a survey about diabetes. The survey asks about your medical and social support and the stress that diabetes may cause you.

The survey can be completed on your own time. For taking the survey, you will be given a chance to win a $\$ 100$ gift card.

- To be eligible you must:

- have type-2 diabetes

- be 18 years or older

- be Black or Non-Hispanic White

- live in Louisville

- Able to read, write, \& speak English

To participate or learn more about the study, contact Sula Hood or Dr. Scott LaJoie. 502-632-2460 or smhood02@louisville.edu.

\begin{tabular}{|c|c|c|c|c|c|c|c|c|c|c|}
\hline 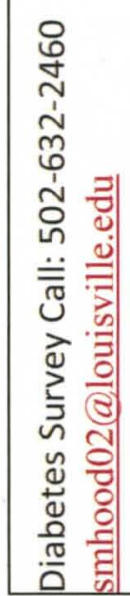 & 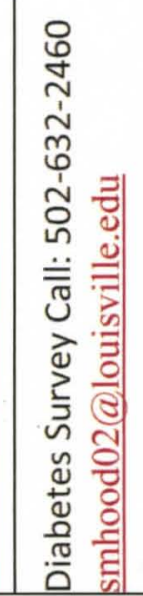 & 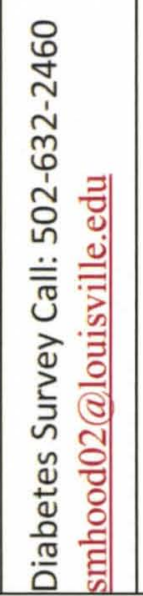 & 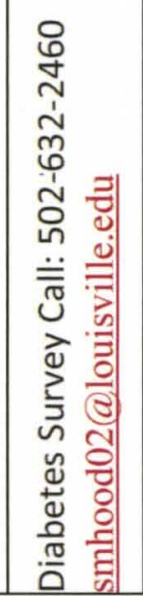 & 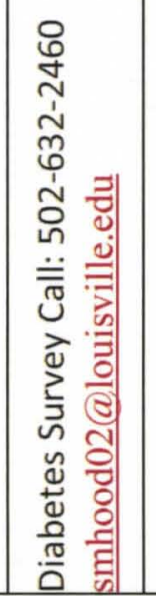 & 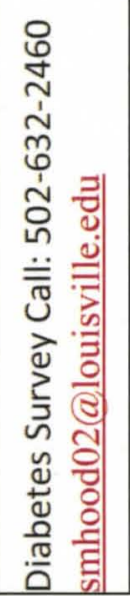 & 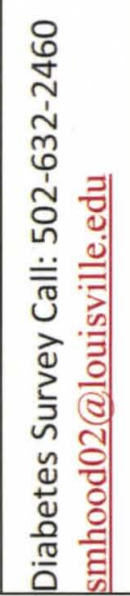 & 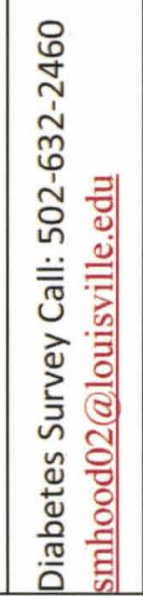 & 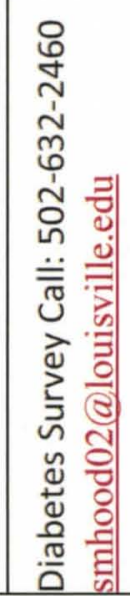 & 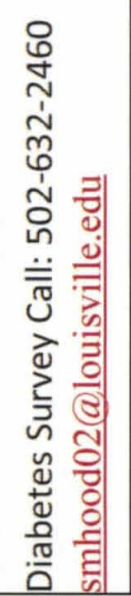 & 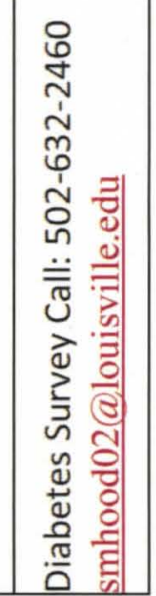 \\
\hline
\end{tabular}


Appendix-B

Subject Informed Consent Document

UNDERSTANDING THE INFLUENCE OF SOCIAL CONTEXTUAL FACTORS ON

TYPE-2 DIABETES OUTCOMES: QUESTIONNAIRES

IRB assigned number: 11.0706

Sponsor(s) name \& address: University of Louisville, Commission on Racial

Diversity and Equality, Administrative Annex, $2301 \mathrm{~S}$. Third Street, Administrative

Annex, Suite 201, Louisville, KY 40292.

Southern Regional Education Board, 592 Tenth Street N.W.

Atlanta, GA 30318-5776.

Investigator(s) name \& address: Scott LaJoie, Ph.D.

School of Public Health and Information

Sciences, Room 211

485 East Gray Street, Louisville, KY 40202,

Sula Hood, MPH

School of Public Health and Information

Sciences, Room 028

485 East Gray Street, Louisville, KY 40202

Site(s) where study is to be conducted: University of Louisville School of Public Health and Information Sciences

Phone number for subjects to call for questions: $502-632-2460$

\section{Introduction and Background Information}

You are invited to participate in a research study. The study is being conducted Scott LaJoie, Ph.D. and Sula Hood, MPH. The study is sponsored by the Southern Regional Education Board and the University of Louisville, Department of Commissions. The study will take place at the University of Louisville School of Public Health and Information Sciences. Approximately 200 subjects will be invited to participate.

\section{Purpose}

The purpose of this study is to understand how social relationships affect the way people living with diabetes manage their disease, and to understand how social relationships impact emotional distress among people with diabetes, so that 
social factors can be taken into consideration in future diabetes support programs.

\section{Procedures}

In this study, you will be asked to answer questions about how much support you feel you receive from your family, friends, and doctor for managing and coping with your diabetes. You will also be asked questions about how often you care for your diabetes, and how living with diabetes affects you emotionally. Lastly, you will be asked to answer questions that will tell us about your background. The survey is 18 pages in length and will take approximately 30 minutes to complete. You may decline to answer any questions that may make you uncomfortable.

\section{Potential Risks}

There are no foreseeable risks other than possible discomfort in answering personal questions. There may also be unforeseen risks.

\section{Benefits}

The information collected in this study may not benefit you directly. The information in this study may be helpful to others. The possible benefits of this study include information that will help inform future support programs for people living with diabetes.

\section{Compensation}

You will be entered into a drawing to be given one of ten $\$ 100$ Wal-mart gift cards as compensation for your time, inconvenience, or expenses while you are in this study.

In the event that your name is selected during a drawing, the University of Louisville must collect your name, address, social security number, ask you to sign a W-9 form, and keep records of how much you are paid. You may or may not be sent a Form 1099 by the University. This will only happen if you are paid more than $\$ 600$ in one year by the University. We are required by the Internal Revenue Service to collect this information and you may need to report the payment as income on your taxes.

This information will be protected and kept secure in the same way that we protect your other private information. If you do not agree to give us this information, we can't pay you for being in this study. You can still be in the study even if you don't want to be paid. 


\section{Confidentiality}

Total privacy cannot be guaranteed. Your privacy will be protected to the extent permitted by law. If the results from this study are published, your name will not be made public. While unlikely, the following may look at the study records:

The University of Louisville Institutional Review Board, Human Subjects Protection Program Office, and Privacy Office.

People who are responsible for research and HIPAA oversight at the institutions where the study is conducted

Government agencies, such as:

Office for Human Research Protections (OHRP) and Office of Civil Rights.

We will do our best to keep your personal information private. Paper copies of the questionnaires will be kept in a locked file, and a code will be used instead of your name. The code connected to your name will be known only by the principle investigator and the project coordinator.

\section{Voluntary Participation}

Taking part in this study is voluntary. You may choose not to take part at all. If you decide to be in this study you may stop taking part at any time. If you decide not to be in this study or if you stop taking part at any time, you will not lose any benefits for which you may qualify.

\section{Research Subject's Rights, Questions, Concerns, and Complaints}

If you have any concerns or complaints about the study or the study staff, you have three options.

You may contact the principal investigator at 502-852-1879.

If you have any questions about your rights as a study subject, questions, concerns or complaints, you may call the Human Subjects Protection Program Office (HSPPO) (502) 852-5188. You may discuss any questions about your rights as a subject, in secret, with a member of the Institutional Review Board (IRB) or the HSPPO staff. The IRB is an independent committee composed of members of the University community, staff of the institutions, as well as lay members of the community not connected with these institutions. The IRB has reviewed this study.

If you want to speak to a person outside the University, you may call 1-877-8521167 . You will be given the chance to talk about any questions, concerns or complaints in secret. This is a 24 hour hot line answered by people who do not work at the University of Louisville. 
This paper tells you what will happen during the study if you choose to take part. Your signature means that this study has been discussed with you, that your questions have been answered, and that you will take part in the study. This informed consent document is not a contract. You are not giving up any legal rights by signing this informed consent document. You will be given a signed copy of this paper to keep for your records.

Signature of Subject/Legal Representative

Date Signed

Signature of Person Explaining the Consent Form (if other than the Investigator)

Date Signed

Signature of Investigator

LIST OF INVESTIGATORS

A. Scott LaJoie, Ph.D.

Sula Hood, MPH
(502) 852-1879

(502) $632-2460$

(502) $632-2460$

For IRB Approval Stamp

Date Signed

PHONE NUMBERS 


\section{Appendix-C}

\section{Subject Informed Consent Document}

\section{TITLE OF RESEARCH STUDY}

\section{UNDERSTANDING THE INFLUENCE OF SOCIAL CONTEXTUAL FACTORS ON}

TYPE-2 DIABETES OUTCOMES: FOCUS GROUPS

IRB assigned number:

Sponsor(s) name \& address:
11.0706

University of Louisville, Commission on Racial Diversity and Equality, Administrative Annex, 2301 S. Third Street, Administrative

Annex, Suite 201, Louisville, KY 40292.

Southern Regional Education Board, 592 Tenth Street N.W. Atlanta, GA 30318-5776.

Investigator(s) name \& address: Scott LaJoie, Ph.D.

School of Public Health and Information

Sciences, Room 211

485 East Gray Street, Louisville, KY 40202, Sula Hood, MPH

School of Public Health and Information

Sciences, Room 028

485 East Gray Street, Louisville, KY 40202

Tiffany Robinson, MPH

School of Public Health and Information

Sciences, Room 027

485 East Gray Street, Louisville, KY 40202

Site(s) where study is to be conducted: University of Louisville School of Public Heath and Information Sciences

Phone number for subjects to call for questions: $.502-632-2460$

Introduction and Background Information

You are invited to participate in a research study. The study is being conducted Scott LaJoie, Ph.D. and Sula Hood, MPH. The study is sponsored by the Southern Regional Education Board and the University of Louisville, Department of Commissions. The study will take place at the University of Louisville School 
of Public Health and Information Sciences. Approximately 80 subjects will be invited to participate.

\section{Purpose}

The purpose of this study is to understand how social relationships affect the way people living with diabetes manage their disease, and to understand how social relationships impact emotional distress among people with diabetes, so that social factors can be taken into consideration in future diabetes support programs. The focus groups in this study are a follow-up part of a related questionnaire study.

\section{Procedures}

In this study, you will be invited to participate in a focus group, where you will be asked to discuss how you feel your relationships with others in your social network, such as family, friends, and your doctor, affect the way you manage your diabetes. You will also be asked to discuss how you feel these social relationships impact any distress that you may feel about your experience of living with diabetes. Additionally, you will be asked to discuss your preferences for characteristics of community-based diabetes resources, so that these needs may be taken into consideration for future programs. Lastly, you will be asked to complete a brief written questionnaire that will tell us about your background. The focus group session will last approximately 90 minutes. You may decline to answer any questions that may make you uncomfortable.

\section{Potential Risks}

There are no foreseeable risks other than possible discomfort in answering personal questions. There may also be unforeseen risks.

\section{Benefits}

The information collected in this study may not benefit you directly. However, you may experience social benefits from the experience of interacting with others who are also living with diabetes. The information in this study may be helpful to others. The possible benefits of this study include information that will help inform future support programs for people living with diabetes.

\section{Compensation}

You will be compensated for your time, inconvenience, or expenses while you are in this study, by receiving a Wal-mart gift card in the amount of $\$ 25$.

Because you will be paid to be in this study the University of Louisville must collect your name, address, social security number, ask you to sign a W-9 form, and keep records of how much you are paid. You may or may not be sent a Form 1099 by the University. This will only happen if you are paid more than 
$\$ 600$ in one year by the University. We are required by the Internal Revenue Service to collect this information and you may need to report the payment as income on your taxes.

This information will be protected and kept secure in the same way that we protect your other private information. If you do not agree to give us this information, we can't pay you for being in this study. You can still be in the study even if you don't want to be paid.

\section{Confidentiality}

Total privacy cannot be guaranteed. Your privacy will be protected to the extent permitted by law. If the results from this study are published, your name will not be made public. While unlikely, the following may look at the study records:

The University of Louisville Institutional Review Board, Human Subjects Protection Program Office, and Privacy Office.

People who are responsible for research and HIPAA oversight at the institutions where the study is conducted

Government agencies, such as:

Office for Human Research Protections (OHRP) and Office of Civil Rights.

We will do our best to keep your personal information private. Paper copies of the questionnaires and focus group transcripts will be kept in a locked file, and a code will be used instead of your name. The code connected to your name will be known only by the principle investigator and the project coordinator.

\section{Voluntary Participation}

Taking part in this study is voluntary. You may choose not to take part at all. If you decide to be in this study you may stop taking part at any time. If you decide not to be in this study or if you stop taking part at any time, you will not lose any benefits for which you may qualify.

\section{Research Subject's Rights, Questions, Concerns, and Complaints}

If you have any concerns or complaints about the study or the study staff, you have three options.

You may contact the principal investigator at 502-852-1879.

If you have any questions about your rights as a study subject, questions, concerns or complaints, you may call the Human Subjects Protection Program Office (HSPPO) (502) 852-5188. You may discuss any questions about your rights as a subject, in secret, with a member of the Institutional Review Board (IRB) or the HSPPO staff. The IRB is an independent committee composed of 
members of the University community, staff of the institutions, as well as lay members of the community not connected with these institutions. The IRB has reviewed this study.

If you want to speak to a person outside the University, you may call 1-877-8521167. You will be given the chance to talk about any questions, concerns or complaints in secret. This is a 24 hour hot line answered by people who do not work at the University of Louisville.

This paper tells you what will happen during the study if you choose to take part. Your signature means that this study has been discussed with you, that your questions have been answered, and that you will take part in the study. This informed consent document is not a contract. You are not giving up any legal rights by signing this informed consent document. You will be given a signed copy of this paper to keep for your records.

Signature of Subject/Legal Representative

Date Signed

Signature of Person Explaining the Consent Form

(if other than the Investigator)

Date Signed

Signature of Investigator

Date Signed

LIST OF INVESTIGATORS

PHONE NUMBERS

A. Scott LaJoie, Ph.D.

Sula Hood, MPH

(502) 852-1879

(502) $632-2460$

For IRB Approval Stamp 


\section{Appendix-D}

\section{Demographic Questionnaire}

Please answer each of the following questions by filling in the blanks with the correct answers or by choosing the single best answer.

1. What is your age?

2. Gender:

$\square$. Male

$\square$. Female

3. Is your ethnicity Hispanic or Latino?
$\square_{1}$ Yes
$\square 2$ No

4. Which race do you most identify with? (check one box)

$\square_{1} \quad$ African-American

$\square 2 \quad$ American Indian/ Alaskan Native

$\square 3 \quad$ Asian

$\square 4$ Caucasian

$\square$ s Native Hawaiin/ Pacific Islander

$\square$ Other:

5. How long have you had diabetes? 
6. How do you take your medication for your diabetes? (check only one box)

$\square$ Insulin only

$\square 2$ Pills only

$\square 3 \quad$ Insulin and pills

$\square_{4} \quad$ I do not take medication for my diabetes

$\square$ Other (please specify)

7. Who helps you the most in caring for your diabetes? (check only one box)

$\square$. Spouse

$\square_{2}$ Other family members

$\square_{3}$ Friends

$\square$ Paid helper

$\square_{\text {s Doctor }}$

$\square$. Nurse

$\square_{7}$ Case manager

$\square_{8}$ Other health care professional

$\square_{9}$ No one

8. What is your marital status? (check one box)

$\square 1 \quad$ Never married

$\square 2 \quad$ Married

$\square 3 \quad$ Separated/Divorced

$\square 4 \quad$ Widowed

9. How many people live with you? (not including yourself) 
10. What is your current yearly household income?

11. How much schooling have you had? (Years of formal schooling completed) (check one box)

$\square 1 \quad 8$ grades or less

$\square_{2} \quad$ Some high school

$\square$. High school graduate or GED

$\square$ प Some college or technical school

$\square_{5} \quad$ College graduate (bachelor's degree)

$\square 6 \quad$ Graduate degree

12. Which of the following best describes your current employment status?

(check one box)

$\square$. Employed

$\square_{2}$ Unemployed

$\square$ 3omemaker

$\square_{4}$ Student

$\square$ s Retired

$\square$ 6 Disabled, not able to work

$\square_{7}$ Something else? (Please specify): 
13. What type(s) of medical insurance do you currently have? (check all that apply)

$\square_{1} \quad$ An individual plan - the member pays for the plan premium

$\square 2$ A group plan through an employer, union, etc. - the employer pays all or part of the plan premium

$\square 3$ U.S. Governmental Health Plan (e.g., Military, CHAMPUS, VA)

$\square 4 \quad$ Passport/Medicaid

$\square$ s $\quad$ Medicare

$\square 6 \quad$ I have not had an insurance plan in the past 12 months

14. What is your zipcode? 


\section{Appendix-E}

\section{Perceived Social Support Received}

My family or friends help and support me a lot to: (circle one answer for each line)

\begin{tabular}{|lcccccc|}
\hline & $\begin{array}{c}\text { Strongly } \\
\text { Disagree }\end{array}$ & $\begin{array}{c}\text { Somewhat } \\
\text { Disagree }\end{array}$ & Neutral & $\begin{array}{c}\text { Somewhat } \\
\text { Agree }\end{array}$ & $\begin{array}{c}\text { Strongly } \\
\text { Agree }\end{array}$ & $\begin{array}{c}\text { Not } \\
\text { Apply }\end{array}$ \\
\hline $\begin{array}{l}\text { a) follow my meal } \\
\text { plan. }\end{array}$ & 1 & 2 & 3 & 4 & 5 & N/A \\
\hline $\begin{array}{l}\text { b) take my } \\
\text { medicine. }\end{array}$ & 1 & 2 & 3 & 4 & 5 & N/A \\
\hline $\begin{array}{l}\text { c) take care of my } \\
\text { feet. }\end{array}$ & 1 & 2 & 3 & 4 & 5 & N/A \\
\hline $\begin{array}{l}\text { d) get enough } \\
\text { physical activity. }\end{array}$ & 1 & 2 & 3 & 4 & 5 & N/A \\
\hline $\begin{array}{l}\text { e) test my sugar. } \\
\text { f) handle my } \\
\text { feelings about } \\
\text { diabetes. }\end{array}$ & 1 & 2 & 3 & 4 & 5 & N/A \\
\hline & 2 & 3 & 4 & 5 & N/A \\
\hline
\end{tabular}




\section{Appendix-F}

\section{Health Care Climate Questionnaire (HCCQ)}

This questionnaire contains items that are related to your visits with your doctor. Physicians have different styles in dealing with patients, and we would like to know more about how you have felt about your encounters with your physician. Your responses are confidential. Please be honest and candid.

1. I feel that my physician has provided me choices and options.

$\begin{array}{ccccccc}1 & 2 & 3 & 4 & 5 & 6 & \begin{array}{c}7 \\ \text { strongly } \\ \text { agree } \\ \text { disagree }\end{array}\end{array}$

2. I feel understood by my physician.

$\begin{array}{ccccccc}1 & 2 & 3 & 4 & 5 & 6 & \begin{array}{c}7 \\ \text { Strongly } \\ \text { disagree }\end{array}\end{array}$

3. My physician conveys confidence in my ability to make changes.

$\begin{array}{ccccccc}1 & 2 & 3 & 4 & 5 & 6 & \begin{array}{c}7 \\ \text { Strongly } \\ \text { disagree }\end{array} \\ & & \text { Neutral } & & & \begin{array}{l}\text { Strongly } \\ \text { agree }\end{array}\end{array}$

4. My physician encourages me to ask questions.

$\begin{array}{ccccccc}1 & 2 & 3 & 4 & 5 & 6 & \begin{array}{c}7 \\ \text { Strongly } \\ \text { disagree }\end{array}\end{array}$


5. My physician listens to how I would like to do things.

$\begin{array}{ccccccc}1 & 2 & 3 & 4 & 5 & 6 & \begin{array}{c}7 \\ \begin{array}{l}\text { Strongly } \\ \text { disagree }\end{array}\end{array} \\ & & \text { Neutral } & & & \begin{array}{l}\text { Strongly } \\ \text { agree }\end{array}\end{array}$

6. My physician tries to understand how I see things before suggesting a new way to do things.

$\begin{array}{ccccccc}1 & 2 & 3 & 4 & 5 & 6 & \begin{array}{c}7 \\ \text { Strongly } \\ \text { disagree }\end{array} \\ & & & \text { neutral } & & & \begin{array}{c}\text { Strongly } \\ \text { agree }\end{array}\end{array}$




\section{Appendix-G}

\section{Basic Need Satisfaction in Diabetes}

Please read each of the following items carefully, thinking about how it relates to your experience of living with diabetes, and then indicate how true it is for you.

1. I feel like I can have a say on how to take care of my diabetes.

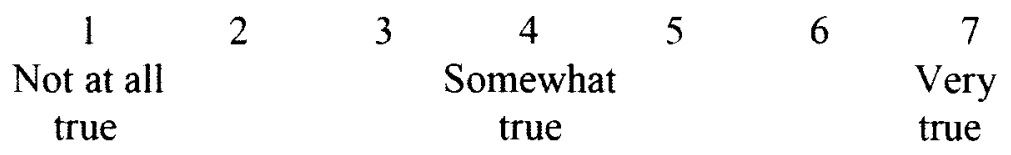

2. I really like the people who are helping me take care of my diabetes.

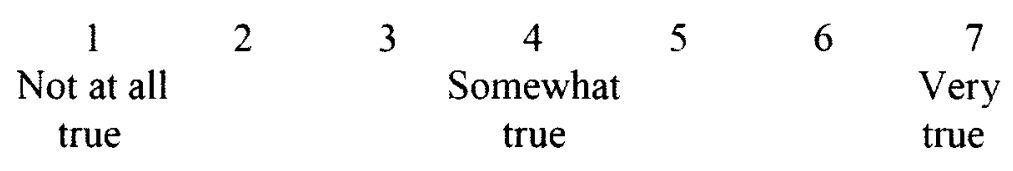

3. I do not feel confident in my ability to take care of my diabetes.

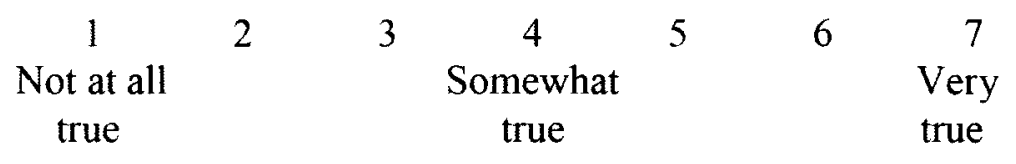

4. I feel pressured to take care of my diabetes.

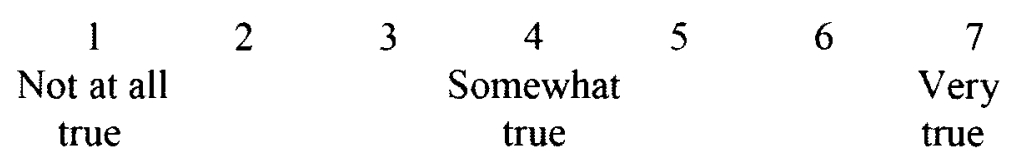

5. People I know tell me I am good at taking care of my diabetes.

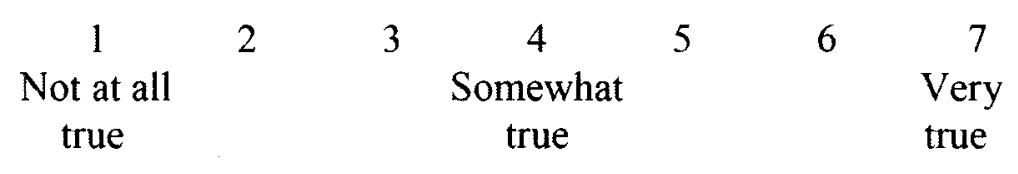


6. I do not get along with people involved in my diabetes care.

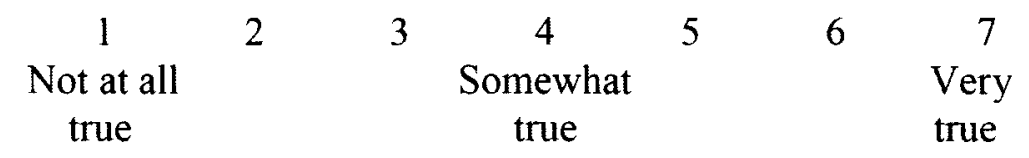

7. I do not depend on others very often for help with taking care of my diabetes.

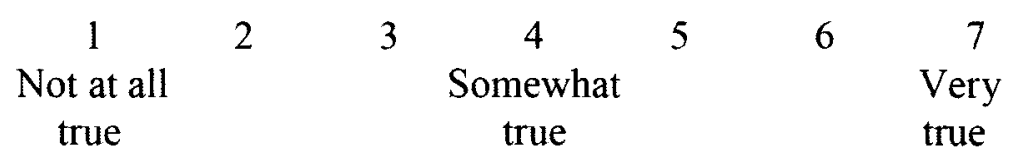

8. I feel free to express my ideas and opinions about how to take care of my diabetes.

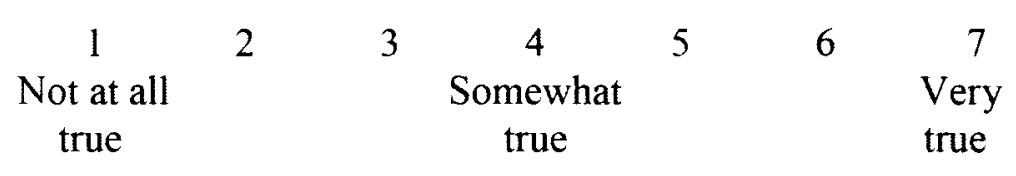

9. I am able to learn new skills for taking care of my diabetes.

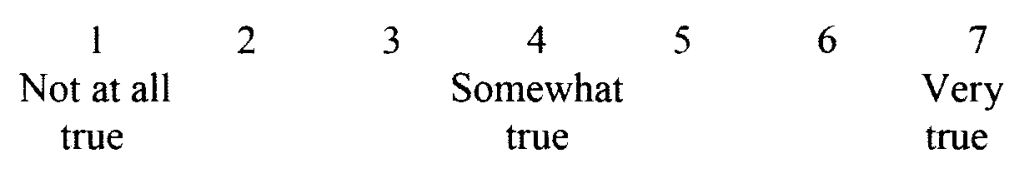

10. In taking care of my diabetes, I have to do what I am told.

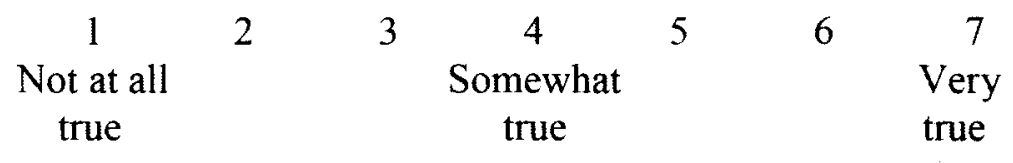

11. I am able to meet the challenge of controlling my diabetes.

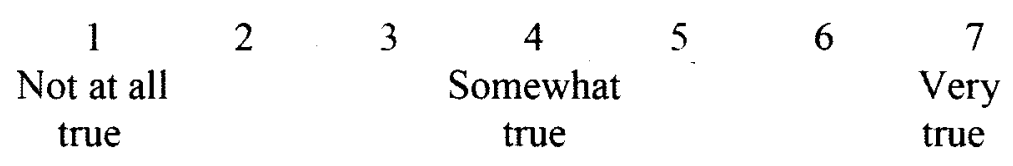


12. People who help me with my diabetes also care about me as a person.

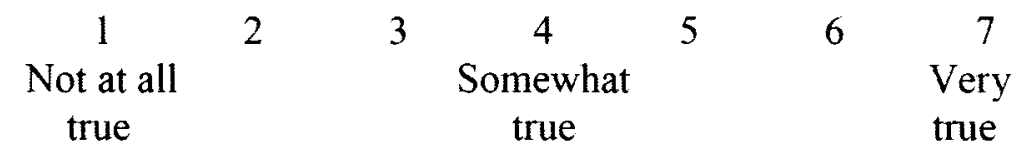

13. Most days I feel a sense of accomplishment from taking care of my diabetes.

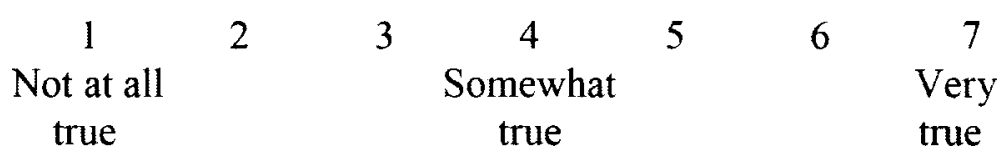

14. My feelings are taken into consideration by the people who help take care of my diabetes.

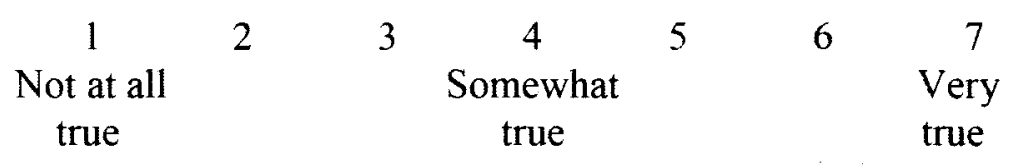

15. I am not capable of managing my diabetes right now.

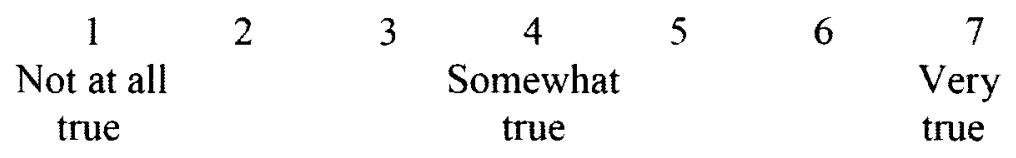

16. Few people I am close to know about my diabetes.

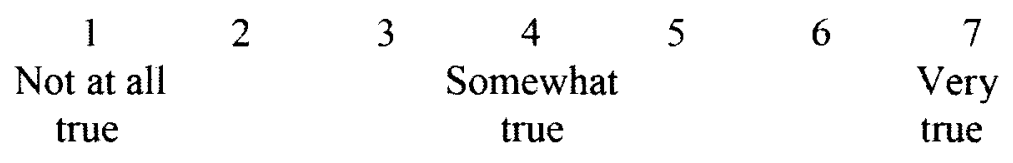

17. I feel like I can pretty much be myself around people who help care for my diabetes.

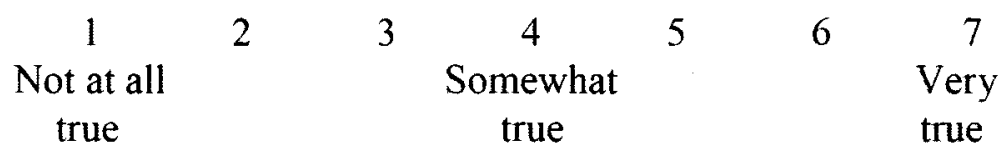


18. The people who help me take care of my diabetes do not seem to like me much.

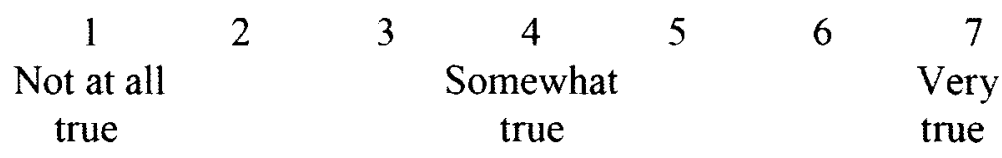

19. I often do not feel very capable to do my daily diabetic care.

$\begin{array}{ccccccc}1 & 2 & 3 & 4 & 5 & 6 & 7 \\ \begin{array}{c}\text { Not at all } \\ \text { true }\end{array} & & & \begin{array}{c}\text { Somewhat } \\ \text { true }\end{array} & & & \begin{array}{c}\text { Very } \\ \text { true }\end{array}\end{array}$

20. I do not get to make decisions about how to take care of my diabetes.

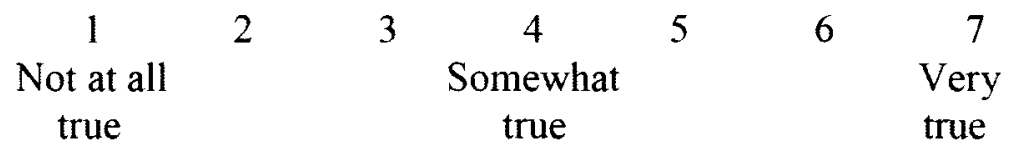

21. People who know about my diabetes are pretty friendly towards me.

$\begin{array}{ccccccc}1 & 2 & 3 & 4 & 5 & 6 & 7 \\ \begin{array}{c}\text { Not at all } \\ \text { true }\end{array} & & & \begin{array}{c}\text { Somewhat } \\ \text { true }\end{array} & & & \begin{array}{c}\text { Very } \\ \text { true }\end{array}\end{array}$




\section{Appendix-H}

\section{Treatment Questionnaire Concerning Diabetes}

There are a variety of reasons why patients take their medications, check their glucose, follow their diet, or exercise regularly. Please consider the following behaviors and indicate how true each of these reasons are for you.

\section{A. I take my medications for diabetes and/or check my glucose because:}

1. Other people would be mad at me if I didn't.

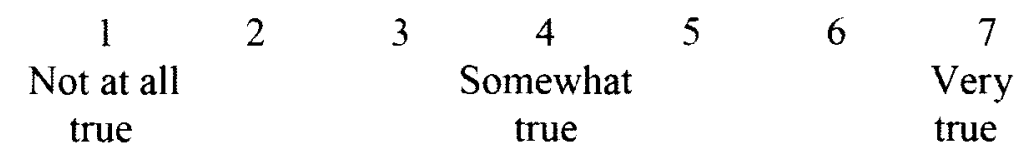

2. I find it a personal challenge to do so.

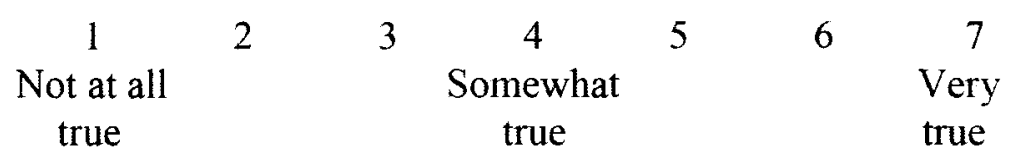

3. I personally believe that controlling my diabetes will improve my health.

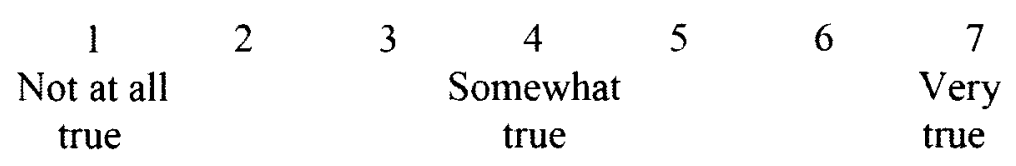

4. I would feel guilty if I didn't do what my doctor said.

$\begin{array}{ccccccc}1 & 2 & 3 & 4 & 5 & 6 & 7 \\ \begin{array}{c}\text { Not at all } \\ \text { true }\end{array} & & & \begin{array}{c}\text { Somewhat } \\ \text { true }\end{array} & & & \begin{array}{c}\text { Very } \\ \text { true }\end{array}\end{array}$

5. I want my doctor to think I'm a good patient.

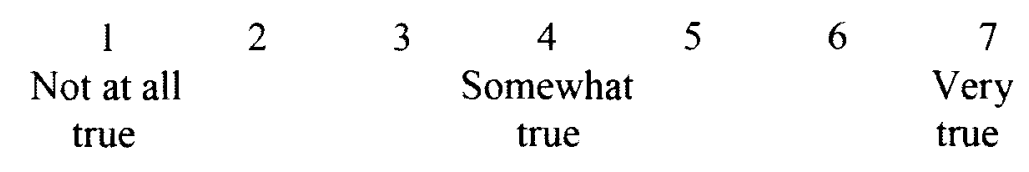


6. I would feel bad about myself if I didn't.

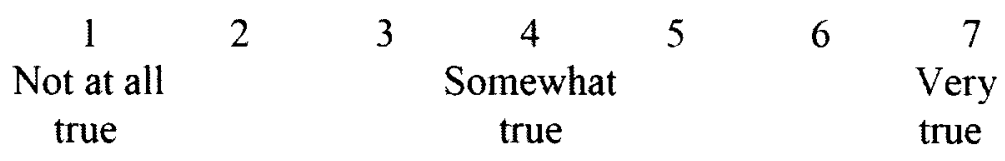

7. It's exciting to try to keep my glucose in a healthy range.

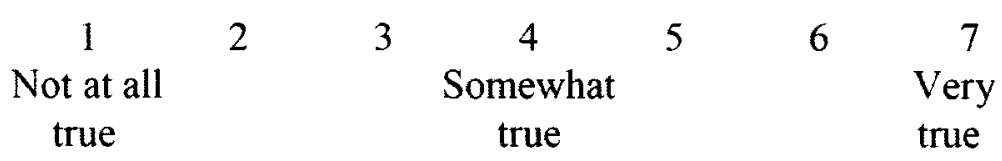

8. I don't want other people to be disappointed in me.

$\begin{array}{ccccccc}1 & 2 & 3 & 4 & 5 & 6 & 7 \\ \begin{array}{c}\text { Not at all } \\ \text { true }\end{array} & & & \begin{array}{c}\text { Somewhat } \\ \text { true }\end{array} & & & \begin{array}{c}\text { Very } \\ \text { true }\end{array}\end{array}$

B. The reason I follow my diet and exercise regularly is that:

9. Other people would be upset with me if I didn't.

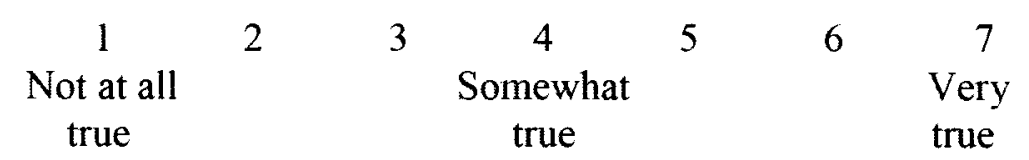

10. I personally believe that these are important in remaining healthy.

$\begin{array}{ccccccc}1 & 2 & 3 & 4 & 5 & 6 & 7 \\ \begin{array}{c}\text { Not at all } \\ \text { true }\end{array} & & & \begin{array}{c}\text { Somewhat } \\ \text { true }\end{array} & & & \begin{array}{c}\text { Very } \\ \text { true }\end{array}\end{array}$

11. I would be ashamed of myself if I didn't.

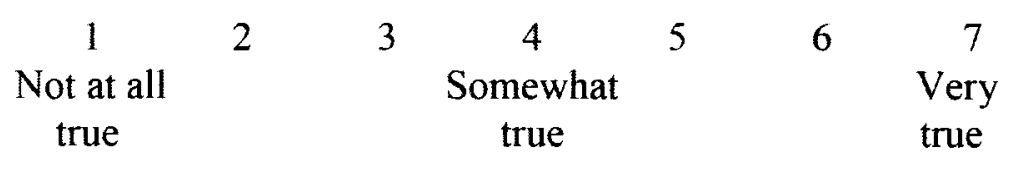

12. It is easier to do what l'm told than to think about it.

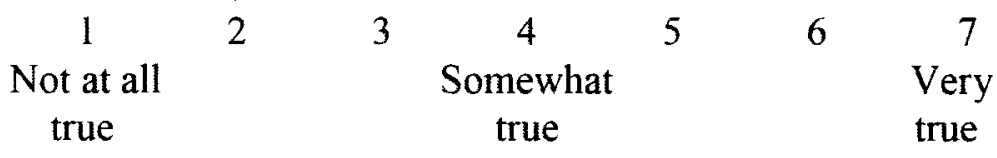


13. I've carefully thought about my diet and exercising and believe it's the right thing to do.

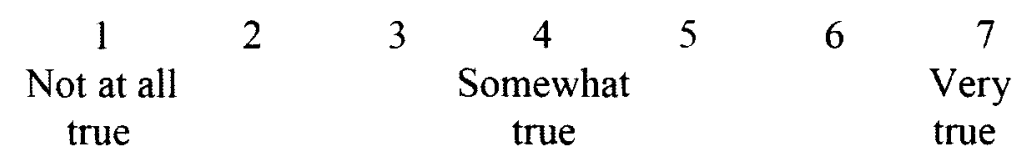

14. I want others to see that I can follow my diet and stay fit.

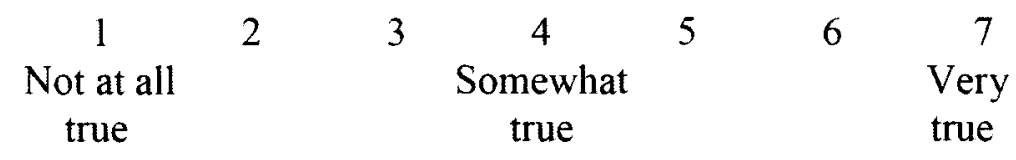

15. I just do it because my doctor said to.

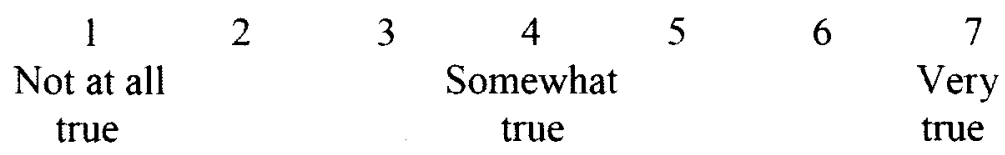

16. I feel personally that watching my diet and exercising are the best things for me.

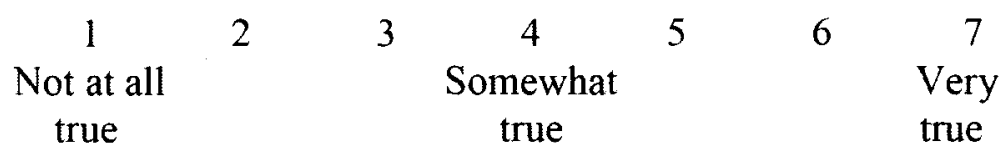

17. I'd feel guilty if I didn't watch my diet and exercise.

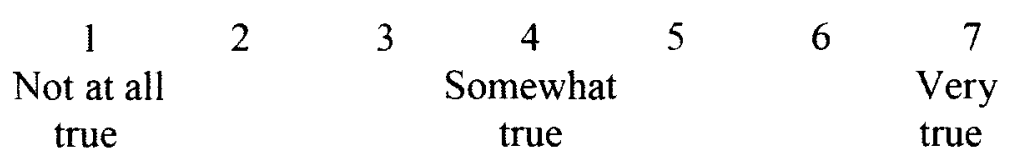

18. Exercising regularly and following my diet are choices I really want to make.

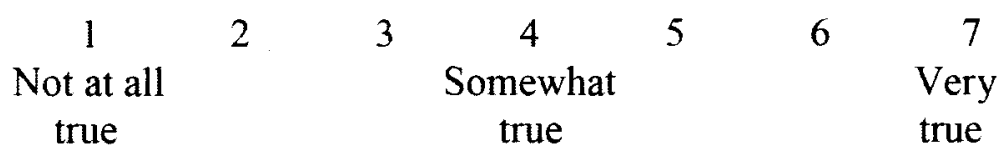

19. It's a challenge to learn how to live with diabetes.

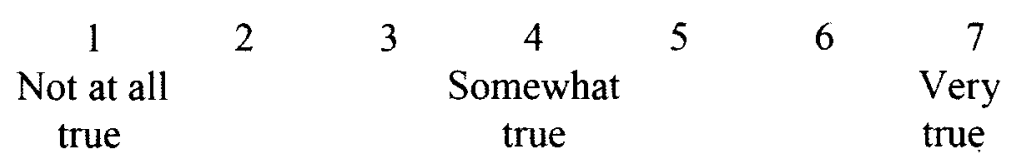




\section{Appendix-I}

\section{Summary of Diabetes Self-care Activities (SDSCA) measure}

The questions below ask you about your diabetes self-care activities during the past 7 days. If you were sick during the past 7 days, please think back to the last 7 days that you were not sick. Please check one box for each question.

\section{Diet}

1. How many of the last SEVEN DAYS have you followed a healthful eating plan?

$$
\sqcap 0 \quad \sqcap 1 \quad \sqcap 2 \quad \sqcap 3 \quad \sqcap 4 \quad \square 5 \quad \square 6 \quad \square 7
$$

2. On average, over the past month, how many DAYS PER WEEK have you followed your eating plan?

$$
\sqcup 0 \quad \square 1 \quad \square 2 \quad \square 3 \quad \square 4 \quad \square 5 \quad \square 6 \quad \square 7
$$

3. On how many of the last SEVEN DAYS did you eat five or more servings of fruits and vegetables?

$$
\sqcap 0 \quad \square 1 \quad \square 2 \quad \sqcap 3 \quad \square 4 \quad \square 5 \quad \square 6 \quad \square 7
$$

4. On how many of the last SEVEN DAYS did you eat high-fat foods, such as red meat or full-fat dairy products?

$\sqcap 0 \quad \square 1 \quad \square 2 \quad \square 3 \quad \square 4 \quad \square 5 \quad \square 6 \quad \square 7$

\section{Physical Activity}

5. On how many of the last SEVEN DAYS did you participate in at least 30 minutes of physical activity? (Total minutes of continuous activity, including walking).

$\sqcap 0 \quad \square 1 \quad \square 2 \quad \square 3 \quad \square 4 \quad \square 5 \quad \square 6 \quad \square 7$

6. On how many of the last SEVEN DAYS did you participate in a specific exercise session (such as swimming, walking, biking) other than what you do around the house or as part of your work?

$\sqcup 0 \quad \square 1 \quad \square 2 \quad \square 3 \quad \square 4 \quad \square 5 \quad \square 6 \quad \square 7$




\section{Blood Sugar Testing}

7. On how many of the last SEVEN DAYS did you test your blood sugar?

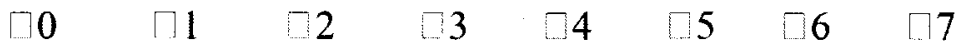

8. On how many of the last SEVEN DAYS did you test your blood sugar the number of times recommended by your health-care provider?

$$
\begin{array}{lllllllll}
0 & \square 1 & \square & \square & \square & \square & \square &
\end{array}
$$

\section{Foot Care}

9. On how many of the last SEVEN DAYS did you check your feet?

$\begin{array}{llllllll}0 & \square 1 & \square & 3 & \square & \square & \square & \square\end{array}$

10. On how many of the last SEVEN DAYS did you inspect the inside of your shoes?

$\square 0 \square 1 \quad \square 2 \quad \square 3 \quad \square 4 \quad \square 5 \quad \square 6 \quad \square 7$




\section{Appendix-J}

\section{Diabetes Distress Scale (DDS-17)}

DIRECTIONS: Living with diabetes can sometimes be tough. There may be many problems and hassles concerning diabetes and they can vary greatly in severity. Problems may range from minor hassles to major life difficulties. Listed below are 2 potential problem areas that people with diabetes may experience. Consider the degree to which each of the 2 items may have distressed or bothered you DURING THE PAST MONTH and circle the appropriate number.

Please note that we are asking you to indicate the degree to which each item may be bothering you in your life, NOT whether the item is merely true for you. If you feel that a particular item is not a bother or a problem for you, you would circle " 1 ". If it is very bothersome to you, you might circle "6".

1. Feeling that diabetes is taking up too much of my mental and physical energy every day.

$\begin{array}{cccccc}\begin{array}{c}\text { Not a } \\ \text { problem }\end{array} & \begin{array}{c}\text { A slight } \\ \text { problem }\end{array} & \begin{array}{c}\text { A } \\ \text { moderate } \\ \text { problem }\end{array} & \begin{array}{c}\text { Somewhat } \\ \text { serious } \\ \text { problem }\end{array} & \begin{array}{c}\text { A } \\ \text { serious } \\ \text { problem }\end{array} & \begin{array}{c}\text { A very } \\ \text { serious } \\ \text { problem }\end{array} \\ 1 & 2 & 3 & 4 & 5 & 6\end{array}$

2. Feeling that my doctor doesn't know enough about diabetes and diabetes care.

$\begin{array}{cccccc}\begin{array}{c}\text { Not a } \\ \text { problem }\end{array} & \begin{array}{c}\text { A slight } \\ \text { problem }\end{array} & \begin{array}{c}\text { A } \\ \text { moderate } \\ \text { problem }\end{array} & \begin{array}{c}\text { Somewhat } \\ \text { serious } \\ \text { problem }\end{array} & \begin{array}{c}\text { A } \\ \text { serious } \\ \text { problem }\end{array} & \begin{array}{c}\text { A very } \\ \text { serious } \\ \text { problem }\end{array} \\ 1 & 2 & 3 & 4 & 5 & 6\end{array}$

3. Feeling angry, scared, and/or depressed when I think about living with diabetes.

$\begin{array}{cccccc}\begin{array}{c}\text { Not a } \\ \text { problem }\end{array} & \begin{array}{c}\text { A slight } \\ \text { problem }\end{array} & \begin{array}{c}\text { A } \\ \text { moderate } \\ \text { problem }\end{array} & \begin{array}{c}\text { Somewhat } \\ \text { serious } \\ \text { problem }\end{array} & \begin{array}{c}\text { A } \\ \text { serious } \\ \text { problem }\end{array} & \begin{array}{c}\text { A very } \\ \text { serious } \\ \text { problem }\end{array} \\ 1 & 2 & 3 & 4 & 5 & 6\end{array}$


4. Feeling that my doctor doesn't give me clear enough directions on how to manage my diabetes.

$\begin{array}{cccccc}\begin{array}{c}\text { Not a } \\ \text { problem }\end{array} & \begin{array}{c}\text { A slight } \\ \text { problem }\end{array} & \begin{array}{c}\text { A } \\ \text { moderate } \\ \text { problem }\end{array} & \begin{array}{c}\text { Somewhat } \\ \text { serious } \\ \text { problem }\end{array} & \begin{array}{c}\text { A } \\ \text { serious } \\ \text { problem }\end{array} & \begin{array}{c}\text { A very } \\ \text { serious } \\ \text { problem }\end{array} \\ 1 & 2 & 3 & 4 & 5 & 6\end{array}$

5. Feeling that I am not testing my blood sugars frequently enough.

$\begin{array}{cccccc}\begin{array}{c}\text { Not a } \\ \text { problem }\end{array} & \begin{array}{c}\text { A slight } \\ \text { problem }\end{array} & \begin{array}{c}\text { A } \\ \text { moderate } \\ \text { problem }\end{array} & \begin{array}{c}\text { Somewhat } \\ \text { serious } \\ \text { problem }\end{array} & \begin{array}{c}\text { A } \\ \text { serious } \\ \text { problem }\end{array} & \begin{array}{c}\text { A very } \\ \text { serious } \\ \text { problem }\end{array} \\ 1 & 2 & 3 & 4 & 5 & 6\end{array}$

6. Feeling that I am often failing with my diabetes routine.

$\begin{array}{cccccc}\begin{array}{c}\text { Not a } \\ \text { problem }\end{array} & \begin{array}{c}\text { A slight } \\ \text { problem }\end{array} & \begin{array}{c}\text { A } \\ \text { moderate } \\ \text { problem }\end{array} & \begin{array}{c}\text { Somewhat } \\ \text { serious } \\ \text { problem }\end{array} & \begin{array}{c}\text { A } \\ \text { serious } \\ \text { problem }\end{array} & \begin{array}{c}\text { A very } \\ \text { serious } \\ \text { problem }\end{array} \\ 1 & 2 & 3 & 4 & 5 & 6\end{array}$

7. Feeling that friends or family are not supportive enough of self-care efforts (e.g. planning activities that conflict with my schedule, encouraging me to eat the "wrong" foods).

$\begin{array}{cccccc}\begin{array}{c}\text { Not a } \\ \text { problem }\end{array} & \begin{array}{c}\text { A slight } \\ \text { problem }\end{array} & \begin{array}{c}\text { A } \\ \text { moderate } \\ \text { problem }\end{array} & \begin{array}{c}\text { Somewhat } \\ \text { serious } \\ \text { problem }\end{array} & \begin{array}{c}\text { A } \\ \text { serious } \\ \text { problem }\end{array} & \begin{array}{c}\text { A very } \\ \text { serious } \\ \text { problem }\end{array} \\ 1 & 2 & 3 & 4 & 5 & 6\end{array}$

8. Feeling that diabetes controls my life.

$\begin{array}{cccccc}\begin{array}{c}\text { Not a } \\ \text { problem }\end{array} & \begin{array}{c}\text { A slight } \\ \text { problem }\end{array} & \begin{array}{c}\text { A } \\ \text { moderate } \\ \text { problem }\end{array} & \begin{array}{c}\text { Somewhat } \\ \text { serious } \\ \text { problem }\end{array} & \begin{array}{c}\text { A } \\ \text { serious } \\ \text { problem }\end{array} & \begin{array}{c}\text { A very } \\ \text { serious } \\ \text { problem }\end{array} \\ 1 & 2 & 3 & 4 & 5 & 6\end{array}$


9. Feeling that my doctor doesn't take my concerns seriously enough.

$\begin{array}{cccccc}\begin{array}{c}\text { Not a } \\ \text { problem }\end{array} & \begin{array}{c}\text { A slight } \\ \text { problem }\end{array} & \begin{array}{c}\text { A } \\ \text { moderate } \\ \text { problem }\end{array} & \begin{array}{c}\text { Somewhat } \\ \text { serious } \\ \text { problem }\end{array} & \begin{array}{c}\text { A } \\ \text { serious } \\ \text { problem }\end{array} & \begin{array}{c}\text { A very } \\ \text { serious } \\ \text { problem }\end{array} \\ 1 & 2 & 3 & 4 & 5 & 6\end{array}$

10. Not feeling confident in my day-to-day ability to manage diabetes.

$\begin{array}{cccccc}\begin{array}{c}\text { Not a } \\ \text { problem }\end{array} & \begin{array}{c}\text { A slight } \\ \text { problem }\end{array} & \begin{array}{c}\text { A } \\ \text { moderate } \\ \text { problem }\end{array} & \begin{array}{c}\text { Somewhat } \\ \text { serious } \\ \text { problem }\end{array} & \begin{array}{c}\text { A } \\ \text { serious } \\ \text { problem }\end{array} & \begin{array}{c}\text { A very } \\ \text { serious } \\ \text { problem }\end{array} \\ 1 & 2 & 3 & 4 & 5 & 6\end{array}$

11. Feeling that I will end up with serious long-term complications, no matter what I do.

$\begin{array}{cccccc}\begin{array}{c}\text { Not a } \\ \text { problem }\end{array} & \begin{array}{c}\text { A slight } \\ \text { problem }\end{array} & \begin{array}{c}\text { A } \\ \text { moderate } \\ \text { problem }\end{array} & \begin{array}{c}\text { Somewhat } \\ \text { serious } \\ \text { problem }\end{array} & \begin{array}{c}\text { A } \\ \text { serious } \\ \text { problem }\end{array} & \begin{array}{c}\text { A very } \\ \text { serious } \\ \text { problem }\end{array} \\ 1 & 2 & 3 & 4 & 5 & 6\end{array}$

12. Feeling that I am not sticking closely enough to a good meal plan.

$\begin{array}{cccccc}\begin{array}{c}\text { Not a } \\ \text { problem }\end{array} & \begin{array}{c}\text { A slight } \\ \text { problem }\end{array} & \begin{array}{c}\text { A } \\ \text { moderate } \\ \text { problem }\end{array} & \begin{array}{c}\text { Somewhat } \\ \text { serious } \\ \text { problem }\end{array} & \begin{array}{c}\text { A } \\ \text { serious } \\ \text { problem }\end{array} & \begin{array}{c}\text { A very } \\ \text { serious } \\ \text { problem }\end{array} \\ 1 & 2 & 3 & 4 & 5 & 6\end{array}$

13. Feeling that friends or family don't appreciate how difficult living with diabetes can be.

$\begin{array}{cccccc}\begin{array}{c}\text { Not a } \\ \text { problem }\end{array} & \begin{array}{c}\text { A slight } \\ \text { problem }\end{array} & \begin{array}{c}\text { A } \\ \text { moderate } \\ \text { problem }\end{array} & \begin{array}{c}\text { Somewhat } \\ \text { serious } \\ \text { problem }\end{array} & \begin{array}{c}\text { A } \\ \text { serious } \\ \text { problem }\end{array} & \begin{array}{c}\text { A very } \\ \text { serious } \\ \text { problem }\end{array} \\ 1 & 2 & 3 & 4 & 5 & 6\end{array}$


14. Feeling overwhelmed by the demands of living with diabetes.

$\begin{array}{cccccc}\begin{array}{c}\text { Not a } \\ \text { problem }\end{array} & \begin{array}{c}\text { A slight } \\ \text { problem }\end{array} & \begin{array}{c}\text { A } \\ \text { moderate } \\ \text { problem }\end{array} & \begin{array}{c}\text { Somewhat } \\ \text { serious } \\ \text { problem }\end{array} & \begin{array}{c}\text { A } \\ \text { serious } \\ \text { problem }\end{array} & \begin{array}{c}\text { A very } \\ \text { serious } \\ \text { problem }\end{array} \\ 1 & 2 & 3 & 4 & 5 & 6\end{array}$

15. Feeling that I don't have a doctor who I can see regularly enough about my diabetes.

$\begin{array}{cccccc}\begin{array}{c}\text { Not a } \\ \text { problem }\end{array} & \begin{array}{c}\text { A slight } \\ \text { problem }\end{array} & \begin{array}{c}\text { A } \\ \text { moderate } \\ \text { problem }\end{array} & \begin{array}{c}\text { Somewhat } \\ \text { serious } \\ \text { problem }\end{array} & \begin{array}{c}\text { A } \\ \text { serious } \\ \text { problem }\end{array} & \begin{array}{c}\text { A very } \\ \text { serious } \\ \text { problem }\end{array} \\ 1 & 2 & 3 & 4 & 5 & 6\end{array}$

16. Not feeling motivated to keep up my diabetes self management.

$\begin{array}{cccccc}\begin{array}{c}\text { Not a } \\ \text { problem }\end{array} & \begin{array}{c}\text { A slight } \\ \text { problem }\end{array} & \begin{array}{c}\text { A } \\ \text { moderate } \\ \text { problem }\end{array} & \begin{array}{c}\text { Somewhat } \\ \text { serious } \\ \text { problem }\end{array} & \begin{array}{c}\text { A } \\ \text { serious } \\ \text { problem }\end{array} & \begin{array}{c}\text { A very } \\ \text { serious } \\ \text { problem }\end{array} \\ 1 & 2 & 3 & 4 & 5 & 6\end{array}$

17. Feeling that friends or family don't give me the emotional support that I would like.

$\begin{array}{cccccc}\begin{array}{c}\text { Not a } \\ \text { problem }\end{array} & \begin{array}{c}\text { A slight } \\ \text { problem }\end{array} & \begin{array}{c}\text { A } \\ \text { moderate } \\ \text { problem }\end{array} & \begin{array}{c}\text { Somewhat } \\ \text { serious } \\ \text { problem }\end{array} & \begin{array}{c}\text { A } \\ \text { serious } \\ \text { problem }\end{array} & \begin{array}{c}\text { A very } \\ \text { serious } \\ \text { problem }\end{array} \\ 1 & 2 & 3 & 4 & 5 & 6\end{array}$




\section{Appendix-K}

\section{Focus Group Questions for Social Context and Diabetes Study by Theme}

\section{Icebreaker}

1. Tell me about your experience with your diabetes. What is it like to have diabetes?

\section{Motivation for self-management}

2. What are some of the reasons why you take care of your diabetes?

\section{Competence}

3. Overall, how confident do you feel about taking care of your diabetes?

4. How does your confidence to care for your diabetes relate to your motivation?

\section{Relatedness}

5. Who are the people who help you with your diabetes management?

\section{Social support}

6. How do others help you with your diabetes management?

\section{Distress}

7. How do you cope with the stress from you diabetes?

8. Who helps you cope with the stress from your diabetes?

9. What are the things that stress you out the most about having diabetes?

\section{Future programs}

10.What would you like to see in a program for people living with diabetes?

\section{Health information seeking}

11. Where do you get information about how to manage your diabetes? 


\section{Appendix-L}

\section{Code Definitions for Social Contexts and Diabetes Focus Group Discussions}

\section{Type of Statement by Participant}

\begin{tabular}{|l|l|}
\hline ANC & $\begin{array}{l}\text { Anecdotes- Any actual health-related story that a participant told about } \\
\text { him/herself or anyone else he or she knows. }\end{array}$ \\
\hline
\end{tabular}

\section{Health Condition/Illness}

\begin{tabular}{|l|l|}
\hline COMORB & $\begin{array}{l}\text { Comorbidity- Applied when a participant discussed any diabetes-related } \\
\text { illness. }\end{array}$ \\
\hline DIAB & Diabetes- Applied when participant made a specific reference to diabetes. \\
\hline OTHILL & $\begin{array}{l}\text { Other illness- Applied when a participant made a reference to illnesses that } \\
\text { are not diabetes-related. }\end{array}$ \\
\hline
\end{tabular}

\section{Topic of Participant's Statement}

\begin{tabular}{|l|l|}
\hline DIAED & $\begin{array}{l}\text { Diabetes education- Applied when a participant discussed diabetes } \\
\text { education as a resource. }\end{array}$ \\
\hline DIAG & $\begin{array}{l}\text { Diagnosis- Applied when a participant discussed their initial diabetes } \\
\text { diagnosis. }\end{array}$ \\
\hline ECON & $\begin{array}{l}\text { Economics- Applied when a participant discussed financial issues or factors } \\
\text { affecting health, such as insurance and money. }\end{array}$ \\
\hline FAM & $\begin{array}{l}\text { Family- Applied when a participant discussed information about a family } \\
\text { member. }\end{array}$ \\
\hline FAMHX & $\begin{array}{l}\text { Family history- Applied when a participant referenced having a family } \\
\text { history of diabetes or other health conditions. }\end{array}$ \\
\hline HCPRF & $\begin{array}{l}\text { Health care professional- Applied when a participant mentioned any } \\
\text { healthcare provider as a source of care, support, information, or intention. }\end{array}$ \\
\hline HCSYS & $\begin{array}{l}\text { Health care system or interaction- Applied when a participant refers to } \\
\text { interaction with health care systems such as clinical staff and personnel, as } \\
\text { well as when a participant discussed a interaction with larger health care } \\
\text { systems, such as insurance, institutional policy, location, and government. }\end{array}$ \\
\hline
\end{tabular}




\section{Topic of Participant's Statement Cont'd}

\begin{tabular}{|c|c|}
\hline INFOSEEK & $\begin{array}{l}\text { Information seeking- Applied when a participant discussed sources and } \\
\text { methods of obtaining health-related information. }\end{array}$ \\
\hline Mortal & $\begin{array}{l}\text { Mortality- Applied when a participant discussed death, such as discussing } \\
\text { death as a consequence of diabetes or in other contexts. }\end{array}$ \\
\hline PEER & $\begin{array}{l}\text { Peer support- Applied when a participant discussed peer support, such as } \\
\text { in the context of benefits of, or a desire for peer support. }\end{array}$ \\
\hline RELIG & $\begin{array}{l}\text { Religion/Spirituality-Applied when a participant invoked God or religion } \\
\text { in regards to his or her health. }\end{array}$ \\
\hline SELF & $\begin{array}{l}\text { Self- Applied when a participant discussed information pertaining to him } \\
\text { or herself. }\end{array}$ \\
\hline SEX & Sex- Applied when a participant discussed sex. \\
\hline SOCIONET & $\begin{array}{l}\text { Social network- Applied when a participant made reference to his or her } \\
\text { social network as a source of support or information. }\end{array}$ \\
\hline
\end{tabular}

\section{Demographics}

\begin{tabular}{|l|l|}
\hline AGE & $\begin{array}{l}\text { Age- Applied when age, such as young or old was mentioned as a factor in } \\
\text { determining behaviors and health outcomes. }\end{array}$ \\
\hline GND & $\begin{array}{l}\text { Gender- Applied when gender was mentioned as a factor in determining } \\
\text { behaviors and health outcomes. }\end{array}$ \\
\hline RACE & $\begin{array}{l}\text { Race- Applied when race or ethnicity was mentioned as a factor in } \\
\text { determining behaviors, health experiences, and health outcomes. }\end{array}$ \\
\hline
\end{tabular}

\section{Self-Determination Theory}

\begin{tabular}{|l|l|}
\hline ATMY & $\begin{array}{l}\text { Autonomy- Applied when a participant discussed exhibiting autonomous } \\
\text { behavior, such as independent decision-making. }\end{array}$ \\
\hline CONFID & $\begin{array}{l}\text { Competence- Applied when a participant discussed confidence as it relates } \\
\text { to his or her overall ability to manage diabetes, and when a participant } \\
\text { discussed sources of his or her confidence. }\end{array}$ \\
\hline
\end{tabular}




\section{Self Determination Theory Cont'd}

\begin{tabular}{|l|l|}
\hline EXTRIN & $\begin{array}{l}\text { Extrinsic- Applied when a participant discussed a motivating factor for } \\
\text { diabetes self-management, other than factors originating from him or } \\
\text { herself. }\end{array}$ \\
\hline INTRIN & $\begin{array}{l}\text { Intrinsic- Applied when a participant discussed aspects of him or herself as } \\
\text { a source of motivation for performing self-management. }\end{array}$ \\
\hline MOTIV & $\begin{array}{l}\text { Motivation- Applied when a participant referenced factors and contexts } \\
\text { influencing his or her motivation, as well as when a participant appraised } \\
\text { his or her motivation for diabetes self-management. }\end{array}$ \\
\hline RELATED & $\begin{array}{l}\text { Relatedness- Applied when a participant discussed his or her sense of } \\
\text { connectedness to others, such as the perceived availability of others, as well } \\
\text { as when a participant discussed his or her sense of social isolation or social } \\
\text { engagement. }\end{array}$ \\
\hline
\end{tabular}

\section{Self-management}

\begin{tabular}{|l|l|}
\hline DIET & $\begin{array}{l}\text { Diet and nutrition- Applied when a participant discussed aspects of diet and } \\
\text { nutrition, including behaviors such as food preparation and shopping. Also } \\
\text { applied when a participant discussed the availability of healthy food. }\end{array}$ \\
\hline EXER & Exercise- Applied when a participant discussed physical activity. \\
\hline FOOT & $\begin{array}{l}\text { Foot- Applied when a participant made reference to performing foot care, } \\
\text { or when a participant discussed complications with her or her feet, such as } \\
\text { diabetic neuropathy. }\end{array}$ \\
\hline MEDS & $\begin{array}{l}\text { Medication- Applied when a participant discussed aspects related to his or } \\
\text { her medication regimen, such as intensity of regimen, and side effects. }\end{array}$ \\
\hline SELFMGT & $\begin{array}{l}\text { Self-management- Applied when a participant made reference to } \\
\text { performing a self-management behavior. }\end{array}$ \\
\hline SMBG & $\begin{array}{l}\text { Self monitoring of blood glucose- Applied when a participant discussed } \\
\text { aspects related to glucose testing, including the act of performing glucose } \\
\text { monitoring and discussion pertaining to perceived barriers to regular } \\
\text { testing. }\end{array}$ \\
\hline
\end{tabular}




\section{Psychosocial}

\begin{tabular}{|l|l|}
\hline COPE & $\begin{array}{l}\text { Coping- Applied when a participant discussed his or her approaches for } \\
\text { coping with diabetes-related distress, as well as when a participant } \\
\text { discussed sources of coping assistance. }\end{array}$ \\
\hline EMOT & $\begin{array}{l}\text { Emotions- Applied when a participant expressed her or her feelings about } \\
\text { the experience of living with diabetes. }\end{array}$ \\
\hline NEG & Negative- Valence of emotions or attitudes. \\
\hline POS & Positive- Valence of emotions or attitudes. \\
\hline SS & $\begin{array}{l}\text { Social support- Applied when a participant discussed receiving specific } \\
\text { types of support from others for in relation to her or her diabetes, including } \\
\text { informational support, emotional support, tangible support, and appraisal } \\
\text { support. }\end{array}$ \\
\hline
\end{tabular}

\section{Support program components}

\begin{tabular}{|l|l|}
\hline PREFER & $\begin{array}{l}\text { Preferences- Applied when a participant discussed specific preferences for } \\
\text { characteristics of future diabetes support programs, such as composition and } \\
\text { location. }\end{array}$ \\
\hline ACTIV & $\begin{array}{l}\text { Activities- Applied when a participant discussed specific activities that they } \\
\text { would like to see included in future diabetes support programs. }\end{array}$ \\
\hline
\end{tabular}




\section{CURRICULUM VITAE}

\section{SULA MARIE HOOD}

\section{Contact Information:}

Department of Health Promotion and Behavioral Sciences

School of Public Health and Information Sciences

University of Louisville

485 Gray Street

Louisville, KY 40202

Phone: 404-808-0434

Email: smhood02@louisville.edu

\section{Education:}

\section{Graduate}

University of Louisville School of Public Health and Information Sciences

Doctor of Philosophy (Ph.D.), Public Health Sciences, Health Promotion

Dissertation: The Influence of Social Contextual Conditions and Basic

Psychological Need Fulfillment on Health Outcomes of Urban African American

Adults with Type-2 Diabetes Mellitus: A Mixed Methods Study.

Completed: 2012

Saint Louis University School of Public Health

Master of Public Health (M.P.H.), Epidemiology, Behavioral Science and

Health Education

Graduated: 2008

\section{Undergraduate}

The College of Wooster

Bachelor of Arts (B.A.), English

Graduated: 2005

Senior Independent Study Thesis: The Humane Caregiver: Physicians and Nurses as Poets.

\section{Internship and Training Experience:}

January 2011

University of California Los Angeles, Minority Training Program in Cancer Control Research (MTPCCR) Doctoral Student Retreat 
June 2008

University of California Los Angeles, Minority Training Program in Cancer Control Research (MTPCCR) Summer Institute

2006-2008

Saint Louis University School of Public Health, Eliminating Health Disparities (EHD) Trainee

2005-2006

Meharry Medical College, Post-baccalaureate Research Education Program (PREP)

June 2004

Case Western University School of Medicine, Summer Medical Education Program (SMEP)

\section{Academic Experience:}

\section{Teaching Assistant}

Spring 2009, 2010, $2011 \& 2012$

University of Louisville School of Public Health and Information Sciences

"Critical Thinking and Program Evaluation"- master's level course in health program evaluation.

\section{Research Assistant}

2008-2011

University of Louisville School of Public Health and Information Sciences, Graduate Assistant

2006-2008

Saint Louis University Health Communication Research Laboratory, Graduate Research Assistant

\section{Honors and Awards:}

2011-2012

University of Louisville, Ethnic Minority Dissertation award recipient

2011

Southern Regional Educational Board (SREB) institutionally-funded Doctoral Scholar

2009

University of Louisville, Research Louisville! Second place public health poster presentation award recipient 
2001-2005

The College of Wooster, Clarence Beecher Allen Scholarship

Grants:

2010-2011

University of Louisville, Committee on Diversity and Racial Equality (CODRE)

Signature Partnership grant

\section{Abstracts:}

Harris, M.J., Hood, S.M. (2010). Evaluation through Community Engagement. Abstract for poster presentation, University of Louisville Community Engagement Showcase, Louisville, KY.

Hood, S., Chlebowy, D.O., LaJoie, A. (2009). Gender Differences in Facilitators and Barriers to Type-2 Diabetes Adherence in African Americans. Abstract for poster presentation, University of Louisville Research Louisville! conference, Louisville, KY.

Cogbill, S., Hood, S., and Thompson, S. (2008). Social and Cultural Factors Affecting African-American Colorectal Cancer Screening Behaviors. Abstract for oral presentation, $136^{\text {th }}$ Annual American Public Health Association meeting, San Diego, CA.

Hood, S., Palmer, P., and Motley, E. (2006). The Role of PKC- $\delta$ in Thrombin Induced Phosphorylation and Activation of Endothelial Nitric Oxide Syntathase. Abstract for poster presentation, Meharry Medical College Graduate Research Day, Nashville, TN.

\section{Publications:}

Chlebowy, D.O., Hood, S., and LaJoie, A.(2010) "Facilitators and Barriers to Self Management of Type 2 Diabetes Among Urban African American Adults: Focus Group Findings." The Diabetes Educator

Hood, S., Thompson, V.L., Cogbill, S., Arnold, L.D., Talley, M., and Caito, N.M.(2010) "African American's Self-Report Patterns Using the National Cancer Institute Colorectal Cancer Screening Questionnaire." Journal of Cancer Education

Caito, N.M., Thompson, V.L., and Hood, S. "Colorectal Cancer Screening: A Qualitative Examination of African Americans Perceptions of Patient - Health Practitioner Communication." Publication under review

Chlebowy, D.O., Hood, S., and LaJoie, A. "Gender Differences in Facilitators and Barriers to Type-2 Diabetes Self- Management Among Urban African American Adults: Focus Group Findings." Publication under review 


\section{University Service:}

2008-2012

University of Louisville, Black Biomedical Graduate Student Organization

(BBGSO), Member,Vice president 2009-2010

2008-2012

University of Louisville, Diversity Committee, member

Public Service:

June 2009

Summer Medical and Dental Education Program, presenter on research and practice based opportunities in public health to pre-medical and pre-dental undergraduate students.

January 2009

Black Achievers, YMCA of Greater Louisville, KY, presenter on the field of public health education and career opportunities to high school students interested in the health sciences.

\section{Professional Memberships:}

American Public Health Association, 2007-present 